\title{
L'ancien diocèse de Senez (Alpes de Haute-Provence) entre Antiquité et Moyen Âge. État des questions et perspectives de recherches
}

\author{
Mathias DUPUIS*, Vincent BUCCIO**, Yann DEDONDER***
}

Les limites de l'ancien diocèse de Senez circonscrivent, à la fin de la période médiévale, un espace d'environ $1250 \mathrm{~km}^{2}$, qui s'étend entre les hautes vallées de l'Asse et du Verdon, dans les Préalpes provençales. Ce territoire - marginal au regard des centres de pouvoir politique et religieux de la Provence médiévale - offre une configuration topographique particulièrement intéressante, puisque le diocèse réunit trois anciennes agglomérations antiques, dont deux abritèrent des sièges épiscopaux éphémères, attestés au cours du Ve siècle. L'objet de cet article est d'apprécier, à partir d'un bilan documentaire critique, appuyé sur les sources textuelles et les vestiges matériels, les dynamiques en jeu dans l'évolution de ces pôles de pouvoir, entre Antiquité et Moyen Âge. La rareté de la documentation disponible permet d'adopter une focale large, aussi bien sur le plan thématique que chronologique, pour aborder l'évolution d'une microrégion de moyenne montagne située à la croisée de la Provence orientale, des zones littorales et des hautes vallées alpines.

Mots-clés : Alpes, Provence, Antiquité, Moyen Âge, diocèse, siège épiscopal, cathédrale, agglomérations, castrum, archéologie du bâti

Les connaissances sur les Alpes provençales entre Antiquité et Moyen Âge demeurent encore très lacunaires, malgré des enquêtes archéologiques régionales renouvelées au cours de ces dernières décennies (Guyon et al. 2001 ; Codou 2003 ; Heijmans et al. 2006 ; Guyon et al. 2013). Cette carence documentaire est particulièrement importante dans la région située à l'est de la Durance et au nord du Verdon, soit les franges orientales des Alpes de Haute-Provence et des Hautes-Alpes. Au sein de cet ensemble, qui s'inscrit dans la partie septentrionale de l'ancien archevêché d'Embrun, le cadre restreint de l'ancien diocèse de Senez, auquel correspondent les hautes vallées de l'Asse et du Verdon, offre l'occasion de se focaliser sur une microrégion méconnue qui a bénéficié ces dernières années de la mise en place de nouveaux projets de recherche. Le choix de cette ancienne circonscription religieuse - bien que discutable d'un point de vue diachronique - permet d'aborder plusieurs questionnements posés par l'évolution et la recomposition des cadres civils et religieux sur le temps long (Mazel 2008 ; Mazel 2016). En effet, le territoire sur lequel les évêques de Senez exercent leur autorité au cours du Moyen Âge semble résulter du regroupement de plusieurs entités administratives antiques, parmi lesquelles figurent les anciennes civitates de Sanitium (Senez) et Salinae (Castellane), ainsi que le siège épiscopal éphémère d'Eturamina (Thorame). Par ailleurs, le diocèse médiéval présente une dichotomie particulièrement intéressante, puisque Senez conserve jusqu'à la Révolution française une prééminence religieuse grâce à la permanence de son siège épiscopal, malgré la nette domination économique et politique qu'exerce Castellane à ses dépens (Vaizey 2002). Ces problématiques invitent donc à reconsidérer l'étude du diocèse à partir de ces trois pôles de pouvoir, dont on pressent qu'ils participent largement à la structuration politique et religieuse des hautes vallées de l'Asse et du Verdon. La synthèse des données textuelles et des découvertes anciennes, croisée avec les apports de nouvelles investigations conduites par le Service départemental d'archéologie des Alpes de Haute-Provence a pour objectif de proposer quelques pistes de réflexion préliminaires. Celles-ci devraient permettre de percevoir les dynamiques qui s'exercent dans l'occupation de ces trois agglomérations entre Antiquité et Moyen Âge et, plus largement, d'appréhender les modalités de peuplement d'un territoire de moyenne et de haute montagne,

\footnotetext{
** Département des Alpes de Haute-Provence, service départemental d'archéologie / Aix Marseille Univ, CNRS, LA3M, Aix-en-Provence, France. ** Département des Alpes de Haute-Provence, service départemental d'archéologie / CIHAM - UMR 5648, Lyon.

*** Département des Alpes de Haute-Provence, service départemental d'archéologie.
} 
délaissé par la recherche archéologique et relégué à la marge de l'historiographie provençale (1).

\section{LE CADRE DE L'ETUDE}

\section{Entre Asse et Verdon : territoire historique et espace géographique}

L'étendue du pouvoir de l'Église de Senez ne se perçoit qu'à partir des $\mathrm{X}^{\mathrm{e}}-\mathrm{XI}^{\mathrm{e}}$ siècle. En l'absence quasitotale d'archives anciennes liées à la cathédrale, les informations proviennent essentiellement des sources monastiques, notamment des cartulaires des abbayes de Saint-Victor de Marseille (Guérard 1857) et de SaintHonorat de Lérins (Moris et Blanc 1883) dans lesquels est évoquée la restitution à ces deux abbayes de biens situés dans le comté (in comitatu), l'évêché (in episcopatu) ou le diocèse (in diocesi) (fig. 1). Encore ces informations demeurent-elles très partielles, car elles ne concernent que les portions du territoire qui correspondent aux points de fixation de ces monastères. Sont également cités d'autres églises, biens et castra que l'on imagine dépendre en totalité ou en partie du pouvoir de l'évêque de Senez, puisque celui-ci les mentionne ou en fait don au monastère, sans toutefois que leur désignation soit accompagnée d'un rattachement explicite au pouvoir épiscopal (2). La portée territoriale de ces mentions paraît très limitée ; d'autant plus si l'on se rapporte à certaines zones de confins, placées sous l'autorité de sièges épiscopaux voisins (3). Le dénombrement précis des paroisses relevant de l'évêque est principalement renseigné par les comptes de décime du $\mathrm{XIV}^{\mathrm{e}}$ siècle, publiés en 1923. La brève notice consacrée dans l'introduction de cet ouvrage au diocèse et à ses limites (Clouzot 1923, p. CLII-CLVIII) s'appuie à la fois sur ces dénombrements et sur la carte de Cassini, qui indique les frontières de la circonscription avant la Révolution, ainsi que sur certains actes des cartulaires de Saint-Victor de Marseille et de Lérins (4). Dès lors, il devient possible de proposer une cartographie du diocèse - entendu comme un ensemble territorial stable et délimité - qui ne peut cependant être considérée comme tout à fait pertinente avant le XIV e siècle (fig. 2).

Le territoire ainsi délimité couvre une superficie de $1257 \mathrm{~km}^{2}$ et s'étend sur la partie sud-est de l'actuel département des Alpes de Haute-Provence. Il englobe une trentaine de communes (5), qui correspondent à une soixantaine de paroisses et succursales au cours de l'Ancien Régime. Au regard des autres évêchés des Alpes méridionales, c'est une circonscription de taille moyenne (6), qui ne se démarque pas des diocèses de dimensions réduites que l'on rencontre sur le littoral méditerranéen ou dans la vallée du Rhône. Le diocèse se développe dans un espace géographique défini par les bassins versants des hautes vallées de l'Asse et du Verdon, deux affluents de la Durance. Il s'agit d'une zone de moyenne et de haute montagne dont les altitudes s'échelonnent entre 600 et $3000 \mathrm{~m}$ environ, cisaillée par d'étroites vallées torrentielles, dans lesquelles se concentrent aujourd'hui les principaux axes de communication et l'habitat. Ces vallées et les cols qui les jalonnent constituent autant de points de passage obligés, qui permettent la circulation entre la Provence orientale et la vallée de la Durance, à partir de laquelle il est possible de gagner l'Italie septentrionale par les voies alpines. L'axe principal qui se détache est celui qui met en communication la vallée du Verdon et la vallée de l'Asse, par le biais du col des Lecques et de la clue de Taulanne. Dans ces vallées encaissées, Castellane se distingue comme un véritable carrefour, disposant d'un point de franchissement sur le Verdon (7) à partir duquel il est possible de gagner au sud Draguignan et le littoral, à l'est la haute vallée du Var, à l'ouest la vallée de la

Ce travail s'inscrit dans le cadre d'un Projet collectif de recherche, amorcé en 2016 et consacré à Senez et son territoire aux périodes historiques. Les réflexions dont cet article est issu sont le fruit de nombreux échanges et discussions avec plusieurs collègues, au premier plan desquels se trouve l'équipe du Service départemental d'archéologie des Alpes de Haute-Provence et les membres du PCR Senez. La préparation de cette publication a bénéficié, au début de l'année 2016, d'une aide du Ministère de la recherche, dans le cadre de l'appel à projet pour l'accueil de chercheurs de l'archéologie préventive dans les UMR du CNRS ; en l'occurrence au sein du LA3M (UMR 7298 - Aix-en-Provence). Nous tenons à exprimer ici notre gratitude à tous ceux qui soutiennent ce projet localement et à remercier particulièrement Laurent Schneider, Michèle Bois, Thierry Pécout et Élisabeth Sauze pour leurs conseils et leurs relectures avisés.

${ }^{2}$ L'introduction de l'édition du cartulaire recense ainsi dans le périmètre du comté de Senez : le castrum de Castellane, Blieux, Robion (com. Castellane), Eoulx (com. Castellane), Peyroules, le castrum de Moriez, le castrum de Thorame, Roca Rufa (?), Allons, le castrum de Bagarris (com. Castellane), la Mure, le Roubaud (?) (Guérard 1857, 1, LXIX). On ne peut donc pas suivre Jacques Cru, lorsqu'il affirme que les cartulaires incluent dès le $\mathrm{XI}^{\mathrm{e}}$ siècle toutes les paroisses du diocèse de Senez, telles qu'elles seront ensuite dénombrées à partir du XIV ${ }^{\mathrm{e}}$ siècle (Cru 1987).

${ }^{3} \mathrm{C}^{\prime}$ est le cas de Thorame : si les mentions du XIII ${ }^{\circ}$ siècle placent son territoire dans le ressort du diocèse de Senez (Guérard 1857, 2 , ${ }^{\circ} 1018,1019$, 1020 et 1022), deux confirmations papales de la fin du XI ${ }^{e}$ et du début du XII ${ }^{e}$ siècle se rapportent au diocèse de Glandèves, dont l'influence s'étend alors sur la rive opposée du Verdon, dans la haute vallée de la Vaïre, jusqu'à la Colle Saint-Michel. En 1079 une bulle de confirmation de Grégoire VII localise ainsi in episcopatu Glanatensi la cellam apud castrum Toramina (Ibid. $\mathrm{n}^{\circ}$ 843), puis en 1135 une bulle d'Innocent II positionne dans le même ressort l'église Sainte-Marie de Toramina (Ibid., n ${ }^{\circ} 844$ ). À partir du début du XIVe siècle, les comptes de décime localisent sans ambiguïté les églises de Thorame dans le diocèse de Senez (Clouzot 1923, 289-295). Pour Damase Arbaud, cette confusion est liée au rattachement au prieuré SaintPons du Fugeret - lui-même situé dans le diocèse de Glandèves - de l'église Notre-Dame du Serret, à laquelle feraient donc référence ces deux mentions (Arbaud 1905).

${ }^{4}$ Tels la charte $n^{\circ} 765$ du cartulaire de Saint-Victor, qui fixe les limites des territoires de Colmars et d'Allos, situés à 1'extrémité nord du diocèse (Guérard 1857, 2, 110) ou la bulle pontificale de 1259, qui confirme les possessions de Lérins dans le diocèse (Moris et Blanc 1883, 4-8).

${ }_{5}^{5}$ Dont deux sont situées dans les départements limitrophes du Var et des Alpes-Maritimes (le Bourguet et Saint-Auban).

${ }^{6}$ Les superficies des autres diocèses de l'archevêché d'Embrun sont les suivantes: Embrun 4092 km² ; Nice 1728 km²; Glandèves 1286 km²; Digne $808 \mathrm{~km}^{2}$; Grasse $486 \mathrm{~km}^{2}$; Vence $402 \mathrm{~km}^{2}$.

${ }^{7}$ La reconstruction du pont de Castellane remonte au $\mathrm{XV}^{\mathrm{e}}$ siècle ; aucun élément ne permet cependant de postuler qu'il existait un ouvrage en pierre à l'Antiquité (Auran, Barruol et al. 2006, 163-164). 


\begin{tabular}{|c|c|c|c|}
\hline Date & Nature du document & Mention & Référence bibliographique \\
\hline c. 150 & Géographie de Ptolémée & $\Sigma \alpha v \iota \tau \iota O v$ & Barruol 1969 \\
\hline $\mathrm{Il}^{\mathrm{e}} \mathrm{s}$ & Epitaphe de Nîmes & decurio Sanit(iensium) & Morabito $2010 \mathrm{~b}$ \\
\hline fin IV $s$ & Notitia Galliarum & ciuitas Sanitiensium & Barruol 1969 \\
\hline 506 & Canons du concile d'Agde & Marcellus episcopo de Sanetio & Roux 1971 \\
\hline 585 & Canons du concile de Mâcon & Vigili episcopi a Senectio & Roux 1971 \\
\hline c. $965-977$ & $\begin{array}{l}\text { CSV : restitution de domaines à Saint-Victor } \\
\text { par l'évêque Honoré de Marseille }\end{array}$ & $\begin{array}{l}\text { et in comitatu Senescience, in termino de castro Petra Castel- } \\
\text { lana, terram quantum pertinet ad beatum Victorem, integre } \\
\text { concedimus }\end{array}$ & Guérard 1857, 1, 23, p. 29 \\
\hline 1005-1006 & $\begin{array}{l}\text { CSV : donation de terres à Sainte-Marie de } \\
\text { Castellane par Stavulus }\end{array}$ & $\begin{array}{l}\text { Et est ipsa terra in comitatu Senecense, in loco quem nominant } \\
\text { Romagnaco }\end{array}$ & Guérard 1857, 2, 774, p. 120 \\
\hline ap. 1024 & $\begin{array}{l}\text { CL: donation de l'église Sainte-Marie de } \\
\text { Moriez par Belildis et ses enfants }\end{array}$ & aecclesiam supradictam que est in comitatu Senecensi & $\begin{array}{l}\text { Moris et al. 1883, 1, CCXXXI, p. } \\
237\end{array}$ \\
\hline c. 1033 & $\begin{array}{l}\text { CSV : donation par Audibert, Guigue et leur } \\
\text { mère Albetrudis assistés de l'évêque de Senez }\end{array}$ & $\begin{array}{l}\text { ecclesiam sancti Petri, que est in comitatu Senecensi et in territo- } \\
\text { rio de castro Bagarri }\end{array}$ & Guérard 1857, 2, 760, p. 104 \\
\hline c. 1030 & $\begin{array}{l}\text { CSV : donation par Pons de biens situés à la } \\
\text { Mure }\end{array}$ & $\begin{array}{l}\text { ecclesia sancte Marie de Mura, que est sita in territorio de castro } \\
\text { quem nominant Morerius, in comitatu Senecensi }\end{array}$ & Guérard 1857, 2, 767, p. 112 \\
\hline 1040 & $\begin{array}{l}\text { CSV : donation par Amiel à Saint-Victor des } \\
\text { églises Sainte-Marie, Saint-Jean-Baptiste, Saint- } \\
\text { Pierre et Saint-Laurent de Castellane }\end{array}$ & $\begin{array}{l}\text { Ideirco ego Amelius, gracia Dei sancte sedis Senecensis epis- } \\
\text { copus, nostrorum filiorum ceterorumque fidelium nostrorum } \\
\text { voluntate ac rogatu, ecclesias nostri diocesii quasdam (...) }\end{array}$ & Guérard 1857, 2, 769, p. 116 \\
\hline c. 1040 & $\begin{array}{l}\text { CSV : donation par Amiel à Saint-Victor de } \\
\text { l'église Sainte-Marie in loco qui vocatur Cimi- } \\
\text { ranus }\end{array}$ & $\begin{array}{l}\text { concedo ad cellam monasterii beati Victoris martiris, que sita est } \\
\text { in nostro episcopio et constructa in honore sancte Dei genitricis } \\
\text { Marie }\end{array}$ & Guérard 1857, 2, 770, p. 117 \\
\hline 1042 & $\begin{array}{l}\text { CSV : donation par Belibildis et ses enfants à } \\
\text { l'église Saint-Marie de la Mure }\end{array}$ & $\begin{array}{l}\text { Et est ipse alodis in comitatu Senecensi, juxta fluvium Viri- } \\
\text { dionem, in loco qui antiquitus vocature Morarius }\end{array}$ & Guérard 1857, 2, 766, p. 111 \\
\hline 1043 & $\begin{array}{l}\text { CSV : restitution de l'église Sainte-Marie de } \\
\text { Castellane à Saint-Victor par Heldebert et } \\
\text { l'évêque de Senez }\end{array}$ & $\begin{array}{l}\text { ecclesiam sancte Marie, que est in comitatu Sinecensi, in territo- } \\
\text { rio Petra Castellane, ad radicem quem vocant Sennaz vel Sennag, } \\
\text { in loco qui antiquitis vocatur Cimira... }\end{array}$ & Guérard 1857, 2, 768, p. 114 \\
\hline c. 1043 & $\begin{array}{l}\text { CSV : donation par Aldebert et Ermengarde à } \\
\text { Saint-Victor de Marseille }\end{array}$ & $\begin{array}{l}\text { in territorio de castro que nominant Petra Castellana, seu in } \\
\text { comitatu Senecensi }\end{array}$ & Guérard 1857, 2, 775, p. 120 \\
\hline c. 1070 & Vie de Saint-Isarn & $\begin{array}{l}\text { In crastino autem cum ob tantam inhumanitatem uir reueren- } \\
\text { dus Amelius Senetiensis episcopus castellum illud - nam ad eius } \\
\text { diocesim pertinabat - excommunicare uellet }\end{array}$ & Caby et al. 2010, XV, p. 41 \\
\hline 1079 & $\begin{array}{l}\text { CSV : confirmation des prieurés de Saint-Victor } \\
\text { par une bulle du pape Grégoire VII }\end{array}$ & $\begin{array}{l}\text { in episcopatu Seneçensi, cellam sancte Marie de Petra Castel- } \\
\text { lana, cellam de Bagarres, cellam sancte Marie de Mura }\end{array}$ & Guérard 1857, 2, 843, p. 218 \\
\hline 1135 & CSV : Bulle d'Innocent II & in epsicopatu Senez & Guérard 1857, 2, 844, p. 227 \\
\hline 1237 & RACP : statuts de la baillie de Senez & terra ecclesie Seneciensis & Benoît $1925,2, n^{\circ} 277$, p. 365 \\
\hline 1252 & $\begin{array}{l}\text { Enquêtes sur les droits et revenus de Charles ler } \\
\text { d'Anjou en Provence }\end{array}$ & cartularium episcopatus senescensis & Baratier 1969, n638-640, p. 376 \\
\hline 1259 & $\begin{array}{l}\text { CL: Bulle du pape Alexandre IV, confirmant } \\
\text { toutes les possessions de l'abbaye de Lérins }\end{array}$ & $\begin{array}{l}\text { In dyocesi Senensi, Sancti Honorati de Clumanco et Sancti Julia- } \\
\text { neti castra... }\end{array}$ & Moris et al. 1883, 2, IV, p. 4-8 \\
\hline 1278 & $\begin{array}{l}\text { Enquêtes sur les droits et revenus de Charles } \text { ler }^{\text {en }} \\
\text { d'Anjou en Provence }\end{array}$ & Senescensem episcopum ; episcopus Seneciensis & Baratier 1969, p. 415-442 \\
\hline
\end{tabular}

CSV = Cartulaire de Saint-Victor de Marseille

$\mathrm{CL}=$ Cartulaire de Lérins

RACP $=$ Recueil des actes des Comtes de Provence

Fig. 1 : Tableau synthétique des principales mentions de Senez, du début de notre ère à la fin du XIII siècle (C) Mathias Dupuis / SDA 04)

Durance et au nord la vallée de l'Ubaye par le col d'Allos. Senez en revanche, occupe une place relativement marginale, le long de la route se dirigeant vers Digne. Le val de Thorame enfin, se situe dans la partie nord de cet espace, au point de contact entre les hautes vallées du Verdon et de l'Issole, au débouché du col d'Allos. Cette région des Préalpes provençale est aujourd'hui très peu peuplée, avec une densité d'environ 4 à 9 habitants au kilomètre carré, c'est-à-dire quatre à deux fois moins que celle estimée dans la première moitié du XIV $\mathrm{XI}^{\mathrm{e}}$ siècle (8).

Le diocèse, suffragant de l'archevêché d'Embrun, est frontalier à l'est des diocèses de Vence et de Glandèves et au nord-ouest du diocèse de Digne, qui appartiennent à la même province ecclésiastique. La partie sud, qui marque la frontière avec la province d'Aix, est limitrophe des diocèses de Fréjus à l'est et de Riez à l'ouest. Plusieurs entités naturelles marquent la limite entre ces circonscriptions. Sur toute sa partie nord-est, la séparation avec le diocèse de Digne est ainsi matérialisée par la ligne de crête qui s'étend depuis la montagne de Coupe jusqu'à la tête de la Sestrière, au nord du massif des Trois évêchés, dont le toponyme rappelle le point de contact entre les diocèses de Senez, Digne et Embrun. Du côté ouest, la frontière avec le diocèse de Glandèves est formée par la ligne de crête qui sépare les bassins

\footnotetext{
${ }^{8}$ La densité de population dans la baillie de Castellane, qui correspond à la partie sud-est du diocèse de Senez, est estimée à environ 16 habitants au $\mathrm{km}^{2}$ d'après les données de l'enquête comtale menée entre 1332 et 1333 (Pécout, Michaud, Roux et al. 2011, 284-288).
} 


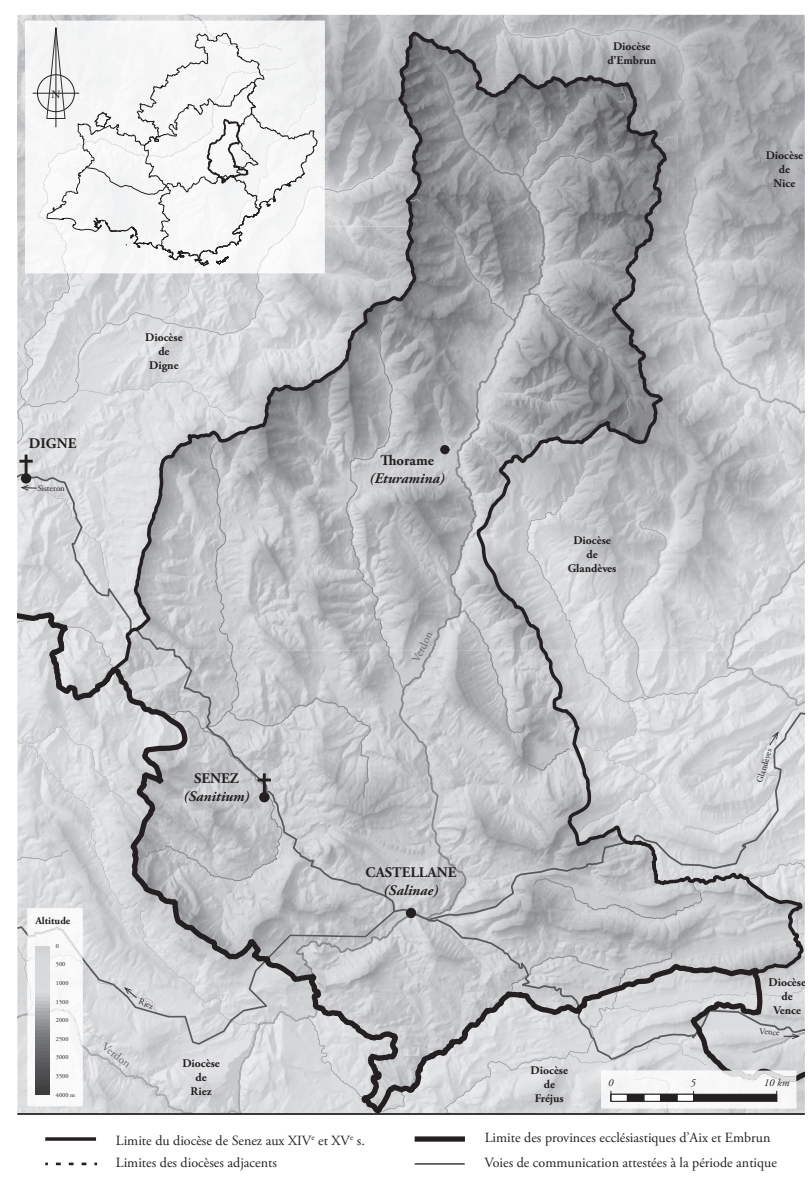

Fig. 2 : Carte de restitution des limites de l'ancien diocèse de Senez à la fin du Moyen Âge (C) Yann Dedonder / SDA 04)

versants du Verdon et du Var. Au sud-est, le diocèse forme une sorte d'incursion vers celui de Glandèves, puisqu'il englobe la haute vallée de l'Estéron, un affluent du Var (communes de Soleilhas et Saint-Auban). Au sud, la frontière avec le diocèse de Fréjus est en grande partie matérialisée par le cours du Jabron, un affluent du Verdon. Enfin, au sud-ouest, la limite avec le diocèse de Riez respecte la ligne de crête qui longe la rive nord du Verdon, depuis la clue de Chasteuil jusqu'au massif du Chiran, pour rejoindre ensuite la vallée de l'Asse à hauteur de Norante.

En dépit de quelques variations, le périmètre du diocèse n'a guère évolué jusqu'à la Révolution (fig. 3), après laquelle il est intégré au nouveau diocèse de Digne, calqué sur les limites du département des Basses-Alpes. Plusieurs indications sur l'étendue de la circonscription ecclésiastique à l'époque moderne sont fournies par les sources relatives aux nombreuses et infructueuses tentatives d'union du diocèse à des entités voisines ou de translation du siège vers Castellane, qui se multiplient à partir de la fin du Moyen Âge. Les conflits qu'occasionnèrent ces projets entre l'évêque, les chanoines, le clergé local voire le roi de France et le pape ont en effet suscité des actes et une correspondance nourris, dans lesquels on ne manque pas de revenir sur la description géographique du diocèse (Ventre 1930).
Les historiens ne se sont guère intéressés à cette région pauvre en textes et en monuments, considérée comme inhospitalière voire hostile. En 1664, Honoré Bouche tente de retracer l'histoire de Senez depuis l'Antiquité et adopte déjà la filiation entre l'antique Sanitium et le bourg de Senez (Bouche 1664, 272-279). Un siècle plus tard, le prieur Joseph Laurensi livre une image plus complète et mieux documentée, dans l'ouvrage qu'il consacre à la ville de Castellane en 1775 . Laurensi fait remonter les origines du diocèse au début $\mathrm{du} \mathrm{IV}^{\mathrm{e}}$ siècle et propose de voir dans Castellane le siège d'un évêché disparu avant l'invasion des " sarrasins ", non sans chercher à démontrer par cette ancienneté une forme de prééminence de sa cité sur la ville épiscopale (Laurensi 1775, 53-65). En dehors de quelques monographies, l'historiographie du $\mathrm{XIX}^{\mathrm{e}}$ siècle n'a guère renouvelé le socle de connaissances établi par ces pionniers (Gras-Bourguet 1842 ; Cruvellier 1889 ; Pellissier 1901). À Senez même, faute d'archives et de découvertes archéologiques marquantes, c'est essentiellement la cathédrale qui attire l'attention des chercheurs et notamment de Jacques Thirion, dans le cadre des travaux qu'il consacre à l'art roman des Alpes (Thirion 1957 ; Thirion 1980, 327-333). Les synthèses réalisées dans la seconde moitié du $\mathrm{XX}^{\mathrm{e}}$ siècle par Paul-Albert Février et Guy Barruol portent une attention soutenue à la topographie singulière de Senez, Castellane et Thorame, sans toutefois qu'aucune investigation soit engagée sur ces différents sites (Février 1964 ; Barruol 1969). Les rares travaux récents, bien qu'ils livrent des éléments de synthèse inédits, souffrent également de ce manque de renouvellement des données archéologiques (Vaizey 2002 ; Morabito 2010b ).

\section{Le contexte, entre Préhistoire et Antiquité}

\section{Avant la conquête}

Les travaux récemment conduits sur le lac d'Allos (2 $230 \mathrm{~m})$, situé à l'extrémité nord de la zone d'étude, ont démontré que la déglaciation complète de la dépression intervenait entre 13500 et 12300 BP (Brisset, Miramont et al. 2014). Le déclin de la sapinière, amorcé à partir de 6000 BP, est interprété, comme ailleurs dans les Alpes, par l'intensité des défrichements néolithiques. Cette observation est jugée cohérente avec la découverte, lors de prospections dans le même secteur, de vestiges d'occupation attribués à cette période (Brisset 2014, 284). La mise en évidence de l'exploitation de la source salée de Beaumeunière à Moriez, dans laquelle ont été découverts en 1998 les vestiges d'un aménagement formé de baguettes taillées en fond de puits (maillage destiné à la collecte du sel ?), datées par radiocarbone vers 6700 6900 BP constitue sans doute un des indices les plus tangibles d'un investissement pérenne des hautes vallées au début de l'Holocène, en lien avec l'exploitation de leurs ressources naturelles (Morin, Lavier et al. 2007). Plusieurs sites funéraires du Néolithique final sont attestés, parmi lesquels seul le dolmen de la Pierre Blanche à Castellane a fait l'objet d'investigations archéologiques. 


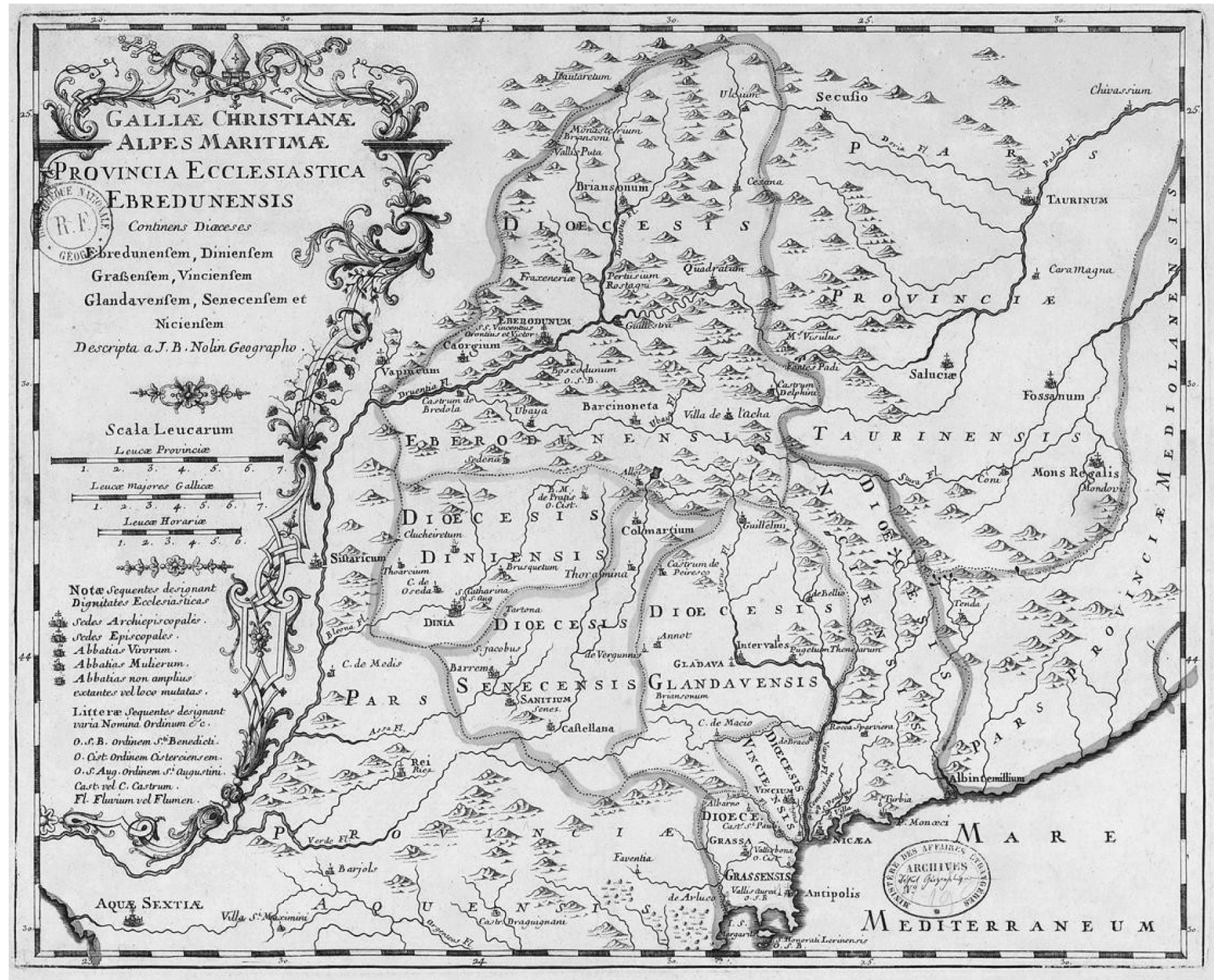

Fig. 3 : La province ecclésiastique d'Embrun au début du XVIII ${ }^{e}$ siècle (C) Jean-Baptiste Nolin, Galliae christianae Provincia ecclesiastica Ebredunensis, 1725 - source gallica.bnf.fr / Bibliothèque nationale de France)

Guy Barruol, dont les travaux font encore autorité pour appréhender le découpage territorial de la région avant la conquête romaine, situe autour de Senez et plus largement dans les trois vallées de l'Asse le peuple des Sentii, connu par un texte de Ptolémée ainsi que celui des Triulatii, mentionné sur le trophée des Alpes à la Turbie (Barruol 1969, 382-385). Il localise les Suetrii autour de Castellane, également sur la foi de Ptolémée, qui cite Salinae comme capitale de ce peuple. Les Vergunii auraient étendu leur petit territoire autour de l'actuel village de Vergons, dans la vallée du Riou. Enfin, le secteur du Haut-Verdon et de la vallée de l'Issole, autour de Thorame, pourrait avoir abrité la tribu des Eguituri(i). Aucune investigation archéologique n'est venue à l'appui de ces recherches, afin de déterminer la nature et la répartition de l'habitat protohistorique et nous ignorons presque tout de ce territoire au cours de la période qui précède l'annexion par Rome des peuples alpins.
Quelques découvertes éparses indiquent des sites d'occupation, comme à Moriez où le Jas de Bernard a livré en 1996, lors de terrassements destinés au captage d'une source ancienne, un lot d'objets métalliques datés de la fin du Bronze final $\left(\mathrm{XI}^{e}-\mathrm{X}^{\mathrm{e}}\right.$ siècles avant notre ère Bronze final IIIb) qui s'apparente aux dépôts métalliques connus dans le reste des Alpes méridionales (Bérard 1997, p. 313 ; Barge 2004). La découverte en 2017, lors de la fouille du site médiéval de Petra Castellana, d'une fosse contenant un lot important de céramique et de mobilier lithique attribués au Bronze ancien atteste d'une occupation ancienne de ce relief (9). Une telle découverte dans un contexte de plein-air revêt un caractère inhabituel dans ce secteur du Verdon et pourrait s'inscrire dans une perspective de renouvellement des connaissances sur le territoire pour ces périodes anciennes. Quant à l'âge du Fer, aucun site d'habitat n'est véritablement localisé, en dehors peut-être d'une 
dizaine de sites de hauteur fortifiés, recensés dans la Carte archéologique de la Gaule et diversement qualifiés d'oppidum, d'enceinte ou d'éperon barré. Cependant, ces interprétations discutables reposent sur l'observation croisée de la topographie naturelle des terrains, de vestiges de murs d'enceinte, de la présence de céramiques dites " indigènes » (communes non tournées) ou d'autres éléments mobiliers jugés caractéristiques, notamment des fragments de meules en rhyolite de l'Estérel. Il est fort probable, dans plusieurs cas de figure, que ces sites de hauteur, attribués par défaut aux périodes protohistoriques, puissent correspondre à des occupations plus précoces, plus tardives, ou bien qui s'étendent jusqu'aux périodes historiques (Leveau et Rémy 2008, 13-26). Seules de véritables opérations archéologiques permettraient de s'en assurer.

\section{Au cour des Alpes Maritimae}

Suite à la victoire d'Auguste en 14 av. J.-C., les peuples des hautes vallées de l'Asse et du Verdon sont rattachés à l'Empire romain. La structuration progressive de la province des Alpes Maritimae a bien été mise en lumière par les travaux récents de Stéphane Morabito (Morabito 2007). D'abord administrées comme une préfecture, les Alpes Maritimae accèdent au statut de province sous le règne de Néron au plus tôt et leurs limites septentrionales sont alors étendues jusqu'au sud de la vallée de l'Ubaye. Au cours des II $^{\mathrm{e}}$ et III ${ }^{\mathrm{e}}$ siècles, la province continue de se développer vers le nord et l'ouest au dépend des Alpes Cottiennes (transfert de l'Embrunais et de l'Ubaye) et de la Narbonnaise, en intégrant le territoire de Dinia (Digne). Initialement administrée depuis Cemenelum (Cimiez), son centre de gravité se déplace progressivement vers le nord au cours de l'Antiquité tardive avec l'élévation d'Eburodunum (Embrun) au rang de métropole, à la charnière des $\mathrm{IV}^{\mathrm{e}}$ et $\mathrm{V}^{\mathrm{e}}$ siècles (Morabito 2010a ; Morabito 2010b). D'après la documentation textuelle et épigraphique, l'émergence des cités de Salinae et de Sanitium remonterait au début du second siècle de notre ère au plus tard, du moins si l'on se réfère à leur mention dans la Géographie de Ptolémée. Le toponyme d'Eturamina en revanche, n'est connu qu'à partir de 442, date à laquelle est mentionné l'évêque Severianus dans les actes du concile de Vaison. La région est marquée par une concentration particulièrement importante d'anciennes capitales de cités, dont le maillage très dense offre un cas de figure assez spécifique dans la géographie de la Gaule romaine (10). Castellane et Senez, malgré leur enclavement dans d'étroites vallées, sont situées sur la voie de communication principale de la province, qui relie Cimiez et Embrun par le biais du tronçon Vence-Digne, dont le tracé a été précisément restitué grâce à la découverte de plusieurs bornes miliaires (Chavane 1995). D'un point de vue archéologique, les indices d'occupation antiques sont plus nombreux que ceux des époques antérieures, mais ils sont encore trop rares pour percevoir l'étendue et la structuration de ces trois agglomérations, voire pour affirmer leur existence sous des formes urbaines comparables à celle que nous connaissons dans la Gaule méridionale. Cette carence documentaire n'est pas spécifique aux hautes vallées de l'Asse et du Verdon, mais concerne la quasi-totalité des Alpes Maritimae, dans lesquelles seule Cimiez a véritablement fait l'objet d'investigations archéologiques poussées (Leveau et Rémy 2008, 321-356).

Le cas de figure le mieux documenté reste celui de Castellane (fig. 4), où l'agglomération paraît se développer dans la plaine du Verdon, sur la rive droite de la rivière et peut-être également à l'ouest du bourg actuel (fig. 7). Cette hypothèse repose sur certaines données textuelles et toponymiques : les chartes du cartulaire de Saint-Victor de Marseille permettent en effet de situer la ville ancienne dans le quartier du Plan, à proximité des sources salées de la Salaou qui lui auraient donné son nom (Ferdière 2004, 393-395). Sa localisation s'appuie également sur des découvertes archéologiques anciennes, mais celles-ci n'ont pas été confirmées par de véritables opérations archéologiques. S'il existe indéniablement un corpus relativement important d'objets mobiliers provenant de ce secteur, notamment des inscriptions funéraires, la nature exacte des découvertes effectuées dans le quartier du Plan et rapportées par Laurensi en 1775 doit cependant être considérée avec prudence. Ainsi, il n'est pas assuré que l'édifice à gradin, très sommairement décrit par cet auteur, corresponde véritablement à un théâtre ou à un amphithéâtre. Les deux diagnostics archéologiques récemment conduits dans cette zone n'ont donné lieu à la découverte d'aucune structure archéologique, mais ils ont permis de mettre en évidence l'épaisseur particulièrement importante des niveaux de recouvrement alluviaux, liés aux dépôts de crues du Verdon (Chadefaux et Sivan 2013 ; Dupuis 2014). Si un horizon d'occupation Haut-Empire se dessine bien à plusieurs mètres de profondeur (entre $4 \mathrm{~m}$ au sud et 2,50 $\mathrm{m}$ au plus près de la colline Saint-Michel), celui-ci se perçoit uniquement à travers la présence de mobilier céramique en position secondaire (fig. 8). L'habitat doit sans doute être recherché ailleurs, peutêtre dans une zone plus resserrée au sud de l'église Notre-Dame du Plan, à l'est du cimetière vers lequel se concentrent les éléments de mobilier découverts lors du diagnostic de 2014. À moins que cette zone corresponde plutôt aux espaces funéraires périphériques, comme pourrait le suggérer la provenance des stèles recensées sur la commune (Morabito 2010a, 120-137).

La localisation de la ville antique de Senez (fig. 5) pose encore question, faute d'investigations suffisam-

\footnotetext{
${ }^{10}$ Le département actuel des Alpes de Haute-Provence compte ainsi sept anciennes capitales de cité mentionnées dans la notice des Gaules, toutes situées à l'est de la Durance, à l'exception de Sisteron. Les distances routières actuelles entre ces différentes agglomérations, depuis Senez, sont les suivantes : Castellane 19 km ; Digne 35 km ; Riez 52 km ; Briançonnet (Alpes-Maritimes) 54 km ; Glandèves 55 km ; Sisteron 63 km ; Faucon-deBarcelonnette $93 \mathrm{~km}$.
} 


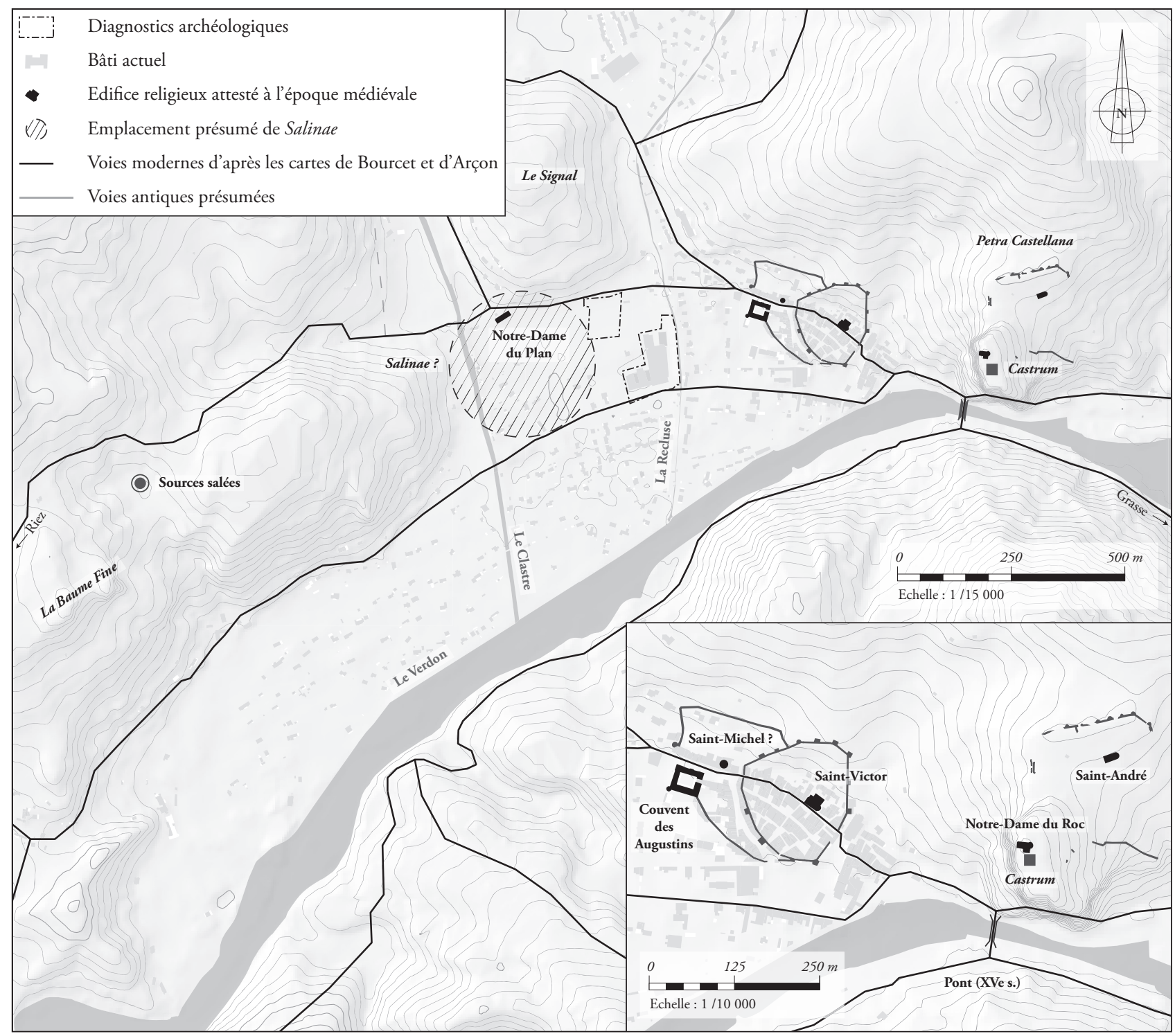

Fig. 4 : Castellane : topographie et principaux vestiges archéologiques et monumentaux reconnus sur la commune (C) Yann Dedonder, Vincent Buccio, Mathias Dupuis / SDA 04)

ment étendues dans le village et ses abords (fig. 9). Les dernières campagnes de fouille réalisées dans la partie sud-est de la cathédrale ont toutefois permis de mettre en évidence la présence d'une maçonnerie orientée nordsud scellée par des niveaux d'abandon attribués à l'Antiquité tardive (Dupuis et al. 2018) (fig. 11). Si la datation absolue de ce mur n'est pas encore acquise, sa position stratigraphique l'assimile clairement à une séquence d'occupation antérieure au développement des premiers espaces funéraires tardo-antiques. Cette phase d'occupation antique semble avoir été déterminante dans la structuration des bâtiments religieux ultérieurs, qui respectent tous la même orientation. Certaines découvertes anciennes indiquent en outre une concentration de vestiges antiques - des monnaies essentiellement - aux abords du village, dans la plaine formée par la confluence de l'Asse et du torrent de la Bonde (Bérard 1997, 448-451).

À Thorame enfin, les indices d'occupation antique se concentrent dans le village de Thorame-Haute (fig. 6). La présence de sépultures antiques ou tardo-antiques est renseignée depuis les années 1930 à proximité de l'église paroissiale et depuis les années 1980 aux abords de la chapelle Notre-Dame du Serret (Bérard 1997, 480-482). En contrebas de cette dernière, des observations récentes effectuées lors des travaux de construction de l'école primaire indiquent la présence probable d'un site d'habitat du Haut-Empire (11).

\footnotetext{
${ }^{11}$ Cette information inédite est redevable à Julie Émeric. Au lieu-dit les Aires, des observations réalisées lors de la construction de l'école primaire ont en effet permis de mettre en évidence la présence, dans une coupe stratigraphique, de maçonneries et de structures en creux qui contenaient du mobilier céramique attribué aux I'-III siècles de notre ère. Un peu plus à l'ouest, dans le quartier des Périers, est également signalée une concentration importante de mobilier céramique antique.
} 


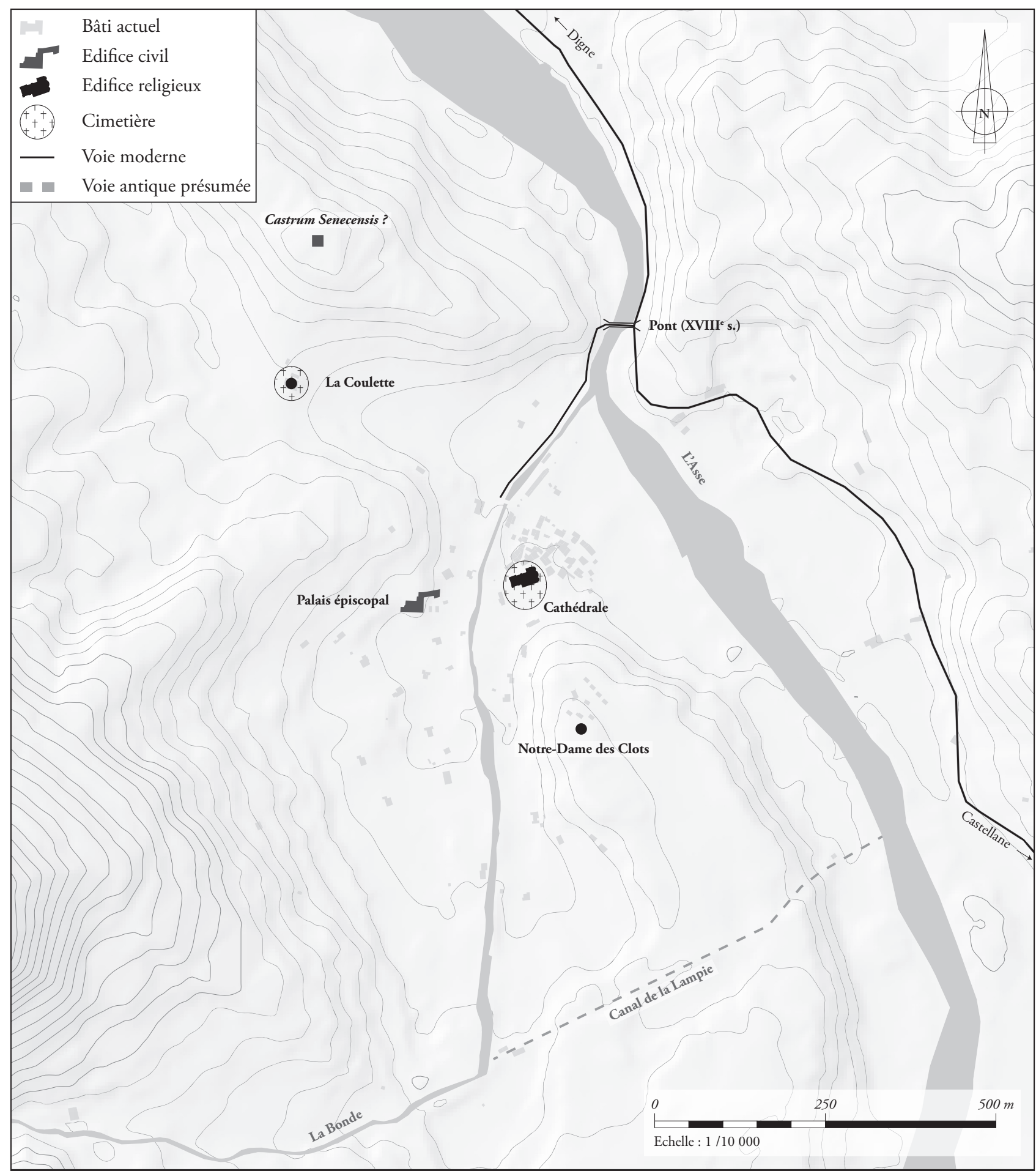

Fig. 5 : Senez : topographie et principaux vestiges archéologiques et monumentaux reconnus sur la commune (C) Yann Dedonder, Mathias Dupuis / SDA 04)

\section{LA CHRISTIANISATION DES HAUTES VALLÉES}

L'apparition du christianisme dans la Provence romaine se perçoit à travers des faisceaux de sources et d'indices convergents, qui nous renseignent à la fois sur la structuration administrative de l'Église et sur la progression de la mission évangélisatrice. Deux difficultés majeures contrarient cependant les tentatives de retracer cette histoire. D'une part les sources textuelles disponibles sont peu nombreuses et masquées par les constructions hagiographiques médiévales et modernes, qui ont longtemps couvert d'un voile légendaire les maigres faits historiques sur lesquels il est réellement possible de s'appuyer (Février 1980). D'autre part, la tentation est parfois grande, en l'absence de sources textuelles avérées, de vouloir sur-interpréter certaines 


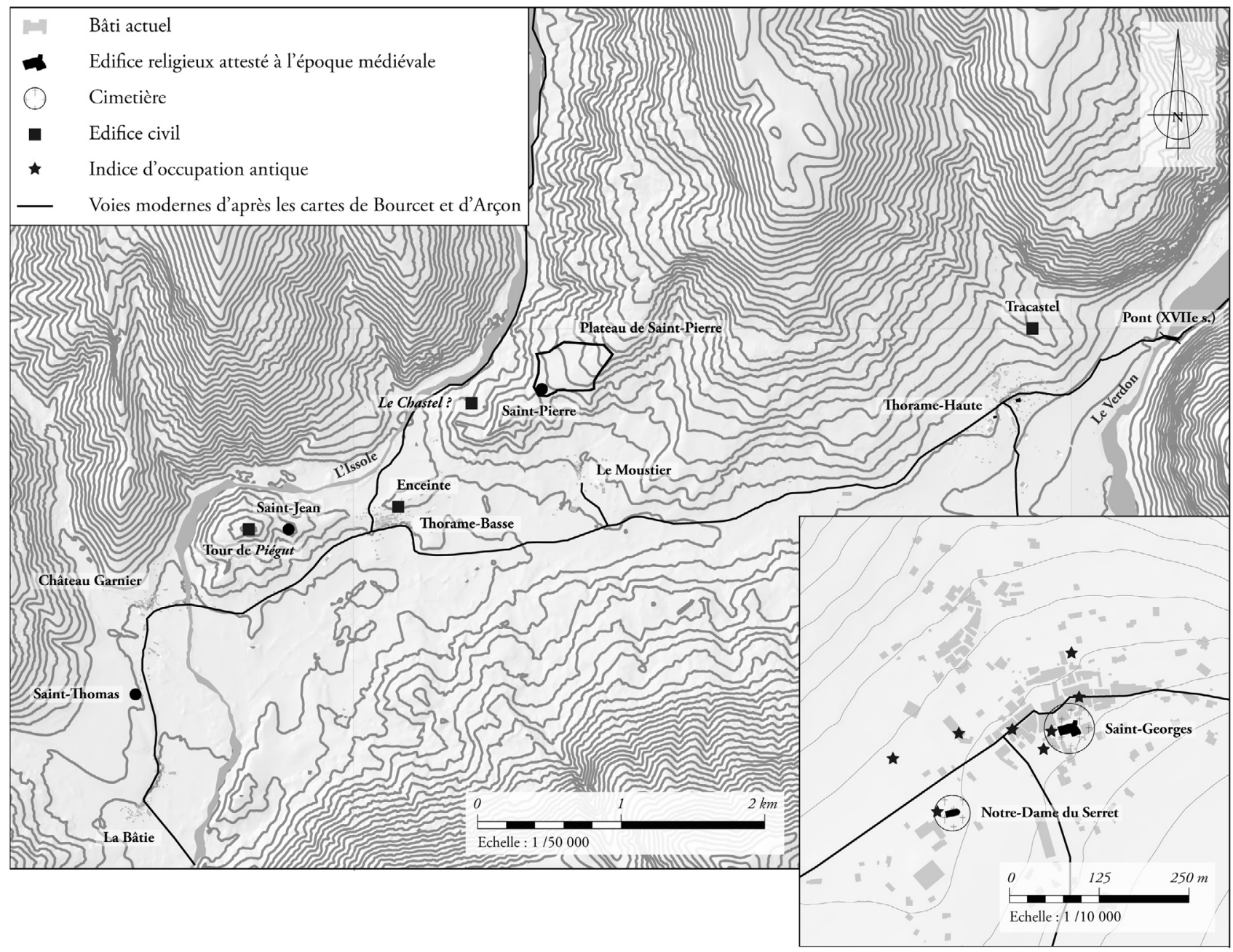

Fig. 6 : Val de Thorame : topographie et principaux vestiges archéologiques et monumentaux reconnus sur les deux communes (C) Yann Dedonder, Mathias Dupuis / SDA 04)

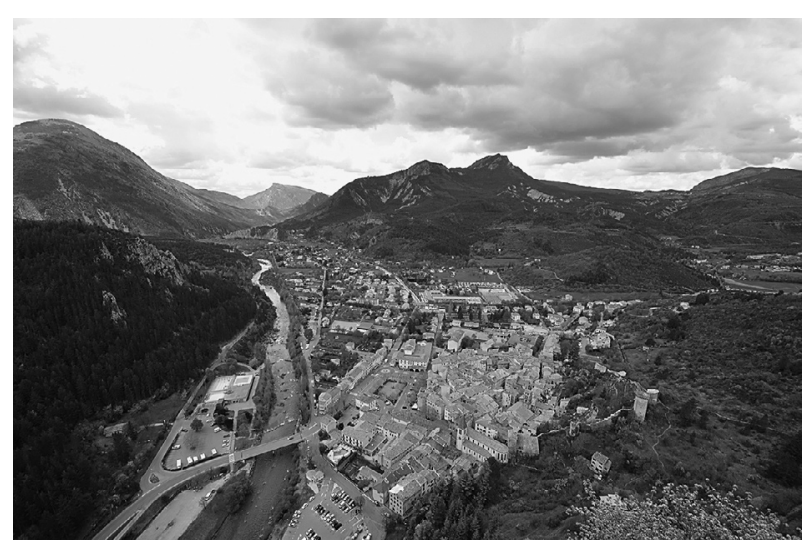

Fig. 7 : Castellane : vue de la plaine du Verdon, en direction de l'ouest, depuis le promontoire du Roc. Au premier plan le bourg entouré de son enceinte du XIV ${ }^{\mathrm{e}}$ siècle, au second plan le quartier du Plan, où se situerait la ville antique de Salinae (C) Mathias Dupuis / SDA 04) traces matérielles comme des évidences archéologiques à même d'illustrer cet épisode historique. La confrontation des sources textuelles et matérielles pose alors de sérieuses difficultés méthodologiques pour appréhender clairement le phénomène multiforme que recouvre le terme de « christianisation » (Codou et Colin 2007). À ces difficultés s'ajoutent, dans le cas particulier du diocèse de Senez, la complexité posée par les modalités de la réorganisation administrative qui intervient au cours de l'Antiquité tardive.

\section{L'héritage hagiographique}

La christianisation des hautes vallées de l'Asse et du Verdon n'a donné lieu à aucun texte hagiographique, ni même à des récits légendaires rapportées par l'historiographie. Tout au plus est-il fait mention d'un évêque Ursus qui aurait occupé le trône épiscopal de Senez au début $d u V^{e}$ siècle, mais son invention paraît relever d'une construction moderne (12). L'existence d'Ursus

\footnotetext{
${ }^{2}$ Son existence est rapportée au XVII ${ }^{\circ}$ siècle dans la Gallia Christiana, sur la base d'une source émanant de Polycarpe de la Rivière, connu pour ses nombreuses falsifications (Duchesne 1907, 1, 293). Faudrait-il le rapprocher de saint Ours, évangélisateur de la vallée d'Aoste, connu par une vita carolingienne?
} 


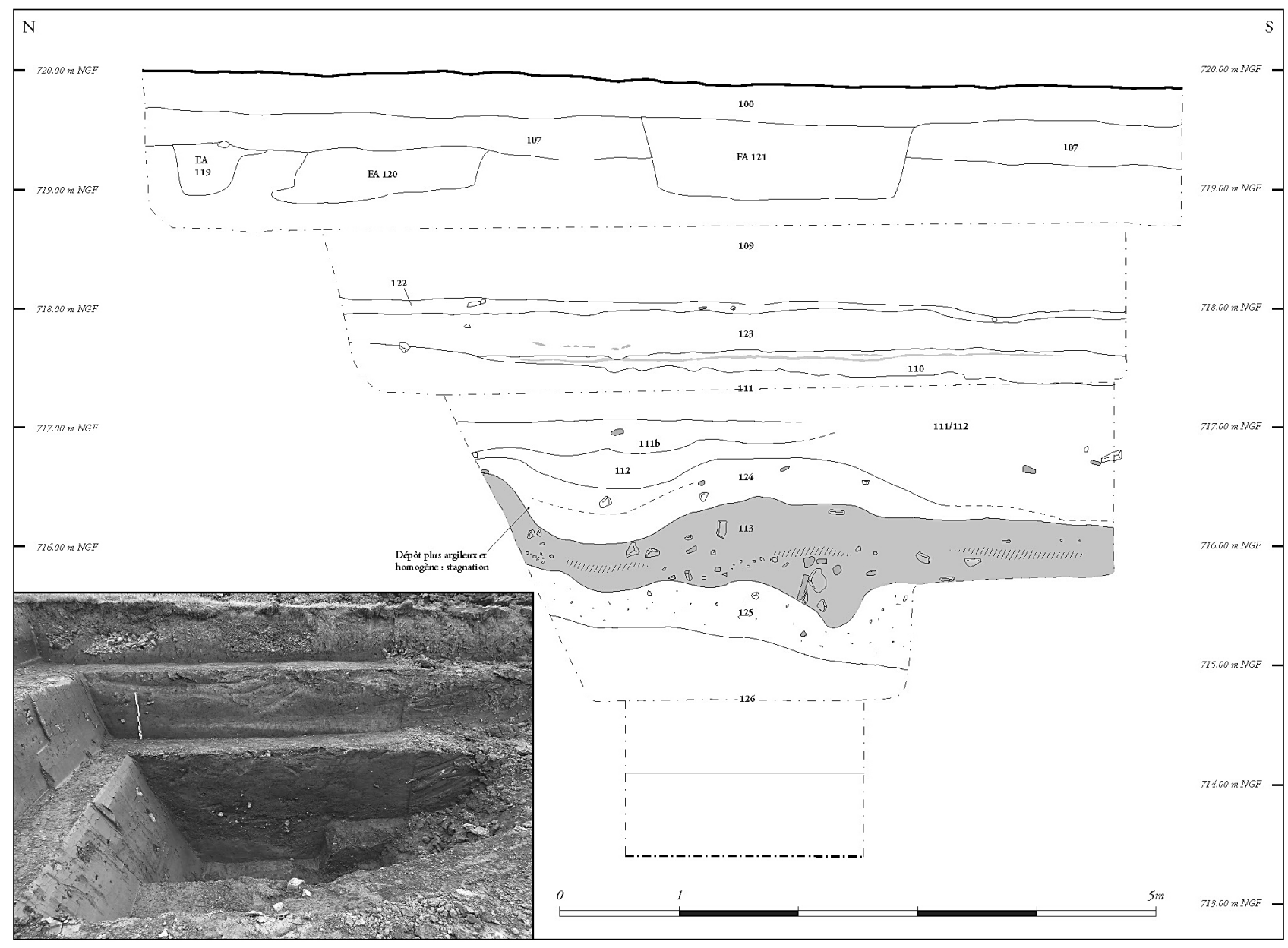

Fig. 8 : Castellane : site du gymnase Notre-Dame, coupe stratigraphique d'un sondage profond. Le niveau grisé était chargé en mobilier céramique antique (C) Mathias Dupuis, Soazic Bezault / SDA 04)

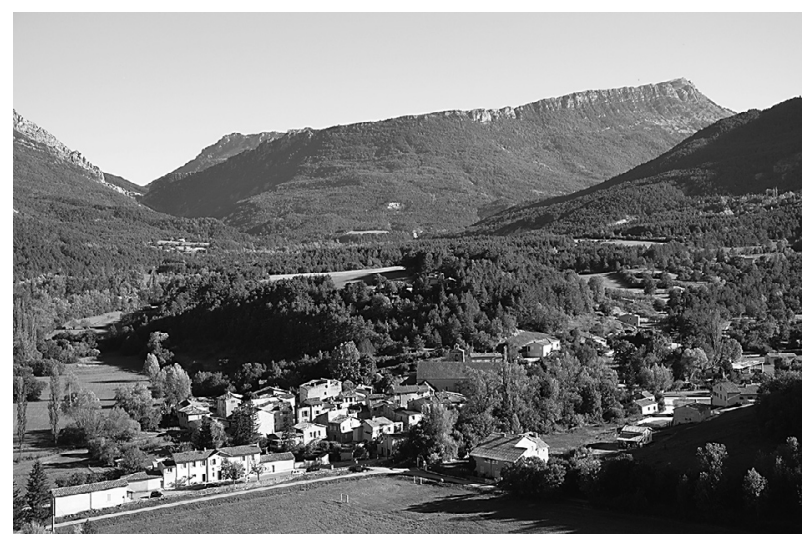

Fig. 9 : Senez : le village vu en direction du sud-est, depuis le site de la Roche (C Mathias Dupuis / SDA 04) n'est nullement confirmée par les actes conciliaires, dans lesquels aucune communauté chrétienne n'est attestée à Senez avant 506. Les premiers évêques de la cité ne connaissent d'ailleurs aucune postérité hagiographique aux périodes médiévales et modernes et les origines de la mission chrétienne dans le diocèse font pâle figure au regard du prestige de personnages voisins, tels que Maxime et Fauste de Riez (Boulhol et al. 2014) (13). Au demeurant, aucun document ne permet de postuler que les hautes vallées des Alpes Maritimae purent constituer un foyer pour l'implantation précoce d'établissements monastiques ou d'ermitages. Du moins, si de tels établissements ont pu exister, il n'en demeure aujourd'hui aucune mémoire. L'investissement de ces espaces de montagne au cours du Moyen Âge central, par les

\footnotetext{
${ }^{13}$ Dans son étude consacrée aux origines chrétiennes de la Narbonnaise seconde et des Alpes Maritimes, Georges de Manteyer ne relève aucune fête patronale célébrée dans le diocèse de Senez et pouvant renvoyer à l'Antiquité tardive, en dehors de celle de saint Antoine ermite (Manteyer 1924, 48). Le même auteur relève l'absence de livres liturgiques mentionnés dans les sources modernes relatives au diocèse (Manteyer 1924, $\mathrm{n}^{\circ}$. 123, 163-164). Cette absence de tradition hagiographique locale transparaît à la lecture d'un calendrier obituaire de la cathédrale conservé à Carpentras et récemment édité par Thierry Pécout, dans lequel les saints de l'Antiquité tardive célébrés sont ceux des diocèses voisins. Comme le rappelle l'auteur « la cathédrale de Senez est dépourvue d'une hagiographie propre à ses origines, ce qui a sans doute défavorisé toute réflexion sur les listes épiscopales aux époques modernes » (Pécout 2016, 19).
} 
abbayes de Saint-Victor de Marseille et de Lérins, ne semble d'ailleurs pas avoir suscité de tentatives, de la part de ces communautés, de raviver le souvenir de traditions antérieurs, ou bien il n'en reste plus aucune trace.

À la fin du XVIII ${ }^{\mathrm{e}}$ siècle, Laurensi proposait de voir dans saint Pons de Cimiez et saint Marcellin d'Embrun les principaux artisans de la christianisation du diocèse (Laurensi 1898, p. 50-65), faisant ainsi référence aux personnalités marquantes des débuts du christianisme dans les Alpes méridionales. De fait, si l'on se rapporte aux sources textuelles disponibles, il est vrai que le littoral niçois et la région d'Embrun semblent constituer les deux principaux viviers à partir desquels se propage la mission chrétienne dans les hautes vallées. Il y a d'abord une évidence géographique, puisque Senez est situé sur l'axe de passage permettant de relier les deux centres administratifs successifs de la province. Quelques indices épars laissent également percevoir l'influence que purent jouer les pôles religieux avoisinants au cours de l'époque médiévale, comme le réseau des possessions monastiques attestées dans les cartulaires ou les titulatures des églises lorsqu'elles renvoient à l'hagiographie locale. Cette démarche doit toutefois être abordée avec toute la prudence qui incombe aux méthodes régressives : d'une part les possessions monastiques connues à partir des $\mathrm{X}^{\mathrm{e}}-\mathrm{XI}^{\mathrm{e}}$ siècles ne reflètent pas nécessairement l'étendue d'un temporel plus ancien ; d'autre part les titulatures des lieux de culte peuvent relever de traditions hagiographiques médiévales, sans lien direct avec la perpétuation d'une mémoire tardoantique (Février 1985). Du reste, les premiers vocables renseignés dans le diocèse apparaissent seulement aux $\mathrm{X}^{\mathrm{e}}-\mathrm{XI}^{\mathrm{e}}$ siècles, dans les cartulaires de Saint-Victor de Marseille et de Lérins, interdisant de fait l'établissement d'une filiation directe entre certaines titulatures médiévales et des usages cultuels ou hagiographiques antérieurs (14). Le travail d'analyse régressive permis par l'analyse synthétique de l'évolution des dédicaces d'églises, tel qu'il a par exemple été conduit sur les paroisses de Touraine par Élisabeth Zadora-Rio (ZadoraRio 2008), est donc impossible à l'échelle de l'ancien diocèse de Senez.

Quels que soient les doutes qui demeurent sur l'évangélisation du diocèse, il paraît cependant évident que la région niçoise, à l'extrémité sud-est de la province, constitue un « avant-poste » majeur pour la mission chrétienne dans les vallées des Alpes provençales (15). Une communauté chrétienne est ainsi attestée à Nice à partir de 314 et Cimiez, qui demeure la capitale provinciale jusqu'à la fin du $\mathrm{IV}^{\mathrm{e}}$ ou le début du $\mathrm{V}^{\mathrm{e}}$ siècle, bénéficie à ce titre d'une influence particulière (Duval, Février et al.
1986, 77-88). Le premier évêque connu de cette cité, Valérien, attesté à partir du concile de Riez en 439, joue un rôle intellectuel notable, à travers les homélies qu'il compose en l'honneur d'un martyr local anonyme du $\mathrm{III}^{\mathrm{e}}$ siècle, par la suite associé à saint Pons, dont le culte connaît un rayonnement important en Provence à l'époque médiévale (Laguerre 1967). Saint Pons laisse son nom à une puissante abbaye niçoise, sans doute fondée ou restaurée à la fin du $\mathrm{VIII}^{\mathrm{e}}$ siècle (Magnani 1999, 28). Les possessions de l'abbaye ne s'étendent pas dans l'ancien diocèse de Senez, mais quatre édifices au moins sont placés sous son vocable au cours du Moyen Âge central (16) et son culte semble avoir été particulièrement développé à Castellane et dans ses environs. Cependant, là encore, les titulatures ne sont pas attestées avant le début du $\mathrm{XII}^{\mathrm{e}}$ siècle et peuvent tout à fait renvoyer à des usages largement postérieurs à la rédaction de la vie du saint (17). Le monastère de Lérins, au large de Cannes, joue également un rôle primordial puisqu'il pourvoit, au cours du $\mathrm{V}^{\mathrm{e}}$ siècle, de nombreux sièges voisins de celui de Senez par des évêques aux personnalités marquantes, tels Valérien à Cimiez (439-451) ; Maxime (433-452) et Fauste (462-485) à Riez ou Theodore à Fréjus (439-452) (Heijmans et al. 2009). L'influence de l'abbaye, restaurée sous l'impulsion de Cluny au $\mathrm{XI}^{\mathrm{e}}$ siècle, se perçoit bien plus tardivement, à travers son réseau de possessions disséminées dans le diocèse et dans l'ensemble de la Provence orientale, sans qu'il soit possible cependant d'établir un lien direct entre la tradition tardo-antique et la constitution du temporel médiéval (Magnani 1999, 287-333).

À l'extrémité septentrionale de la province, Embrun constitue un second pôle, dont l'influence se manifeste essentiellement à travers la personnalité légendaire de son premier évêque, saint Marcellin, dont la vita nous apprend qu'il serait venu d'Afrique et aurait été installé sur le siège épiscopal vers 370 par les évêques Eusèbe de Verceil et Émilien de Valence (18). D'après ce document, c'est à partir d'Embrun que se seraient ensuite dirigés les deux disciples de Marcellin, Vincent et Domnin, pour évangéliser la ville de Digne (19). Grégoire de Tours relate le culte porté par la ville d'Embrun à Marcellin, ainsi qu'aux pseudo-martyrs milanais Nazaire et Celse (Duval, Février et al. 1986, 69-72). Malgré l'imprécision du récit de Grégoire et les doutes qui subsistent sur la véracité des faits rapportés dans la Vita S. Marcellini, ces éléments mettent en lumière un second vecteur d'influence : celui des grands foyers d'Italie septentrionale (Turin, Milan, Vercelli), auxquels conduisent les hautes vallées de l'Asse et du Verdon par le biais des voies alpines.

\footnotetext{
${ }^{14}$ Pour la liste et la cartographie des églises médiévales attestées dans le diocèse, se rapporter à Pécout 2016.

${ }^{15}$ Sur les origines du diocèse de Nice, voir la synthèse récente de Marc Bouiron et Yann Codou (Bouiron, Codou 2015)

${ }^{16}$ Saint-Pons d'Eoulx à Castellane ; Saint-Pons de Peyroules ; Saint-Pons de Blieux ; Saint-Pons de Barrême.

${ }^{17}$ Le martyr de saint Pons est relaté dans une Passion que Jean-Pierre Weiss attribue à un anonyme du dernier quart du VIII ${ }^{\mathrm{e}}$ siècle (Weiss 1990 ).

${ }^{18}$ L'origine tardo-antique de la Vita S. Marcellini est douteuse et ce texte a été vivement critiqué par Paul-Albert Février (Février 1985, 19 ; Duval, Février et al. 1986, 69-72 ; Démians d'Archimbaud 1990, 17-18). D'après cet auteur, le récit pourrait avoir été composé aux VIII'-IXe siècle, afin de légitimer les prétentions métropolitaines d'Embrun. Il n'existe aucune certitude sur l'existence de textes hagiographiques relatifs à saint Marcellin antérieurs à cette époque. Le premier évêque d'Embrun attesté dans les conciles est Armentarius, mentionné en 439.

${ }^{19}$ Le premier évêque attesté avec certitude à Digne est en réalité Pentadius, mentionné lors du concile d'Agde en 506, aux côtés de Marcellus de Senez (Roux 1971).
} 


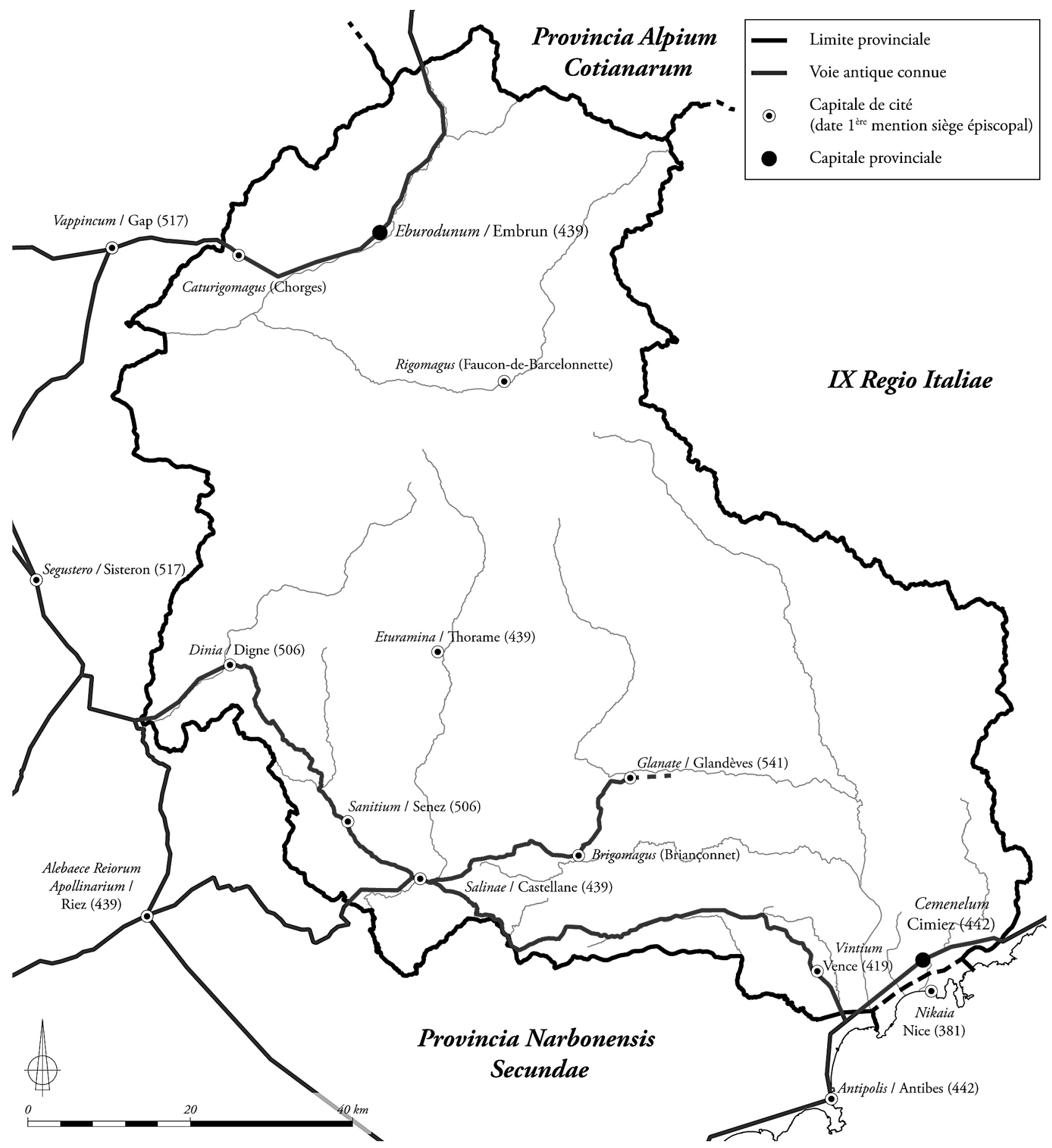

Fig. 10 : La province des Alpes Maritimae à la fin de l'Antiquité (C Yann Dedonder, Mathias Dupuis / SDA 04)

La création des sièges épiscopaux : des textes à l'archéologie

Les actes conciliaires mettent en lumière la situation singulière du diocèse de Senez qui regroupe, outre le siège épiscopal, les évêchés éphémères de Castellane et de Thorame, qui ne paraissent pas avoir survécu aux réorganisations administratives de la fin $\mathrm{du}^{\mathrm{e}} \mathrm{siècle.} \mathrm{En}$ effet, au début du $\mathrm{V}^{\mathrm{e}}$ siècle, la Notitia Galliarum présente les Alpes Maritimae découpées en huit civitates (Mommsen 1892, 611-612) (fig. 10). Parmi celles-ci, apparaissent alors Sanitium (Senez) et Salinae (Castellane). Or, dès le milieu du $\mathrm{V}^{\mathrm{e}}$ siècle, la seconde est dotée d'un évêque qui assiste aux conciles de Riez en 439 et de Vaison en 442, tandis que la cité de Senez n'est pas représentée (Palanque 1951 ; Roux 1971). Les actes du concile de Vaison indiquent en outre la présence d'un évêque Severianus à Eturamina (Thorame), qui n'apparaît pas dans la Notitia Galliarum. Le statut administratif de cette dernière agglomération demeure incertain, mais il est possible que Thorame ait été pourvue d'un siège 
L'ANCIEN DIOCĖSE DE SENEZ (ALPES DE HAUTE-PROVENCE) ENTRE ANTIQUITÉ ET MOYEN ÂGE.

ÉTAT DES QUESTIONS ET PERSPECTIVES DE RECHERCHES

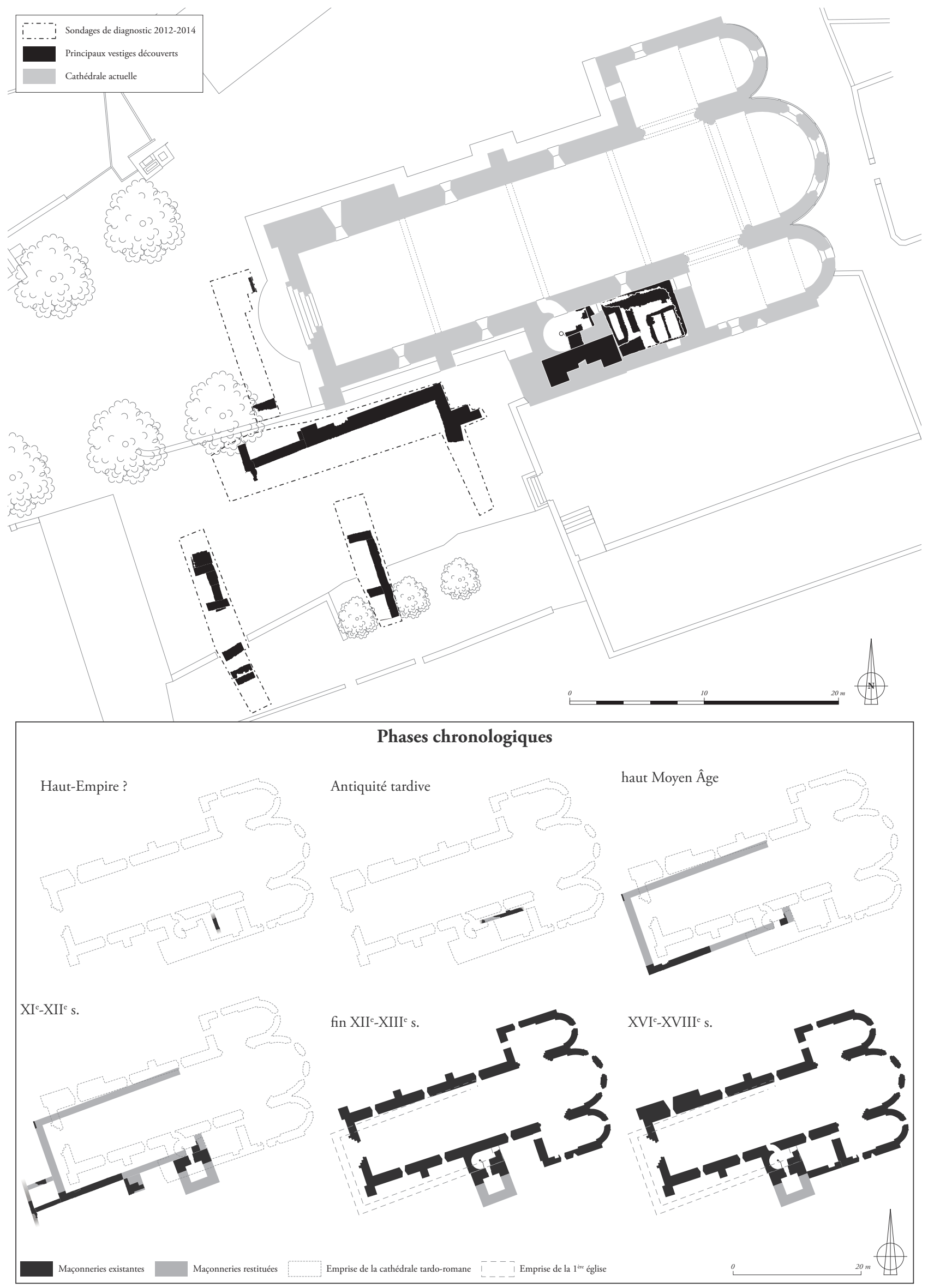

Fig. 11 : Senez : plan de la cathédrale et localisation des différentes découvertes archéologiques à ses abords. Hypothèses de phasage chronologique des vestiges. (C) Mathias Dupuis / SDA 04)

15 
épiscopal sans jamais avoir accédé au statut de capitale de cité (20). À partir du début du $\mathrm{VI}^{\mathrm{e}}$ siècle, les évêques de Salinae et d'Eturamina disparaissent totalement de la documentation, tandis qu'émerge le siège de Sanitium attesté à partir du concile d'Agde en 506, au cours duquel est mentionné l'évêque Marcellus. Les agglomérations de Castellane et de Thorame auraient alors déjà été absorbées par le nouveau siège de Senez, puisque leurs territoires respectifs - la moyenne et la haute vallée du Verdon - apparaissent ultérieurement comme relevant de ce diocèse.

\section{La cathédrale de Senez.}

Les connaissances archéologiques sur Senez ont été enrichies par les découvertes effectuées ces dernières années sur le site de la cathédrale Notre-Dame de l'Assomption, presque entièrement reconstruite à partir de la fin du XII siècle (Dupuis et al. 2017, Dupuis et al. 2018) (fig. 11).

Les fouilles archéologiques conduites dans la sacristie, au sud-est de la cathédrale, démontrent qu'une première zone d'inhumation succède aux niveaux d'abandon tardo-antique que nous avons précédemment évoqués. Les six sépultures découvertes au cours de la campagne 2017 - disposées dans des coffrages de tuiles ou de lauzes qui renvoient à la période fin $\mathrm{IV}^{\mathrm{e}} /$ début VIII $^{\mathrm{e}}$ siècle (21) - ont été progressivement installées contre un édifice dont seul le mur méridional a été dégagé, sur une longueur de 7,30 m environ, au pied du mur gouttereau de la cathédrale actuelle. La nature exacte de ce bâtiment est inconnue à ce jour, mais la présence des tombes agglomérées contre l'un de ses murs ne laisse aucun doute sur sa fonction funéraire (fig. 12). Cette découverte doit être mise en relation avec les résultats des sondages de diagnostic réalisés en 2012 et 2014, qui avaient révélé la présence de deux sépultures sous le terrain attenant au flanc sud de la cathédrale, soit à une quarantaine de mètres au sud-ouest la sacristie. L'une d'elles correspondait à une inhumation déposée dans un coffrage en bâtière de tegulae et de lauzes, accompagnée par deux dépôts secondaires plus tardifs, regroupant les restes de six individus au minimum. L'analyse radiocarbone de l'inhumation primaire indique une date large, comprise entre la fin du $\mathrm{IV}^{\mathrm{e}}$ et le début du $\mathrm{VI}^{\mathrm{e}}$ siècle (22). À ces découvertes récentes, s'ajoute celle, beaucoup plus ancienne, d'un coffret en plomb décoré d'un chrisme, mis au jour en 1854, dans le jardin de la maison Raynard, immédiatement au sud-est de l'abside de la cathédrale (Igolen 1952) (23) (fig. 13). Ces différents éléments indiquent qu'un espace funéraire de l'Antiquité tardive s'étendait assez largement au sud de la cathédrale actuelle et couvrait en partie des structures plus anciennes, au moins en partie abandonnées au cours du Bas-Empire.

Dans une séquence chronologique qu'il est encore difficile de situer avec précision, une église d'assez grandes dimensions est construite en lien avec cet espace funéraire, ou bien lui succède. Trois angles de ce bâtiment ont été reconnus au cours des différentes campagnes de fouille, permettant de restituer un plan rectangulaire, long de $23 \mathrm{~m}$ pour $12,30 \mathrm{~m}$ de large horsœuvre, dont les dispositions intérieures et la partie orientale demeurent inconnues. Cette église est décalée de quelques mètres vers le sud-ouest, par rapport à la cathédrale tardo-romane, sans doute en raison d'une contrainte topographique liée au déroulement du chantier de construction de la fin du XII ${ }^{e}$ siècle (fig. 14). L'orientation de l'église primitive respecte celle des bâtiments auxquels elle succède, indiquant ainsi que la trame monumentale antique est encore déterminante lors de sa construction. Sa datation absolue nous échappe encore, mais sa chronologie relative peut être déduite à partir de l'analyse de son contexte stratigraphique. Nous constatons ainsi que sa partie sud-est, dont les élévations ont été partiellement intégrées à la cathédrale tardo-romane, est postérieure au bâtiment funéraire contre lequel sont accolées les tombes de l'Antiquité tardive. Un terminus ante quem est donné par la présence d'une sépulture datée entre la fin du VII ${ }^{\mathrm{e}}$ et la fin du $\mathrm{IX}^{\mathrm{e}}$ siècle, reconnue contre son mur sud. Sa construction se situe donc au cours du haut Moyen Âge. L'église primitive est progressivement transformée au cours de l'époque médiévale, comme en témoignent plusieurs adjonctions architecturales, et notamment la construction d'un clocher-tour accolé contre son angle sud-est. Cet ouvrage devait présenter un plan carré et mesurer environ 5,90 m de côté hors-œuvre, pour une hauteur estimée à $12 \mathrm{~m}$ minimum. Sa mise en œuvre est très similaire à celle du clocher construit entre la fin du $\mathrm{XI}^{\mathrm{e}}$ et le début du XII ${ }^{\mathrm{e}}$ siècle contre l'église qui précède la cathédrale Notre-Dame du Bourg à Digne : comme celui-ci, il s'agit d'une tour formée par un soubassement en appareillage de moellons, sans doute doté à sa base d'une salle voûtée d'arêtes, au-dessus duquel s'élevait une superstructure en petit appareil de tuf, décorée de moulures à doubles chanfreins et percée d'ouvertures (fig. 15). Enfin, plusieurs sépultures installées contre le mur méridional de cette église, dont les plus récentes remontent à la

\footnotetext{
${ }^{20}$ C'est également le cas, en Provence, de Nice et de Toulon, qui sont chacune pourvue d'un évêque en 381 pour l'une et 441 pour l'autre (Duval, Février et al. 1986, p. 61-63 et 77-88). Mais il s'agit toutefois de deux ports maritimes et ces sièges perdurent ensuite au cours du Moyen Âge. La situation de Thorame pourrait se rapprocher de celle du siège éphémère créé plus tardivement, à la fin du $\mathrm{VI}^{\mathrm{e}}$ siècle, dans le vicus d'Arisitum, aux confins septentrionaux de la cité de Nîmes. Ce minuscule diocèse, disparu au cours du Moyen Âge, reçu l'administration d'un réseau d'une quinzaine d'églises (dioceses minores), sans doute situées dans son immédiat ressort territorial (Schneider 2008).

${ }^{21}$ Ces sépultures n'ont pas encore fait l'objet de datations radiocarbone permettant d'affiner cette fourchette chronologique.

${ }^{22}$ Échantillon Beta-416943, intervalles à 395-425 AD (68\% de probabilité) et 380-535 AD (95\% de probabilité).

${ }^{23}$ Nous remercions François Baratte pour les indications fournies sur la typologie des reliquaires métalliques paléochrétiens, dans laquelle paraît s'inscrire cet objet qui a désormais disparu (Buschhausen 1971). L'hypothèse émise par Marie-Madeleine Viré, selon laquelle ce reliquaire serait en réalité celui du cœur de l'évêque Duchaine, décédé en 1671 (Viré 1992, 149), doit être rejetée.
} 


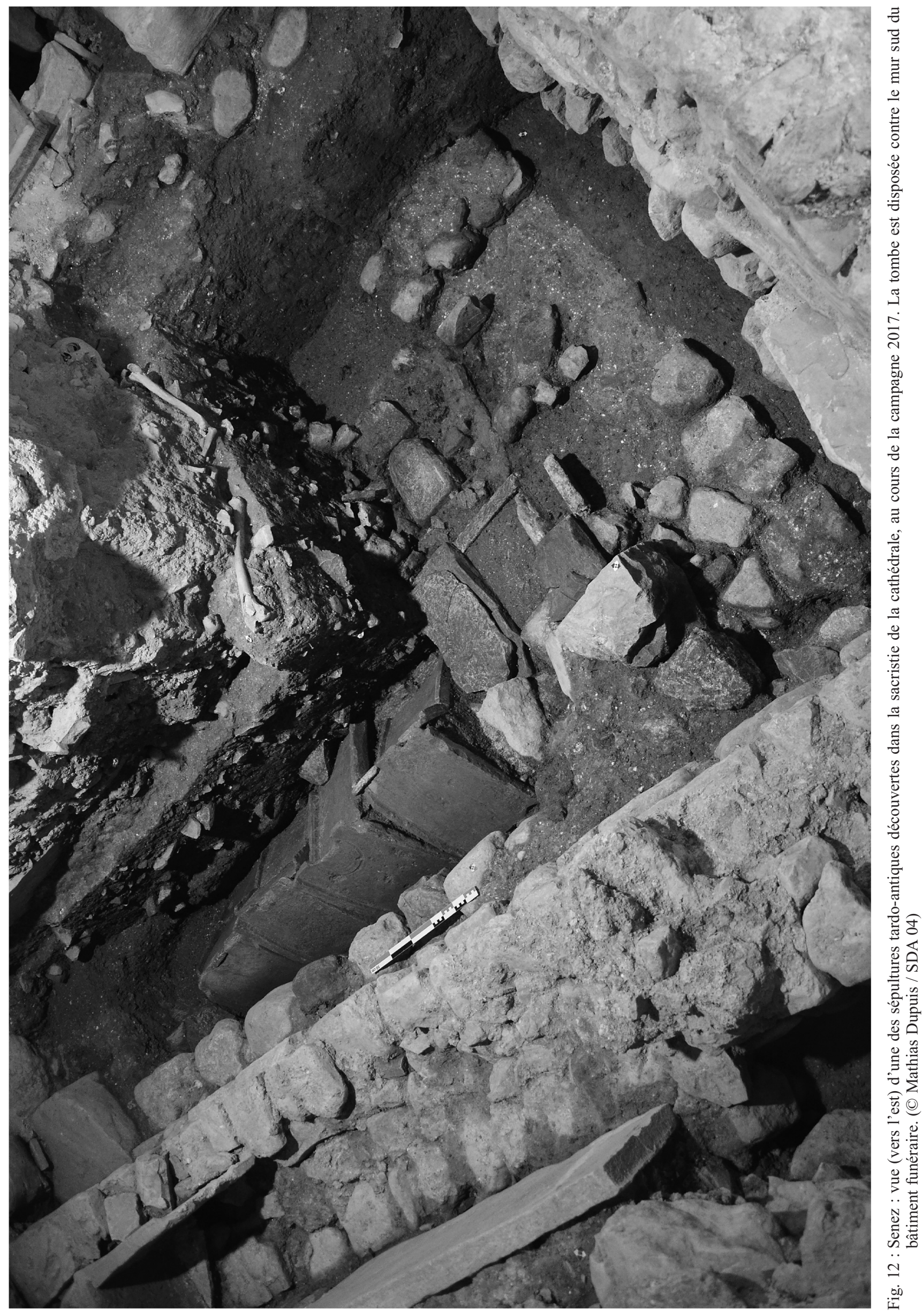



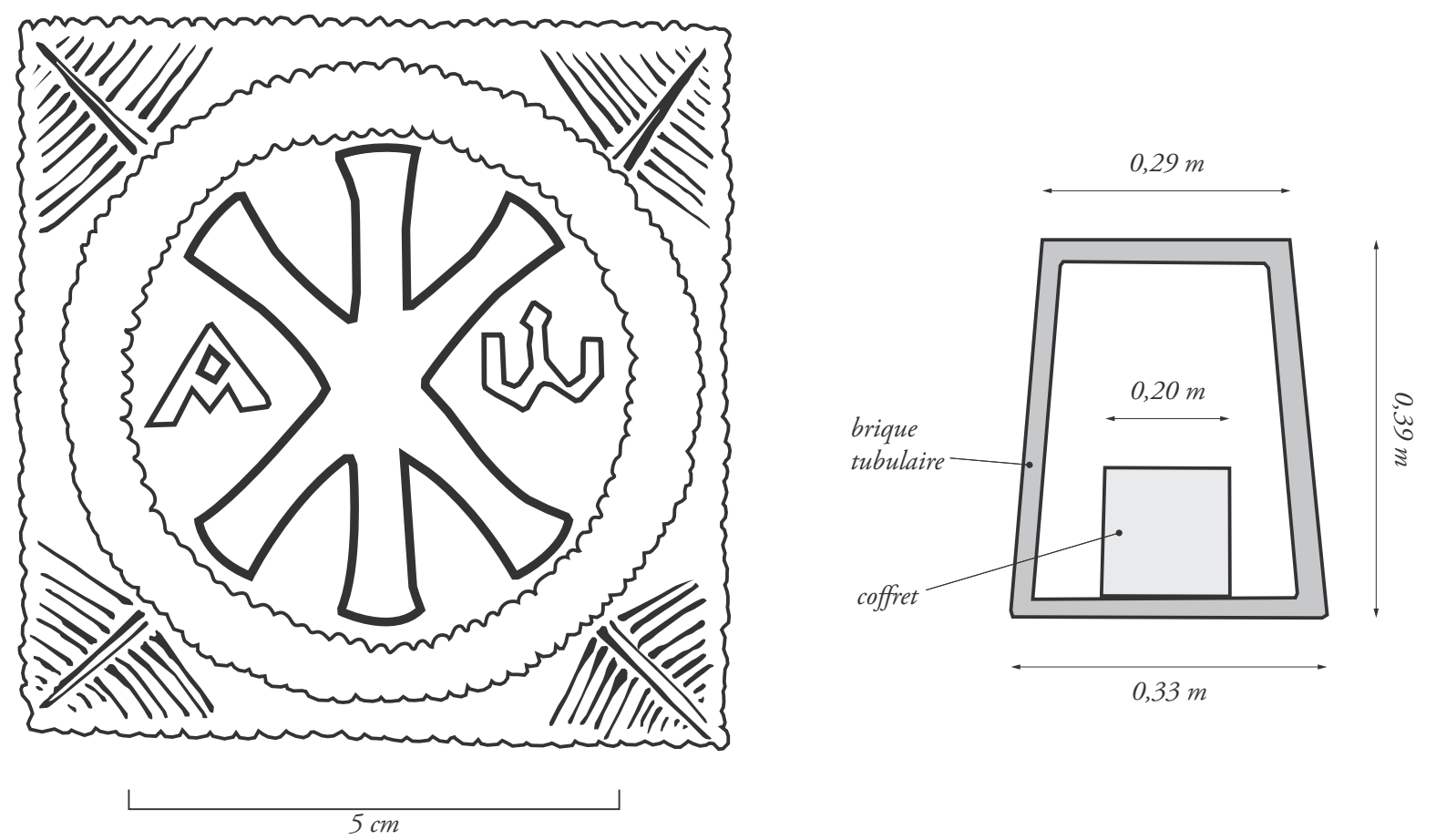

Fig. 13 : Senez : dessin du reliquaire en plomb découvert en 1854 aux sud-est de la cathédrale (C Mathias Dupuis, d'après Igolen 1952)

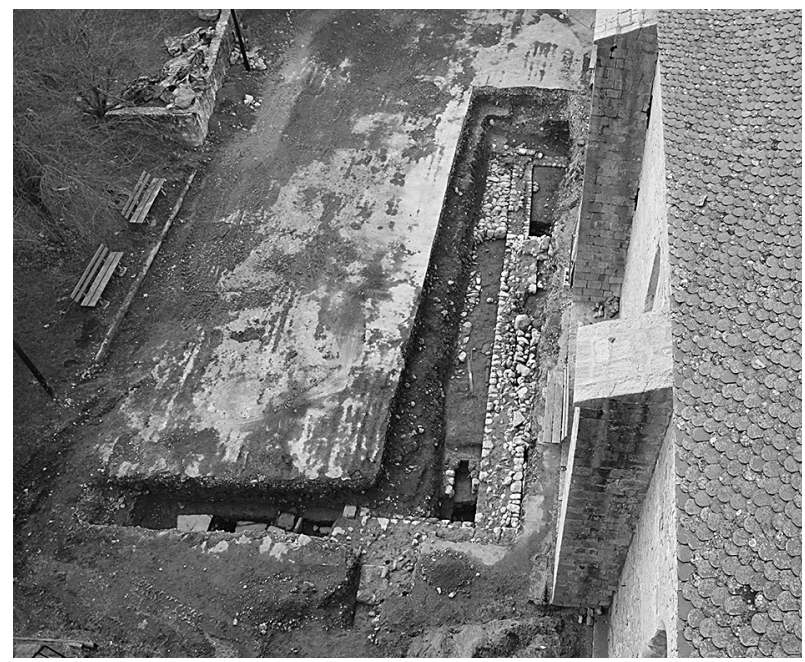

Fig. 14 : Senez : vue (vers l'ouest) du mur sud de l'église primitive, dégagé lors du diagnostic de 2012. (C) Mathias Dupuis / SDA 04)

période des $\mathrm{XI}^{\mathrm{e}}-\mathrm{XII}{ }^{\mathrm{e}}$ siècle, indiquent que l'édifice est encore en fonction juste avant la reconstruction de la cathédrale à la fin du XII ${ }^{\mathrm{e}}$ siècle. L'église primitive est alors détruite, mais son clocher roman est conservé et intégré au nouveau bâtiment.

\section{Castellane et Thorame}

En l'absence de nouvelles recherches archéologiques, la configuration topographique des sièges éphémères de Castellane et de Thorame demeure à peu près aussi méconnue qu'elle l'était par le passé (Barruol 2004a ; Barruol 2004b ; Barruol 2004c).

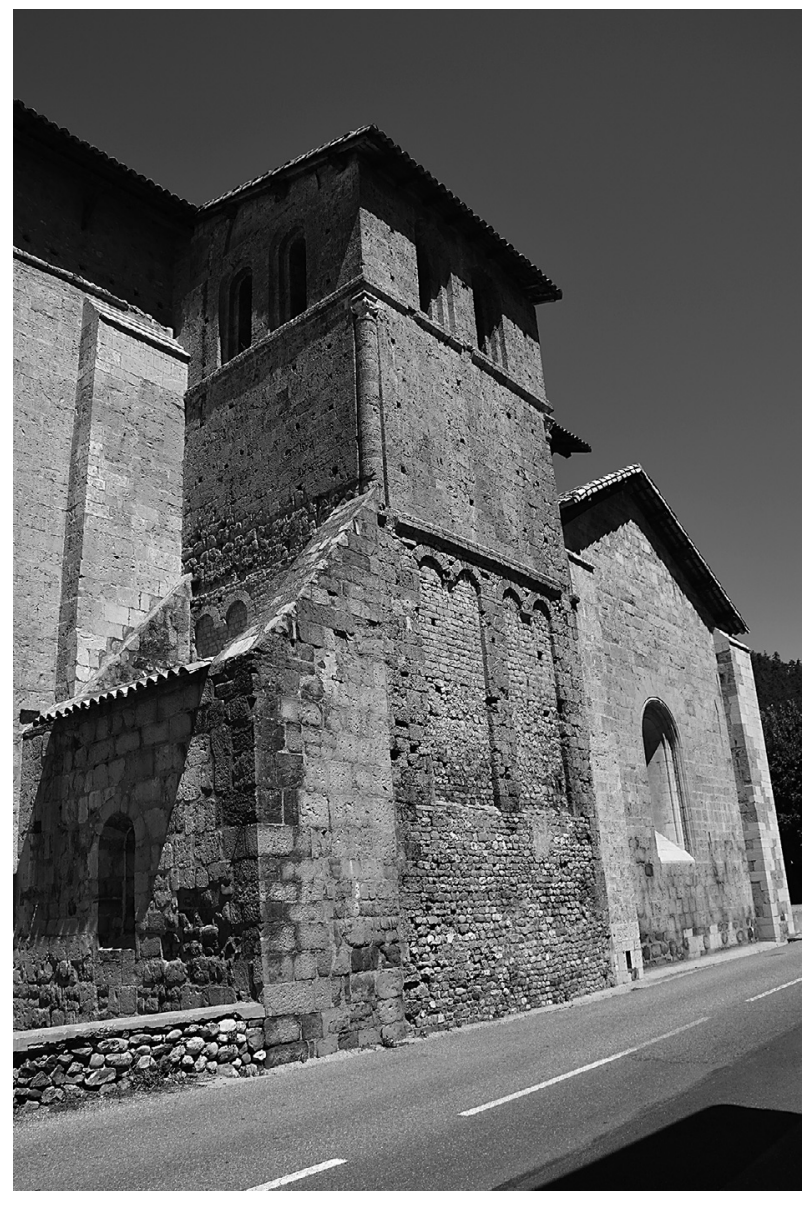

Fig. 15 : Digne-les-Bains : clocher roman intégré à la cathédrale Notre-Dame du Bourg lors de sa reconstruction (@) Mathias Dupuis) 
Si l'on se rapporte aux indices archéologiques connus, aucune découverte ne permet actuellement de localiser les traces d'une occupation tardo-antique à Castellane, mais aucune investigation n'a jamais été conduite aux abords des différentes églises de la ville. Une idée tenace consiste cependant à positionner le groupe épiscopal primitif à l'emplacement de l'église prieurale Notre-Dame, située dans le quartier du Plan, dans l'emprise supposée de la ville antique. Cette hypothèse, autrefois avancée avec prudence par Paul-Albert Février (Février 1964, p. 57-58), repose uniquement sur des actes du cartulaire de Saint-Victor de Marseille, dans lesquels sont restituées à l'abbaye les églises SainteMarie avec Saint-Jean Baptiste, Saint-Pierre et SaintLaurent (Guérard 1857, 2, nº 769 ; Magnani 1999, 219). Concernant Thorame, Paul-Albert Février émet la même hypothèse à propos des églises de Piégut, dédiées à Sainte-Marie, Saint-Etienne protomartyr et celle construite depuis lors et dédiée à Saint-Jean, données en 1056 par Rostaing à Saint-Victor de Marseille (Guérard 1857, 2, $\mathrm{n}^{\circ}$ 764). Dans ces deux cas de figure, l'auteur suggère que ces vocables multiples pourraient avoir conservé le souvenir d'une église cathédrale double, placée sous la titulature de la Vierge et d'un protomartyr. À Castellane comme à Thorame cependant, les sites en question n'ont jamais fait l'objet de la moindre découverte significative permettant d'attester une occupation aussi ancienne ou d'une quelconque mémoire épiscopale. Paul-Albert Février avait lui-même souligné les difficultés posées par ce type de raisonnement régressif (Février 1964, 58), qui a également été critiqué par Michel Fixot et Yann Codou (Fixot, Codou 1996). Ces derniers avancent que la multiplicité de vocables pourrait tout aussi bien renvoyer à un contexte monastique, cohérent avec le rattachement de ces établissements à SaintVictor de Marseille.

Quant à Thorame, nous avons évoqué plus haut les quelques découvertes qui indiquent la présence d'au moins trois espaces funéraires, dans lesquels ont été découvertes des sépultures sous bâtière de tegulae, un mode d'inhumation assez caractéristique de la fin de l'Antiquité en Haute-Provence. Ces vestiges se situent autour de l'église paroissiale Saint-Julien et de la chapelle Notre-Dame du Serret à Thorame-Haute ainsi que sur le site de hauteur du plateau de Saint-Pierre à Thorame-Basse. Dans les deux premiers cas, il est fort probable que la présence de ces inhumations puisse renvoyer à une origine ancienne des lieux de culte auxquels elles sont associées (24). Les tombes de NotreDame du Serret paraissent ainsi s'inscrire dans un petit bâtiment de plan carré, qu'il conviendrait d'étudier de façon plus poussée. Dans le cas du plateau de SaintPierre (1 $270 \mathrm{~m}$ ), situé à mi-chemin entre les deux
Thorame, l'occupation antique semble avoir été pérennisée par l'existence d'une chapelle placée sous la titulature de saint Pierre et par le toponyme du hameau situé en contrebas du plateau, le Moustier, qui conserve la mémoire d'un site monastique ancien (25). La présence de grands bâtiments arasés à proximité des sépultures interroge sur leur fonction et sur la nature de l'établissement de hauteur auxquels ils pourraient correspondre. Tout travail ultérieur sur la topographie antique de Thorame devra porter en premier lieu sur une analyse plus approfondie de ce site.

\section{Du diocèse à la cathédrale : problèmes de topographie}

La synthèse des données disponibles sur la christianisation de l'ancien diocèse de Senez appelle quelques remarques, en guise de conclusion provisoire.

La réorganisation du diocèse de Senez, dont témoignent la disparition des sièges éphémères de Castellane et de Thorame peut être interprétée de deux façons : soit ces deux sièges sont transférés vers un évêché de Senez qui aurait pu exister dès le $\mathrm{V}^{\mathrm{e}}$ siècle, sans pour autant avoir laissé de trace dans les actes conciliaires, soit ils sont regroupés sous l'autorité d'un siège nouvellement créé au début du $\mathrm{VI}^{\mathrm{e}}$ siècle ; cette dernière option étant jugée la plus probable (Vaizey 2002). Au-delà de la seule question du statut de ces territoires à l'époque antique, la disparition des sièges de Castellane et de Thorame et l'émergence tardive du siège de Senez posent le problème des modalités de réorganisation administrative des civitates en lien avec l'apparition des premières communautés chrétiennes. Ce cas de figure paraît alors s'inscrire dans un ensemble de transformations que connaît la province des Alpes Maritimae au cours de l'Antiquité tardive : élévation d'Embrun au rang de capitale provinciale en lieu et place de Cimiez; intégration des civitates de Chorges et Rigomagus dans le ressort du siège d'Embrun ; disparition de Briançonnet au profit de Glandèves ; fusion des sièges de Nice et Cimiez (Morabito 2010b, 23-68). On retiendra que l'existence éphémère des sièges de Castellane et de Thorame a fréquemment permis d'illustrer la question de l'instabilité des cadres administratifs et religieux entre Antiquité et Moyen Âge (Roux 1971 ; Février, Bats et al. 1989, p. 405 ; Beaujard, Prévot 2004). Cet exemple soulève aussi les limites de la méthode régressive, qui consiste à déduire de la documentation médiévale l'organisation administrative des territoires épiscopaux au cours du haut Moyen Âge et des circonscriptions civiles de l'Antiquité tardive (Mazel 2016, 160-165). De fait, la situation fluctuante que connaissent les frontières politiques entre Antiquité tardive et haut Moyen Âge - que

\footnotetext{
${ }^{24}$ L'église Saint-Julien, dans son état actuel, ne paraît pas remonter avant la fin du Moyen Âge et l'une des chapelles latérales porte la date de 1539. La présence de deux colonnes engagées à base prismatique, à l'entrée du chœur, pourrait éventuellement indiquer une construction plus ancienne, mais ces colonnes - composites et non monolithes - ne paraissent pas remonter à l'Antiquité

${ }^{25} \mathrm{Il}$ subsiste aujourd'hui quelques vestiges des murs arasés d'un petit édifice de plan carré qui correspond à cette chapelle. Au moins deux sépultures sous tuiles ont été récemment signalées dans les zones de pâturage qui la surplombent. Les observations réalisées sur place indiquent la présence de nombreux pierriers et murs arasés, dans lesquels on retrouve des fragments de tegulae ainsi que des moellons de grès taillés.
} 
l'on pressent à travers la mise en perspective des sources épigraphiques, de la Notitia Galliarum et de la maigre documentation conciliaire - n'est pas sans incidence sur l'organisation ecclésiastique de la Provence et interdit de voir dans le diocèse médiéval de Senez le reflet d'un unique espace administratif antique. La nature même des relations au sein du clergé séculier, dans lesquelles les rapports interpersonnels et l'autorité de certains évêques transcendent la rigueur des circonscriptions administratives, invite à relativiser la notion de diocèse considéré comme une entité spatiale délimitée et à privilégier l'image d'une zone d'influence plus mouvante (Lauwers 2008) (26). Enfin, toute ambition de vouloir établir une stricte continuité territoriale entre les limites supposées du diocèse au début du $\mathrm{VI}^{\mathrm{e}}$ siècle et celles qui nous sont connues à partir du Moyen Âge central s'efface devant la vacuité des sources textuelles du haut Moyen Âge, sur lesquelles nous reviendrons plus loin.

La mise en perspective de ces données avec les témoignages matériels fournis par la recherche archéologique pose également plusieurs difficultés. Le principal écueil réside dans l'interprétation des édifices découverts en fouille. En ce qui concerne Castellane et Thorame, nous ne savons absolument pas à quelle réalité matérielle renvoie l'existence de sièges épiscopaux éphémères, uniquement connus par des mentions dans les actes conciliaires. En revanche, le plan comme les dimensions de l'église découverte sous la cathédrale de Senez la rapprochent d'autres édifices de l'Antiquité tardive connus sur des sites épiscopaux de la région, à Nice par exemple (27). L'exemple le plus proche et le mieux documenté demeure celui de la cathédrale Notre-Dame du Bourg de Digne, avec lequel la comparaison est particulièrement frappante, aussi bien pour ce qui concerne les formes architecturales que les rythmes de transformation respectifs des deux monuments (Démians d'Archimbaud et al. 2010). Cependant, s'il est assuré que l'édifice de plan rectangulaire découvert sous la cathédrale de Senez correspond à une église, peut-on pour autant affirmer qu'il s'agit de l'ecclesia du siège Sanitium ? La permanence architecturale manifestée par la reconstruction in situ de la cathédrale des $\mathrm{XII}^{\mathrm{e}}-\mathrm{XIII}{ }^{\mathrm{e}}$ siècles parait aller dans ce sens. La proximité d'un espace d'inhumation est en revanche plus surprenante et parait offrir un contre-point au schéma de développement des groupes épiscopaux de l'Antiquité tardive mis en évidence par l'équipe de la Topographie chrétienne des cités de la Gaule (28). Les résultats obtenus à Senez, encore provisoires, trouvent alors un écho particulier avec les découvertes effectuées sur le site de NotreDame du Bourg, qui restait jusqu'à présent - de ce point de vue - un unicum dans le corpus des cathédrales paléochrétiennes archéologiquement attestées en Gaule (29). Dans les deux cas de figure, la proximité d'un espace funéraire paraît avoir été, sinon déterminante, du moins structurante dans l'implantation de l'église paléochrétienne, à partir de laquelle se développe la cathédrale médiévale. De fait, l'interprétation « épiscopale » de la première église découverte sous la cathédrale Notre-Dame du Bourg de Digne a toujours été présentée avec prudence par Gabrielle Démians d'Archimbaud (30). Le principal argument en faveur de cette hypothèse repose sur l'absence de sépultures tardoantiques contemporaines ou postérieures à cette première église, installées à l'intérieur de l'édifice et dans son pourtour immédiat, distinguant ainsi le monument mis au jour à Digne des basiliques funéraires découvertes dans d'autres agglomérations (Démians d'Archimbaud 1995 ; Démians d'Archimbaud 2002). La nature des aménagements liturgiques identifiés dans l'édifice (solea, jubé), ainsi que le choix d'une reconstruction in situ à la fin du XII ${ }^{\mathrm{e}}$ siècle offrent des arguments supplémentaires, puisqu'ils induisent une permanence topographique et fonctionnelle entre l'ecclesia primitive et la cathédrale médiévale (31).

\footnotetext{
${ }^{26}$ Les derniers travaux consacrés à ce sujet par Florian Mazel tendent à caractériser le diocèse du haut Moyen Âge non pas uniquement comme un espace administratif géographiquement figé - ce qui ne paraît pas être véritablement le cas avant le XIII ${ }^{\circ}$ siècle - mais surtout comme un espace vécu et fluctuant, défini par des relations de domination, de dépendance ou d'échange symboliques et spirituels, qui s'exercent entre l'évêque, son clergé, ses fidèles et l'aristocratie laïque (Mazel 2016).

${ }^{27}$ Les restes de l'ecclesia primitive de Nice, découverts sur le site de la colline du château par Marc Bouiron et son équipe, permettent de restituer un bâtiment de plan rectangulaire, large de $10 \mathrm{~m}$ pour $22 \mathrm{~m}$ de long, prolongé dans un second par une abside à chevet plat (Prévot, Gaillard et al. 2014, 198-200). C'est sur cet édifice que sera progressivement reconstruite la cathédrale romane, avant son transfert dans la ville basse au cours du $\mathrm{XVI}^{\mathrm{e}}$ siècle (Bourion et al. 2015).

${ }^{28}$ Selon lequel les premières cathédrales sont construites à l'intérieur des agglomérations, dans des zones dont les morts sont exclus, à l'inverse des présupposés historiographiques antérieurs (Gauthier 2014).

${ }^{29}$ L'exemple de Digne est mentionné comme un cas particulier par les auteurs de la Topographie chrétienne ; une exception confirmant la règle en quelques sortes (Gauthier 2014, 367). D'autres cas de figure posent question, comme celui d'Alba, pour lequel l'interprétation de l'église double découvert sous l'église Saint-Pierre, à proximité d'une des nécropoles de la ville antique, demeure problématique : l'hypothèse d'un édifice funéraire a été récemment privilégiée (Prévot, Gaillard et al. 2014, 26-29) au dépens de celle, précédemment émise, d'un groupe cathédral paléochrétien (Duval et al. 1986, 205-210).

${ }^{30}$ L'interprétation de cet édifice comme une première cathédrale avait déjà été critiquée par Michel Fixot et Yann Codou (Fixot, Codou 1996).

${ }^{31}$ Sur la question de la localisation topographique des cathédrales antiques par rapport aux édifices médiévaux, Jean Guyon souligne la rareté des déplacements de groupes épiscopaux au cours de l'Antiquité tardive en Provence, qui se résument à deux cas de figure (Arles et Aix). Ce constat justifie selon lui le parti-pris, adopté dans la Topographie chrétienne des cités de la Gaule, de situer par défaut les cathédrales antiques sous celles du Moyen Âge, sauf lorsque les auteurs disposent d'arguments solides qui s'y opposent (Guyon 2006 ; Codou, Pécout 2015, 52-60). Dans le cas de Digne, la présence sous la basilique tardo-antique de structures monumentales du Haut-Empire, assimilées aux vestiges du forum, semble exclure un cas de figure semblable à celui de Saint-Paul-Trois-Châteaux par exemple, où la cathédrale romane fût édifiée hors-les-murs, au-dessus d'une église funéraire périurbaine, tandis que la cathédrale primitive devait se situer intra-muros, à l'emplacement de l'actuelle église Saint-Jean (Prévot, Gaillard et al. 2014, 1, 251-252 ; Hartmann-Virnich 2015)
} 


\section{LE VIDE DOCUMENTAIRE DU PREMIER MOYEN ÂGE}

La carence documentaire qui caractérise la Provence du haut Moyen Âge est d'autant plus accrue dans l'espace de l'ancien diocèse de Senez que celui-ci se situe à l'écart des grands centres de pouvoir qui demeurent encore actifs aux époques mérovingiennes et carolingiennes, Arles ou Marseille notamment (Février, Bats et al. 1989, 443-492). Au début du $\mathrm{VI}^{\mathrm{e}}$ siècle, la frontière entre Burgondes et Ostrogoths suit à peu près la vallée de la Durance. Les hautes vallées de l'Asse et du Verdon sont alors sous la domination du royaume de Théodoric, auquel appartient l'ancienne province des Alpes Maritimae, depuis les raids conduits en 507 contre les Burgondes et les Francs et à la défaveur des Wisigoths. Vers 536 ou 537 la région passe sous domination franque, lorsque de larges portions des territoires ostrogoths sont concédées par le souverain Vitigès. Après le partage de 561, les vallées de la Durance et du Verdon sont rattachées au royaume bourguignon de Gontrand, dont la domination s'exerce par le biais des patrices. Les régions alpines sont encore soumises aux incursions fréquentes des Lombards et des Saxons, qu'illustrent les victoires obtenues par le patrice Mummolus. Avant 573, ce dernier repousse les troupes saxonnes venues d'Italie à Estoublon, agglomération située dans la moyenne vallée de l'Asse, sur le territoire de la cité de Riez, à quelques dizaines de kilomètres de Senez. D'après Grégoire de Tours, les troupes saxonnes pillent alors les villes et les villages voisins (Grégoire de Tours, Histoire des Francs, $4^{\mathrm{e}}$ livre, ch. 37). Certains évêques paraissent avoir joué un rôle de relais auprès du nouveau pouvoir bourguignon, tels les frères Sagittarius et Salonius, installés par Gontrand sur les sièges de Gap et d'Embrun et qui prirent part en 571, aux côtés de Mummolus, à la bataille de Mustias Calmes, à proximité d'Embrun.

\section{La lente émergence de la province ecclésiastique d'Embrun}

Comme nous l'avons déjà rappelé, rien n'assure que la présence d'un évêque à Senez à partir de 506 reflète alors l'existence d'une circonscription religieuse strictement étendue aux anciennes limites des cités de Castellane et de Senez. Au cours de la période des $V^{e}$ et $\mathrm{VI}^{\mathrm{e}}$ siècles, cette confusion est bien illustrée par la prééminence qu'exerce l'Église arlésienne au-delà de ses frontières provinciales et jusque dans les vallées alpines (Duchesne 1907, 86-142 ; Palanque 1951 ; Roux 1971 ; Février, Bats et al. 1989, 379-492 ; Bertrand et al. 1994). Il est ainsi décidé, lors du concile de Riez, en 439, convoqué sous l'autorité de l'évêque Hilaire d'Arles et auquel souscrivent les évêques Claudius de Castellane et Severianus de Thorame, que les consécrations épiscopales dans les provinces de Viennoise, de Narbonnaise seconde et des Alpes Maritimes doivent recevoir l'accord du métropolitain arlésien. Ce concile est d'ailleurs convoqué pour casser l'investiture d'Armentarius d'Embrun, ce qui indique bien que cette dernière ville est considérée, à certains égards, comme un simple évêché et non pas comme une métropole, malgré son statut de capitale provinciale. Le concile de 442, organisé à Vaison et auquel souscrivent également ces deux évêques, s'inscrit dans la même influence. Puis, en 450, l'évêque de Thorame signe la supplique adressée au pape Zosime en faveur des droits métropolitains d'Arles sur les trois provinces. La concession accordée par le pape de scinder en deux la province de Viennoise pour en accorder la partie méridionale à l'église arlésienne ne paraît pas avoir favorisé l'émergence d'une véritable province ecclésiastique des Alpes Maritimes, puisque l'évêque d'Embrun Ingenius continue à soutenir la cause arlésienne. En 455, le même se voit reprocher par le pape de ne pas être intervenu dans la décision de fusion des sièges de Nice et de Cimiez, censés relever de son autorité. La métropole aixoise semble alors avoir temporairement pris le pas sur Arles dans le contrôle des Alpes Maritimes, jusqu'à ce qu'émerge le siège provincial d'Embrun vers 465. Cependant, quelques décennies plus tard, le grand concile d'Agde organisé par Césaire d'Arles avec l'aval du pouvoir wisigothique - et auquel assiste l'évêque de Senez Marcellus - témoigne encore du poids de l'Église arlésienne. Confirmant cette influence, Césaire reçoit en 514 du pape Symmaque la reconnaissance de sa juridiction sur les provinces de Narbonnaise seconde et des Alpes Maritimes. Malgré l'annexion franque, l'autorité arlésienne sur les vallées alpines est encore évidente en 554, lorsque l'évêque Sapaudus réunit en Arles les représentants de dix-huit diocèses de Narbonnaise Seconde et des Alpes Maritimes, parmi lesquels apparaît l'évêque Simplicius de Senez (32).

Bien que la primatie arlésienne s'effrite progressivement après la disparition de Césaire, l'autorité d'Arles sur les Alpes Maritimes n'est pas remise en cause avant l'époque carolingienne, lorsqu'au concile de Francfort, en 794, les évêques d'Aix et d'Embrun demandent et obtiennent leur élévation au rang métropolitain en se basant sur l'organisation administrative décrite dans la Notitia Galliarum. Les évêques de Senez ont alors entièrement disparu de la documentation conciliaire depuis le début du VII ${ }^{\mathrm{e}}$ siècle avec la présence d'un second Marcellus au concile de Paris en 614, pour ne réappa-

\footnotetext{
${ }^{32}$ Faut-il voir les traces de cette ancienne influence arlésienne dans les vocables de certaines églises du diocèse ? La question pourrait être posée à propos des chapelles Saint-Césaire d'Eoulx et Saint-Trophime de Robion à Castellane, sans exclure cependant la possibilité d'une tradition hagiographique exclusivement médiévale, peut-être influencée par l'extension des possessions monastiques aux XI-XII ${ }^{\circ}$ siècles (Février 1985). On retiendra, en outre, que le calendrier obituaire de Senez, composé entre la fin du XII ${ }^{\circ}$ et le XIII ${ }^{\mathrm{e}}$ siècle, comporte des célébrations liturgiques en l'honneur des martyrs arlésiens Trophime et Geniès, ainsi que des évêques Hilaire et Césaire (Pécout 2016).
} 
raître que près de quatre siècles plus tard, en 993, lorsqu'il est fait mention de l'évêque Pierre (33). Toutefois, ce document aujourd'hui introuvable paraît douteux et Thierry Pécout à récemment proposé d'associer ce Pierre à un évêque plus tardif, attesté entre 1089 et 1108 (Pécout 2016, 24, n. 40). C'est donc l'évêque Amiel de Castellane, mentionné dans le cartulaire de Saint-Victor de Marseille avant 1021, qui marquerait la fin de cette interruption longue de plus de 400 ans (Pécout 2016).

Malgré ce hiatus dans les listes épiscopales, les recherches archéologiques conduites aux abords de la cathédrale de Senez montrent une continuité d'occupation du site au cours du haut Moyen Âge. On identifie ainsi, à l'extérieur du bâtiment rectangulaire qui précède la cathédrale, une inhumation installée dans un coffre de lauzes en grès, datée entre la fin du $\mathrm{VII}^{\mathrm{e}}$ et la fin du IX ${ }^{\mathrm{e}}$ siècle (34), preuve que l'espace funéraire qui jouxte l'édifice est encore en fonction à cette époque. Par ailleurs, le diagnostic réalisé en 2014 a mis en évidence, dans les tranchées situées au sud de cet édifice, un ensemble de constructions arasées, conservées sur quelques assisses, qui présentent plusieurs phases et s'étendent sur une superficie d'au moins $200 \mathrm{~m}^{2}$. La période d'abandon de ces bâtiments reste difficile à établir, en particulier dans la tranchée occidentale où l'arase des murs est directement couverte par les niveaux de remblais modernes. Les observations réalisées dans la tranchée orientale montrent toutefois que les bâtiments sont antérieurs à une série de sépultures dont une est datée entre la fin du $\mathrm{X}^{\mathrm{e}}$ et le début du XII ${ }^{\mathrm{e}}$ siècle (35) (fig. 16). La présence de tombes datées des alentours de l'an mil indique une extension de l'espace funéraire au sud du bâtiment primitif, avant la reconstruction de la cathédrale tardo-romane (36).

\section{Un territoire déserté ?}

La situation de vide documentaire dans laquelle se trouve le territoire de Senez ne surprend pas, dans un contexte où les mentions d'évêques provençaux se raréfient, voire disparaissent durant une grande partie du haut Moyen Âge. La longue interruption de la liste épiscopale pose évidemment la question de la nature, sinon de l'existence du siège de Senez au cours de cette période. On notera cependant que ces lacunes ne doivent pas être uniquement interprétées comme le reflet d'une vacance des sièges épiscopaux, mais qu'elles traduisent aussi la raréfaction des conciles provinciaux ainsi qu'un basculement plus général du centre de gravité de

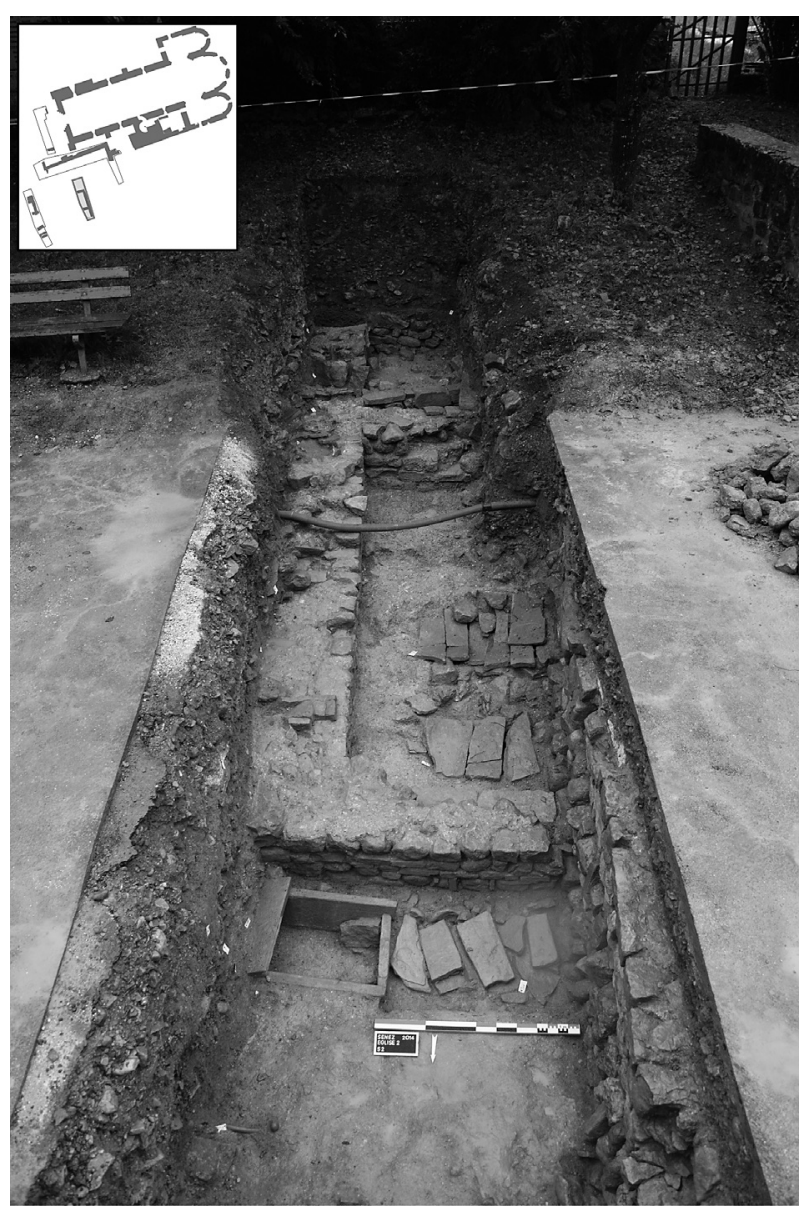

Fig. 16 : Senez : vue des bâtiments identifiés au sud de la cathédrale en 2014 et antérieurs à l'extension de la nécropole $\mathrm{XI}^{\mathrm{e}}-\mathrm{XII}^{\mathrm{e}}$ siècles (C) Mathias Dupuis / SDA 04)

l'Empire vers le nord de la Gaule (Roux 1971). Elles trahissent en outre l'absence de documentation textuelle complémentaire permettant d'étoffer les mentions provenant des actes conciliaires. Dans le cas des hautes vallées de l'Asse et du Verdon, cette situation transparaît négativement, après un examen sommaire des quelques documents qui nous renseignent sur la répartition des possessions aristocratiques et ecclésiastiques dans les Alpes provençales du haut Moyen Âge.

Aucun toponyme relatif à Senez et à sa région n'est ainsi mentionné dans le testament qu'effectue le patrice Abbon en 739, en faveur de l'abbaye de Novalaise, qu'il a fondé 13 ans auparavant (Geary 1985 ; Magnani 2013 ;

\footnotetext{
${ }^{33}$ Petrus episcopus Senecensis. Cet évêque apparaît dans une charte de donation à l'abbaye de Lérins des églises Saint-Martin et Saint-Maxime (ou Maximin) situées dans le castrum de Menta. Ce document n'est pas publié dans l'édition du cartulaire, dont elle a été extraite par dom Fournier qui l'a communiqué aux auteurs de la Gallia Christiana (Fisquet 1864, 200). Elle est donc transcrite dans les instrumenta de ce dernier ouvrage (SainteMarthe 1725, col. 233-234), dans lequel la date de 993 est avancée sans preuve concrète. Sur la base des indications de l'abbé Féraud, qui y situe un ancien prieuré de Lérins, G. Bérard suggère que le castrum de Menta puisse se situer à l'emplacement de l'ancien village du Coulet-de-Ville, sur la commune de Moriez (cant. Castellane), où ont été recensées plusieurs structures archéologiques (Bérard 1997, 315)

${ }^{34}$ Échantillon Beta-346506 : intervalles à 690-780 AD (68\% de probabilité) et $680-870 \mathrm{AD}(95 \%$ de probabilité).

${ }_{35}^{35}$ Échantillon Beta-416944 : intervalles à 1010-1025 AD (68\% de probabilité) et 985-1115 AD (95\% de probabilité).

${ }^{36}$ Cet espace funéraire concerne une vingtaine de sépultures identifiées dans les tranchées de diagnostic. La plupart sont formées de coffrages trapézoïdaux, parfois avec logettes céphaliques, agencés à l'aide de moellons ou de grandes dalles de grès.
} 
Barruol, Falque-Vert 2004). Parmi les pagi mentionnés qui correspondent à des anciens chefs-lieux de cités du Bas-Empire dont la plupart sont devenus sièges d'évêchés - apparaissent toutefois des biens situés dans les territoires voisins de Riez, Digne, Rigomagus (vallée de l'Ubaye), Embrun ou Sisteron (37). De fait, le territoire de Senez semble correspondre à la limite sud-est des possessions du patrice, dont les domaines ne s'étendent ni vers les hautes vallées de l'Asse et du Verdon, ni vers la région niçoise.

Le second document, le polyptyque de Wadalde, recense les possessions des églises de Marseille en 813814 (Guérard 1857, 2, 633-656 ; Zerner 1981 ; Devroey 2004). Bien que les anciennes cités de Senez, Castellane ou Thorame n'y soient pas explicitement évoquées, ce document marque une emprise assez nette de l'Église marseillaise sur cette partie de la Provence orientale. La localisation des exploitations agricoles mentionnées dans ce texte a fait l'objet d'âpres discussions. Les biens colonicae et vercariae - ne sont en effet jamais énumérés par diocèses, ni même situés dans les pagi ou les comitatus, qui servent généralement de cadre pour la répartition des biens fiscaux à la période carolingienne, comme cela est le cas dans le testament d'Abbon (Poly 1976, 79). La localisation des domaines se fonde donc uniquement sur des indices toponymiques, sans qu'il soit toujours possible de trancher entre les différentes hypothèses. Jean-Pierre Poly a pensé pouvoir situer certains domaines à Castellane, puisqu'il identifie la villa ou l'ager Sinaca et ses dix-sept colonicae avec Cioune et le mont Sennag mentionnés dans une charte du cartulaire de Saint-Victor en 1033 (Guérard 1857, 2, 639-641). Il associe les colonicae situées in Eleuici et in Bagarris aux hameaux actuels d'Eoulx et de Bagarry, appartenant à la commune de Castellane. Cette hypothèse a été reprise par Jacques Cru, qui voit dans le toponyme actuel de Signal - désignant la colline située au nord du Plan de Castellane - un dérivé du toponyme Sinaca du polyptyque puis Sennag et Segnal connus dans les textes médiévaux et modernes (Cru 2001, 21-22). Toutefois, cette localisation a été contredite par l'étude d'Élisabeth Sauze, qui situe la villa ou l'ager Sinaca sur une partie de la vallée de la Laye, au pied de la montagne de Lure (Sauze 1983, 15-17). Un seul domaine est localisé avec certitude dans l'aire d'influence du diocèse médiéval de Senez, puisque les auteurs s'accordent pour associer la villa Virgonis et ses sept colonicae avec le village actuel de Vergons (Guérard 1857, 2, 649-650). D'autres biens se situent à la périphérie immédiate des hautes vallées de
l'Asse et du Verdon, tels l'ager Galadius, formant un très vaste domaine de 75 exploitations localisé autour de Chaudol, sur la commune de la Javie, dans la vallée de la Bléone (Devroey 2006, 469-471 ; Aulagnier 2013) ; la villa Tregentia, associé à Trigance (83), située sur la rive sud du Verdon ou la villa Rovagonis, soit Rougon (04), située entre Castellane et la Palud-sur-Verdon. D'après Jean-Pierre Devroey, les biens localisés dans ce secteur, placés sous la seule invocation de la Vierge auraient relevé de la cathédrale de Marseille plutôt que de l'abbaye Saint-Victor (38). La nouvelle analyse proposée par cet auteur conduit en outre à nuancer l'interprétation et la portée de ce document, à la fois comme indicateur de l'emprise des possessions marseillaises (39) et comme révélateur d'une forme de récession démographique et agricole au cours du haut Moyen Âge.

On constate enfin, au début du $\mathrm{X}^{\mathrm{e}}$ siècle, que l'espace $\mathrm{du}$ diocèse de Senez échappe aux possessions de Fouquier, le père de Maïeul, recensées dans une des chartes du cartulaire de Cluny (Bernard et al. 1871, 1, $\mathrm{n}^{\circ}$ 106). L'étude des possessions de la famille, réalisée par Jean-Pierre Poly, montre pourtant l'étendue de ces biens dans la cité voisine de Riez, où ceux-ci semblent avoir été formés par d'anciens domaines publics ecclésiastiques, constitués aux premiers temps du siège épiscopal et accaparés au cours du VIII ${ }^{\mathrm{e}}$ siècle par des fidèles du pouvoir carolingien (Poly 1997).

De la même manière que l'interruption dans les listes épiscopales ne signifie pas la disparition du siège de Senez, la quasi-absence de mentions relatives au territoire des hautes vallées de l'Asse et du Verdon reflète avant tout les carences de la documentation écrite. Cette explication paraît plus plausible qu'une hypothétique désertification de la région, que l'historiographie a longtemps associée à l'instabilité chronique du haut Moyen Âge et particulièrement à l'impact des raids « sarrasins » (Thirion 1980, 335-336). En dehors du cas précis de Senez, dans lequel la datation des structures funéraires laisse entrevoir une trame d'occupation continue entre Antiquité et Moyen Âge aux abords de la cathédrale, aucune donnée archéologique ne permet toutefois d'appréhender les modalités d'organisation du territoire au cours de cette période. On constate cependant que les quelques documents disponibles reflètent une forme de permanence de l'héritage antique, qui se manifeste par la transmission de biens publics appartenant aux anciennes cités, progressivement morcelés et accaparés par les milieux aristocratiques et ecclésiastiques. De ce point de vue, la situation de Castellane est particulièrement révé-

\footnotetext{
${ }^{37}$ On retiendra cependant que la curtis de Lavars (Isère), acquise par Abbon, commandait des biens situés dans les pagi de Sisteron, Gap et Die ainsi que des salines qui seraient localisées sur le Verdon (salines ad uerdone, voir Geary 1985, 64-65, 89; Devroey 2006, 467-468). Rien ne précise où se situent exactement ces exploitations, mais les seules salines attestées à l'époque moderne et localisées stricto sensu sur le Verdon sont celles de Castellane. Les autres gisements sont situés soit sur le Var (Castellet-les-Sausses), soit sur l'Asse (Moriez et Tartonne). Cette localisation géographique a toutefois été contredite récemment par Michèle Bois, pour qui ces exploitations seraient plutôt situées dans la Drôme (information communiquée par Michèle Bois).

${ }^{38}$ Depuis la fin du VIII ${ }^{\mathrm{e}}$ siècle, les biens de Saint-Victor de Marseille sont administrés par l'évêque. La distinction entre les possessions de l'église cathédrale et celles de l'abbaye est notée, dans le polyptyque, en fonction de l'invocation sous laquelle sont placés les actes (Devroey 2004).

${ }^{39}$ D'une part, le polyptyque constituerait avant tout un inventaire partiel des richesses appartenant à la cathédrale et à l'abbaye, d'autre part, les tenures recensées ne relèveraient que d'une des composantes de l'Église de Marseille (clercs de la cathédrale ou moines de l'abbaye).
} 
latrice. Les actes du cartulaire de Saint-Victor de Marseille montrent à quel point cette ville occupe une place privilégiée dans le réseau des possessions de l'abbaye marseillaise. Celle-ci est confirmée au cours du XI siècle par les pérégrinations de l'abbé Isarn, dont le séjour à Castellane et dans ses environs est relaté dans la vita du saint (Caby et al. 2010, 38-39). Les terres de Saint-Victor situées dans le castrum de Petra Castellana apparaissent dès 977 dans la donation qu'effectue l'évêque Honorat de Marseille et sur la base de laquelle s'appuie la restauration de la communauté monastique, vraisemblablement à partir d'un noyau de possessions d'origine carolingienne (Magnani 1999, 528-529 ; Mazel 2009). Les actes du cartulaire nous apprennent que les restitutions engagées à partir de 1038 par Amiel de Senez sont légitimées par l'ancienneté des possessions dont se réclament les moines. En 1040, le même Amiel rend à Saint-Victor les églises Sainte-Marie avec Saint-Jean Baptiste, Saint-Pierre et Saint-Laurent, qui avaient été données à l'église cathédrale de Senez avant 1032. La restitution est réitérée en 1043 et les moines ne manquent pas alors de faire valoir l'ancienneté de leurs droits sur ce territoire, puisqu'ils précisent revendiquer ces églises depuis l'abbatiat de Guifred (1005-1020), à l'appui de titres très anciens (Arbaud 1905 ; Magnani 1999, 219 ; Cru 2001, 46-49). Même si l'on peut s'interroger sur le bien-fondé de ces prétentions et l'authenticité des documents qu'exhibent les moines, il n'en demeure pas moins que la mention de Castellane dans le premier noyau de donations de 977 paraît confirmer l'ancienneté de son appartenance victorine. L'étude des chartes postérieures permet en outre de localiser assez précisément l'étendue de ces possessions, qui paraît coïncider avec l'emplacement supposé de la ville antique (40). D'une certaine manière, le temporel primitif de l'abbaye marseillaise aurait donc pu fossiliser l'emplacement des domaines publics antiques, progressivement entrés dans le giron de l'Église avant leur accaparement par l'aristocratie bourguignonne (41).

\section{LA STRUCTURATION MEDIEVALE}

Ce n'est qu'à l'aube de l'an mil que les actes du cartulaire de Saint-Victor de Marseille évoquent à nouveau le territoire de Senez. Là encore, au long du XI ${ }^{\mathrm{e}}$ siècle, la cité épiscopale n'apparaît qu'à la marge d'une documentation textuelle qui concerne en premier lieu les abbayes de Marseille et de Lérins. Le document le plus ancien, précédemment évoqué, est la charte datée vers 965-977 dans laquelle sont mentionnés des biens situés à Castellane in comitatu Senscience et restitués à l'abbaye Saint-Victor par l'évêque de Marseille Honorat (Guérard 1857, $\left.1, \mathrm{n}^{\circ} 23\right)$. Le terme de comitatus est largement privilégié au cours du $\mathrm{XI}^{\mathrm{e}}$ siècle, par rapport à celui d'episcopatus, pour situer les biens qui apparaissent dans les actes de la pratique. Pour Florian Mazel, la prédominance de ce terme dans la première moitié du $\mathrm{XI}^{\mathrm{e}}$ siècle révèle l'imbrication encore importante entre pouvoir comtal, vicomtal ou seigneurial et épiscopal avant la réforme grégorienne (Mazel 2016, 294). Cette imbrication est particulièrement forte dans le territoire de Senez, puisque le lignage aristocratique des Castellane pourvoit en évêques le siège de Senez tout au long du $\mathrm{XI}^{\mathrm{e}}$ siècle et au-delà. Cette situation pose la question du développement parallèle, au sein du même diocèse, d'un pôle seigneurial laïc et d'un pôle épiscopal. Les relations complexe qu'entretiennent le clergé épiscopal de Senez et la famille de Castellane ont déjà été analysées et discutées et il ne nous revient pas ici d'en proposer une nouvelle lecture (Magnani 1999 ; Vaizey 2002). Une approche archéologique permet cependant de nuancer la vision partiale offerte par les sources textuelles et de mesurer, sur le temps long, la part de l'héritage antique dans la "renaissance " que connaît chacune de ces agglomérations à partir du Moyen Âge central.

\section{Confirmer la ville épiscopale : la reconstruction de la cathédrale de Senez}

Comme nous l'avons précisé plus haut, les listes épiscopales de Senez s'interrompent au plus tard jusqu'à l'épiscopat d'Amiel, qui débute avant 1021. Même si le siège n'est pas pourvu à l'aube de l'an mil, l'église cathédrale est déjà attestée dans les textes entre 993 et 1032 sous le vocable de sainte Marie du Siège (Sancta Maria in sede Senece) lorsqu'il est fait mention de la donation à cette dernière, sous le règne de Rodolphe III, des églises de Petra Castellana (Pécout 2016, 23) (42). Le chantier de la cathédrale actuelle n'étant pas antérieur à la fin du $\mathrm{XII}^{\mathrm{e}}$ siècle, il restait jusqu'alors difficile d'identifier l'édifice auquel cette mention correspondait. Les dernières recherches archéologiques permettent aujourd'hui d'apporter un regard renouvelé sur cette question.

Si l'identification de la cathédrale paléochrétienne fait encore problème, comme nous l'avons rappelé précédemment, il paraît probable que l'église SainteMarie-du-Siège mentionnée sous le règne de Rodolphe III corresponde bien à l'édifice de plan rectangulaire découvert sous la cathédrale actuelle et plusieurs fois transformé avant sa reconstruction complète. La construction du clocher pourrait se situer dans une période identique à celle qui voit s'étendre la nécropole vers le sud, sur les ruines d'un ensemble monumental plus ancien, qui reste encore à caractériser. La mise en œuvre de ces travaux peut être analysée comme résultant

\footnotetext{
${ }^{40} \mathrm{D}$ 'autres indices pourraient confirmer cette localisation, comme la numérotation des bornes miliaires découvertes aux abords de l'agglomération (Chavane et al. 1995). Mais il n'est pas non plus exclu que Saint-Victor se soit constitué un temporel péri-urbain : il faut se méfier, dans ce cas précis, d'un raisonnement circulaire où les quelques évidences archéologiques confirmeraient des hypothèses préétablies.

${ }^{41}$ L'étude réalisée par Jean-Pierre Poly sur les territoires de Valensole et de Riez démontre bien de quelle manière certains de ces biens publics sont cédés à l'Église à partir de la fin de l'Antiquité. Le domaine de Valensole est ainsi d'abord accaparé par l'Église de Valence, avant d'être restitué à Saint-Victor de Marseille puis cédé à Fouquier, le père de Mayeul de Cluny (Poly 1997).

${ }^{42}$ Ce sont ces églises qui seront ensuite restituées à Saint-Victor par l'évêque Amiel en 1040 (Magnani 2013, 219).
} 
d'une forme de reprise en main du pouvoir épiscopal, au milieu du $\mathrm{XI}^{\mathrm{e}}$ siècle, sur les édifices dont il assume la charge, préfigurant ainsi les chantiers de plus grande envergure qui seront engagés à partir de la fin du XII ${ }^{e}$ siècle. Concernant Notre-Dame du Bourg, Gabrielle Démians d'Archambaud situe ce tournant architectural sous l'épiscopat d'Hugues de Chaudol (1038-1066) (Démians d'Archimbaud et al. 2010, 68). Ce dernier, membre d'un important lignage aristocratique, s'illustra par ses nombreuses donations à Saint-Victor de Marseille (43).

Comme à Digne, c'est donc à partir de la fin du XII siècle - en mai 1176 si l'on en croit une date donnée par la Gallia Christiana mais qui demeure invérifiée (SainteMarthe 1725, coll. 1255-1256) - qu'est engagé le chantier de reconstruction de la cathédrale de Senez (fig. 17). L'édifice aurait été au moins en partie achevé en 1246 , date à laquelle il fût consacré par l'évêque Guillaume (44). L'ancienne église est alors entièrement arasée, à l'exception du clocher qui est conservé pour être intégré au nouvel édifice. Un pan de mur appartenant à l'angle sud-est de l'église précédente est également préservé, pour asseoir la voûte qui couvre le vestibule d'accès à cet escalier. La nouvelle église n'est pas strictement reconstruite sur les fondations du bâtiment antérieur, mais elle est décalée de quelques mètres vers le nord-est, sans doute en raison de contraintes topographiques inhérentes au déroulement du chantier (45). L'examen des élévations indique que la construction se déroule d'est en ouest, depuis le chœur vers la nef et qu'elle connaît une interruption importante après la construction du transept. Au sud, un imposant escalier, construit selon le principe de la vis de Saint-Gilles, est installé dans l'espace disponible entre le mur gouttereau et l'ancien clocher, pour desservir les différents niveaux de ce dernier ouvrage. Un passage est conservé à la base de l'escalier, afin d'accéder à la salle basse du clocher, qui revêt peut-être une fonction liturgique particulière (46). Dans l'espace compris entre le bras sud du transept et l'escalier, une pièce voûtée donne accès aux bâtiments canoniaux, également desservis par l'escalier en vis. La nouvelle organisation de la communauté cano-

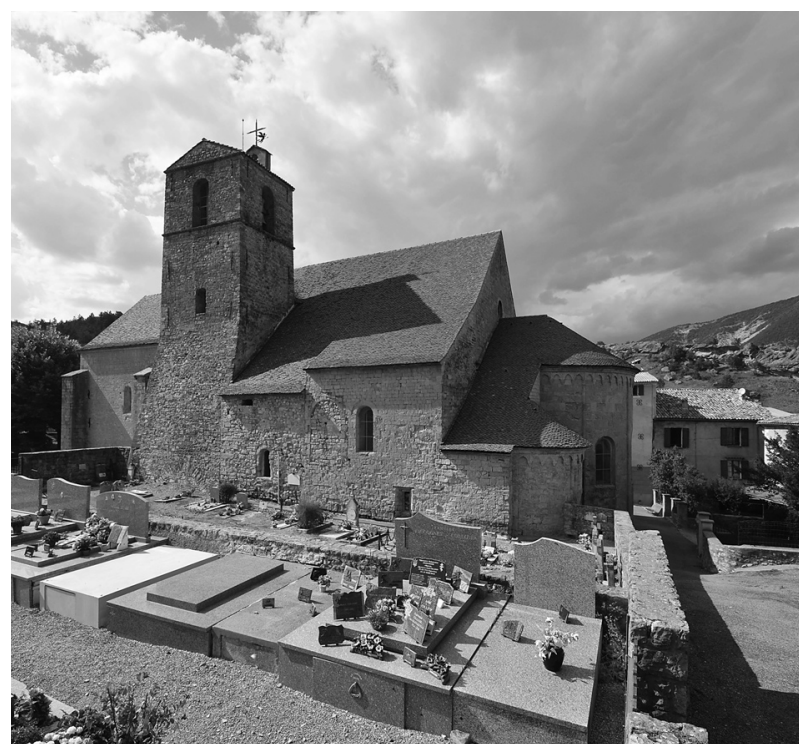

Fig. 17: Senez : vue de la cathédrale depuis le sud-est (C) Mathias Dupuis / SDA 04)

niale, probablement régularisée depuis la fin du $\mathrm{XII}^{\mathrm{e}}$ siècle (47), influence sans doute alors largement la distribution topographique du nouvel ensemble architectural. Le chantier de construction de la cathédrale marque un changement profond dans la conception globale de l'édifice et de son environnement, s'inscrivant ainsi dans un mouvement architectural d'ampleur, au cours duquel sont entièrement reconstruites les églises cathédrales des Alpes provençales (Codou 2015). Une forme de continuité architecturale est tout de même assurée, à la fois par la permanence topographique des bâtiments successifs et par l'intégration dans le nouvel édifice d'ouvrages architecturaux antérieurs : le chantier de la fin du XII ${ }^{\mathrm{e}}$ siècle confirme autant matériellement que symboliquement l'ancrage du siège épiscopal au cœur de l'antique civitas Sanitiensium.

\footnotetext{
${ }^{43}$ On pourrait ajouter que ce même personnage est réputé avoir assisté, en 1040, à la consécration de l'église abbatiale de Saint-Victor aux côtés de l'évêque de Senez, Amiel de Castellane, autre bienfaiteur de l'abbaye issu d'une des grandes familles de l'aristocratie provençale. De sérieux doutes pèsent cependant sur la véracité de ce document, qui semble procéder d'une interpolation de la fin du XI siècle et qui doit donc être manié avec précaution (Lauwers 2007). On retiendra en outre que quelques décennies plus tard, Hugues, le successeur d'Amiel sur le trône de Senez et probablement le petit neveu de ce dernier, assiste à la consécration de l'église Saint-Saturnin d'Apt aux côtés de l'archevêque d'Arles et de l'évêque d'Apt (Barruol 1977, 86-87). L'emprise de la famille de Castellane sur le siège épiscopal de Senez perdure jusqu'au milieu du XII siècle, avec l'épiscopat d'Aldebert, fils de Boniface $1^{\text {er }}$ de Castellane (Vaizey 2002).

${ }^{44}$ Comme la date de démarrage des travaux, celle de la consécration a longtemps été considérée comme douteuse car uniquement mentionnée dans la Gallia Christiana. Elle vient toutefois d'être confirmée par l'étude du calendrier obituaire conservé à Carpentras (Pécout 2016, 22).

${ }^{45}$ La découverte, lors d'une prospection géophysique conduite sur le site en 2017, d'une anomalie dans la nef de la cathédrale actuelle pourrait ainsi suggérer la présence d'une abside liée à l'église primitive, dont le décalage vers le nord aurait conditionné la reconstruction de la cathédrale tardoromane (Dupuis et al. 2018).

${ }^{46}$ À la cathédrale Notre-Dame du Bourg, cette salle basse paraît avoir fait office d'oratoire et peut-être d'espace funéraire par la suite (Démians d'Archimbaud et al. 2010, 74-76). Concernant Senez, des témoignages de la fin du XVIII' siècle, relatés par Marie-Madeleine Viré, nous apprennent que cette pièce était voûtée et qu'on y trouvait des ossements (Viré 1992, 141-142).

${ }^{47}$ La première attestation d'un chapitre respectant la règle de saint Augustin à Senez remonte à la bulle de provision de l'évêque Bertrand en 1317 (Pécout 2011, 514-515). D'après l'accord conclu en 1287 avec la prévôté de chanoines de Saint-Jacques de Barrême, les deux communautés suivent déjà la même règle à la fin du XIII ${ }^{c}$ siècle. Son adoption remonterait à la fin du XII ${ }^{\mathrm{c}}$ siècle, le XIII ${ }^{\mathrm{e}}$ siècle correspondant plutôt à l'affaiblissement de la règle de saint Augustin qu'à sa diffusion (information transmise par Thierry Pécout).
} 


\section{Fortifier la ville seigneuriale : topographie de l'habitat groupé à Castellane}

Nous avons évoqué précédemment les questions que soulèvent la localisation de la ville antique de Castellane et les doutes qui subsistent sur celle-ci, en l'absence de découvertes archéologiques avérées permettant de préciser son emplacement et son étendue. L'historiographie traditionnelle tend à considérer que l'abandon du site de plaine aurait été causé par les crues du Verdon au cours de l'Antiquité tardive ou du très haut Moyen Âge ainsi que par les invasions « sarrasines », qui auraient provoqué le perchement de l'habitat sur le site de hauteur de Petra Castellana (Février 1964 ; Thirion 1980 ; Chavane et al. 1995) (fig. 18). Toutefois, à l'inverse de cette idée reçue, les premières recherches conduites sur ce site en 2016 et 2017 ne laissent entrevoir aucun indice d'occupation antérieur à la période des $\mathrm{XI}^{\mathrm{e}}-\mathrm{XII}^{\mathrm{e}}$ siècles (Buccio et al., à paraître). La courtine nord à tours pleines semble dater de la même époque, une attribution à l'Antiquité tardive étant exclue (48). Sa construction est relativement uniforme, sans qu'aucune maçonnerie ne puisse être attribuée à un état plus ancien (fig. 19). L'église SaintAndré, dont les caractéristiques architecturales situent la construction entre la fin du $\mathrm{XII}^{\mathrm{e}}$ et le début du
XIII ${ }^{e}$ siècle, paraît un peu plus tardive. L'agglomération perchée connaît une période d'existence assez brève, qui peut être estimée entre 150 et 300 ans maximum, puisque l'église Saint-André perd son statut de paroissiale en 1259 et que la quasi-totalité des habitations sont abandonnées au milieu du $\mathrm{XIV}^{\mathrm{e}}$ siècle, lorsque le roi diligente l'enquêteur Leopardo da Foligno pour recenser ses droits dans la baillie de Castellane (Pécout, Michaud et al. 2011). Le castrum à proprement parler, mentionné dans la donation de 977, se situait vraisemblablement au sommet du Roc, l'imposante falaise rocheuse qui domine la clue du Verdon et qui forme une sorte d'excroissance au sud du relief occupée par Petra Castellana. Le château est pris par Charles d'Anjou en 1262 et détruit sur l'ordre de Louis XI en 1483. L'ancienne chapelle castrale Notre-Dame du Roc, dont le mur méridional indique une phase de construction aux alentours des $\mathrm{XII}^{\mathrm{e}}$-XIII ${ }^{\mathrm{e}}$ siècle (fig. 20), ainsi que quelques éléments de la fortification orientale et une citerne creusée dans la roche sont les seuls témoignages de l'occupation médiévale du promontoire. Des observations récentes, conduites dans le cadre de travaux de restauration de cette église, indiquent cependant la présence de maçonneries pouvant appartenir à un bâtiment antérieur (49).

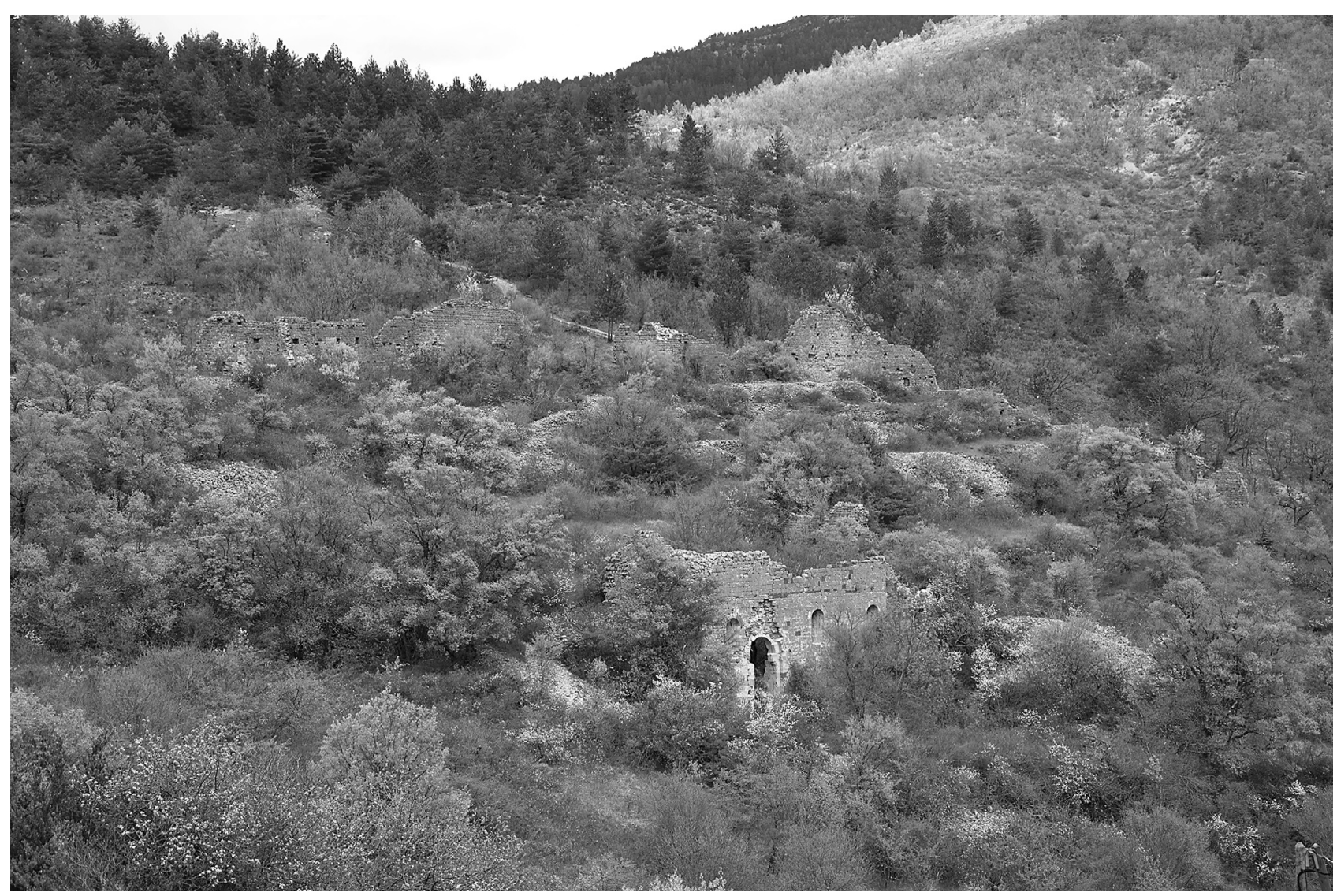

Fig. 18 : Castellane : le site de Petra Castellana vu depuis la montée du Roc. Au premier plan apparait l'église Saint-Victor. Au second plan la partie nord de l'enceinte à tours pleines. (C) Mathias Dupuis / SDA 04)

\footnotetext{
${ }^{48}$ Cette datation reposait essentiellement sur la typologie des tours pleines (Poteur 1981).

${ }^{49}$ Le suivi archéologique des travaux de restauration de la chapelle Notre-Dame du Roc a été conduit au cours de l'année 2017 par Vincent Buccio et Erwan Dantec.
} 


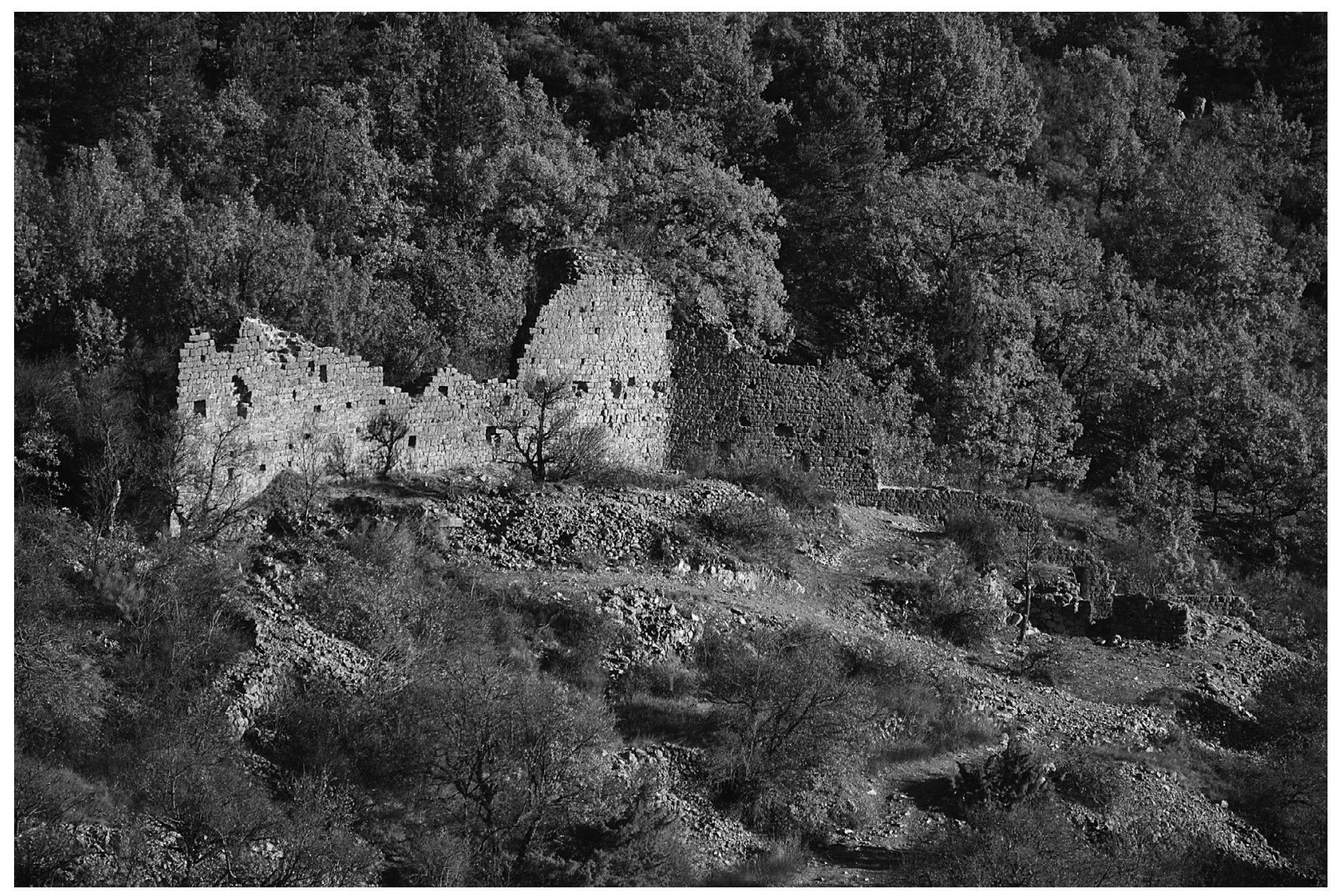

Fig. 19 : Castellane : vue de l'angle nord-est de l'enceinte de Petra Castellana (C Vincent Buccio / SDA 04)

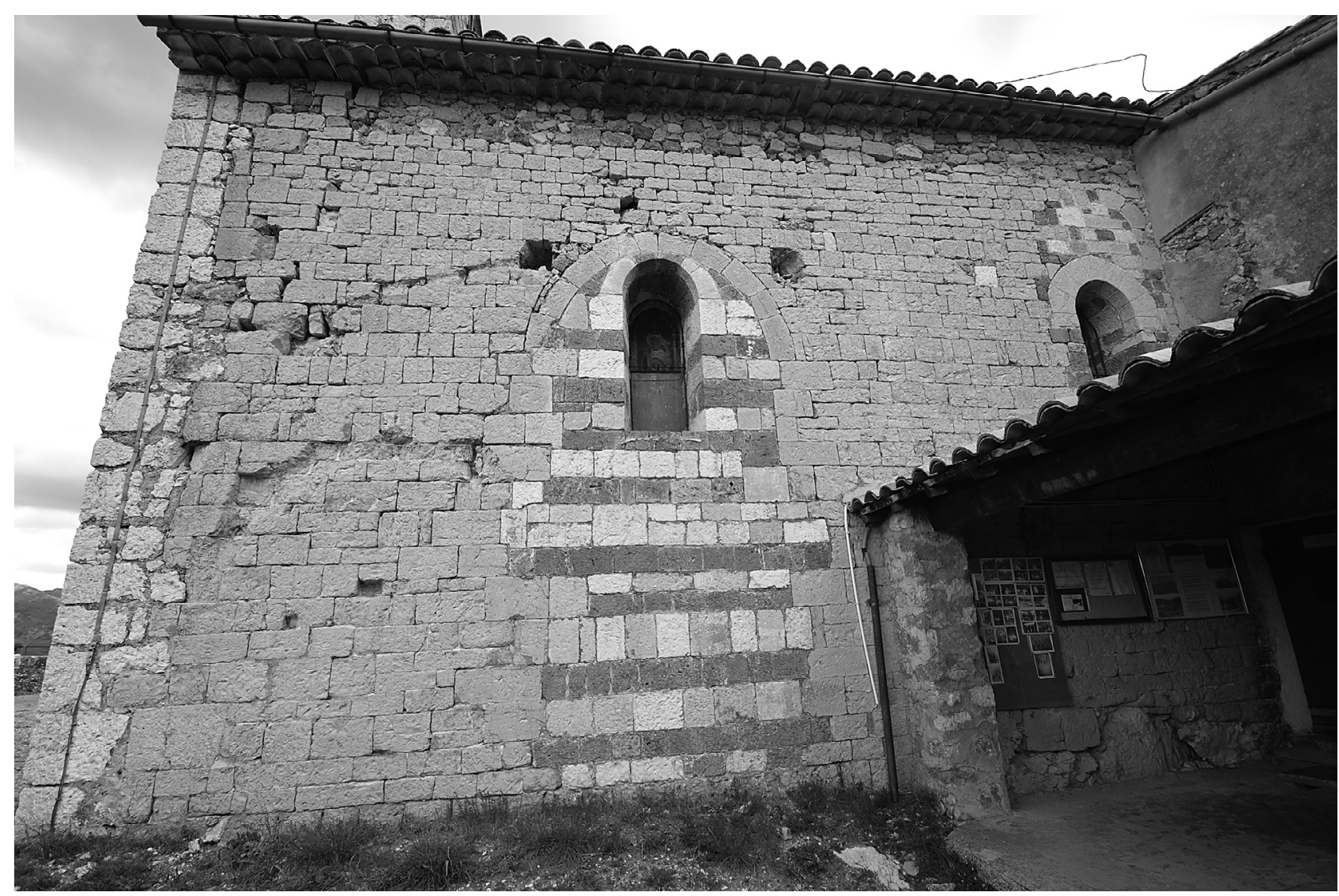

Fig. 20 : Castellane : façade méridionale de la chapelle Notre-Dame du Roc (C Mathias Dupuis / SDA 04) 
D'autres structures, reconnues dans une tranchée creusée aux abords de l'église, paraissent correspondre à la forteresse médiévale, dont des vestiges semblent donc avoir été conservés après la démolition de la fin du $X V^{\mathrm{e}}$ siècle. Une occupation ancienne de ce promontoire, particulièrement remarquable et stratégique dans la topographie de Castellane, est donc tout à fait envisageable, même si aucune observation archéologique ne peut le confirmer à l'heure actuelle.

Par ailleurs, plusieurs indices historiques semblent plaider en faveur d'une permanence de l'occupation dans le site de plaine au cours du haut Moyen Âge. Nous avons déjà évoqué, à ce propos, l'ancienneté des droits dont se réclament les moines de Saint-Victor, dont le temporel paraît remonter à l'époque carolingienne si l'on se fie à la donation de l'évêque Honorat en 977. La permanence médiévale des toponymes considérés comme anciens, Ducelia et Cimirianis, pourrait également indiquer une permanence des structures, même si cet indice doit être considéré avec une grande prudence. Entre les sites de Salinae, du Roc et de Petra Castellana, se pose également la question de l'occupation de la ville basse, située au plus près de la clue du Verdon. Nous ne savons pas à quelle période elle remonte, si ce n'est que le prieur Laurensi affirme que l'église fut bâtie au plus tard en 1040 (Laurensi 1898, 108), mais cette interprétation paraît fondée sur une lecture erronée d'une donation $\mathrm{du}$ baron Adelbert, par ailleurs transcrite dans le Cartulaire de Saint-Victor de Marseille (Guérard 1857, $\left.2, n^{\circ} 776\right)$. La première mention explicite de cet édifice remonte en réalité à 1259 , lorsqu'un accord passé dans la cathédrale de Senez acte le transfert de l'église paroissiale depuis Saint-André vers Saint-Victor et le rattachement de cette dernière au prieuré de Notre-Dame du Plan (Pécout, Michaud et al. 2011, 312, n. 200). En l'absence de toute investigation archéologique dans l'emprise du bourg, rien n'exclut que la ville antique se soit étendue vers l'est et se soit également développée à son emplacement (50). Au vu de ses caractéristiques architecturales, la construction de l'église Saint-Victor ne peut pas être reculée avant la fin du XII siècle au plus tôt (Thirion 1980, 335-340). La mise en défense du bourg, caractérisée par la construction d'une enceinte urbaine qui enserre l'habitat, est nettement postérieure. La nature des ouvrages défensifs incite à situer ce chantier au milieu du $\mathrm{XIV}^{\mathrm{e}}$ siècle, après 1359 si l'on en croit les écrits du prieur Laurensi. L'existence d'une fortification plus ancienne n'est pas exclue, mais aucun indice archéologique ne permet à ce jour de l'attester.
Même si les recherches archéologiques restent encore balbutiantes dans cette commune, le schéma qui semble se dessiner à Castellane n'est donc pas celui d'une succession linéaire de sites d'habitat groupé, mais plutôt d'une forme de multipolarité, qui aurait atteint son apogée aux $\mathrm{XI}^{\mathrm{e}}$-XIII ${ }^{\mathrm{e}}$ siècles, avant la prise de pouvoir de la dynastie angevine, lorsque les différents sites de plaine et de hauteur semblent occupés concurremment (51). Le maillage religieux du territoire en constitue sans doute l'indice le plus probant, puisque l'intensité des fondations ecclésiastiques - monopolisées par Saint-Victor de Marseille qui bénéficie, à partir de la seconde moitié du $\mathrm{XI}^{\mathrm{e}}$ siècle, des largesses de la famille de Castellane - se perçoit nettement dans les actes du cartulaire de l'abbaye marseillaise. Il ne subsiste cependant aucun témoignage monumental des lieux de culte du $\mathrm{XI}^{\mathrm{e}}$ siècle ; mais des investigations archéologiques plus systématiques permettraient sans doute d'en retrouver les traces, comme le montre l'exemple de la chapelle Notre-Dame du Roc (52). Toutes ces églises - Saint-André à Petra Castellana, Notre-Dame du Plan, Saint-Victor dans le bourg et même la chapelle castrale Notre-Dame du Rocsont entièrement reconstruites à la fin $\mathrm{du} \mathrm{XII}^{\mathrm{e}}$ ou au cours $\mathrm{du} \mathrm{XIII}^{\mathrm{e}}$ siècle ; sans nul doute avant 1259 , date à laquelle l'église Saint-André perd son statut paroissial. Les similitudes entre les différents monuments sont frappantes, surtout en ce qui concerne le traitement de leurs façades méridionales (rythme et forme des ouvertures, types d'appareillage). La mise en œuvre contemporaine de ces chantiers, en différents points de l'agglomération, confirme cette multipolarité qui semble caractériser Castellane entre Antiquité et Moyen Âge. Par la suite, la mise en défense du bourg dans une nouvelle enceinte, à partir de la seconde moitié du XIV $\mathrm{XI}^{\mathrm{e}}$ siècle, amorce un phénomène inéluctable de concentration de l'habitat autour de la ville basse.

\section{Une occupation éclatée : le cas particulier de Thorame}

Contrairement à Senez et Castellane, Thorame ne conserve pas au cours du Moyen Âge un statut religieux ou politique particulier qui puisse refléter son importance présumée à l'époque tardo-antique. Les indices d'une continuité d'occupation entre Antiquité et Moyen Âge existent cependant, comme l'indique la permanence entre espaces funéraires et lieux de culte, attestée à Notre-Dame du Serret, Saint-Julien et sur le plateau de Saint-Pierre. Le cas de Thorame soulève une autre question : à partir de quel moment Eturamina cède la place aux bourgs de Thorame-Basse et Thorame-Haute, autour

\footnotetext{
${ }^{50}$ Comme pourraient le suggérer des découvertes anciennes réalisées à l'emplacement du couvent des Augustins et aux abords de la porte de l'horloge (Gras-Bourguet 1842).

${ }^{51}$ On peut alors comparer la situation de Castellane à celle d'autres agglomérations voisines, dans lesquelles paraissent se dessiner des trames d'occupation semblables. C'est le cas par exemple à Entrevaux, où les travaux de Clotilde Bigot et les recherches archéologiques récentes mettent en évidence des phases d'occupation conjointes de l'ancienne agglomération antique de Glandèves, du castrum épiscopal homonyme et du site castral d'Intervalles (Bigot 2004 ; Dupuis et al. 2015). Une véritable dichotomie de l'habitat au cours de l'époque médiévale a également été soulignée à Digne par les travaux de Gabrielle Démians d'Archimbaud (Démians d'Archimbaud 1999).

${ }^{52}$ On retiendra également que les travaux conduits lors de la restauration de l'église Saint-Victor en 2012, malheureusement sans accompagnement archéologique, ont permis de mettre en évidence, dans une tranchée de drainage créée au chevet de l'église, une maçonnerie arrondie (abside ?), vraisemblablement antérieure à l'église actuelle (information communiquée par Amandine Delarbre).
} 
desquels se multiplient les sites fortifiés et les édifices religieux au Moyen Âge central ?

Le toponyme réapparaît seulement à partir de 1009, dans les actes du cartulaire de Saint-Victor de Marseille, lorsqu'est confirmée à l'église Sainte-Marie in Monasterium la possession d'un manse situé in castro que vocant Toramena (Guérard 1857, 2, $\mathrm{n}^{\circ} 772$; Magnani Soares-Christen 1999, 219-221). Thorame est désigné dans une seconde charte, en 1026, sous le terme de villa (in villa quam nominant Toraminas) (Guérard 1857, 2, $\mathrm{n}^{\circ}$ 762). Le toponyme est encore mentionné à plusieurs reprises au cours des $\mathrm{XI}^{e}$ et $\mathrm{XII}^{e}$ siècles, sans qu'aucune distinction ne soit faite entre les deux Thorame. Cette dissociation n'apparaît qu'à partir du début du $\mathrm{XIII}^{\mathrm{e}}$ siècle, en 1218, lorsque Guillaume Féraud fait, in castro Toramine Superioris, une donation à Sainte-Marie de Thorame, qui dépend alors de Saint-Victor de Marseille (Guérard 1857, 2, n 1019). La désignation Thorame-Basse, quant-à-elle, n'est pas attestée avant 1237, dans les statuts de la baillie de Senez, où sont évoqués les castra de Toramena Inferiori et Toramena Superiori (Benoit 1925, $\mathrm{n}^{\circ}$ 277). Cette double appellation apparaît à nouveau au début du $\mathrm{XIV}^{\mathrm{e}}$ siècle dans les comptes de décimes qui dénombrent les églises de Thoramine Inferioris et de Thoramine Superioris (Clouzot 1923, 289-295). Il est donc impossible, avant le début du XIII ${ }^{\mathrm{e}}$ siècle, de distinguer les deux Thorame et il n'est pas exclu que ce toponyme ait avant tout désigné un territoire étendu entre la haute vallée de l'Issole et le Verdon.

La difficulté à identifier les lieux de culte médiévaux est accrue par cette confusion, ainsi que par la présence de nombreuses églises dans un espace réduit. La première mention d'un lieu de culte remonte à 1056, lorsque Rostaing, affilié aux Castellane, donne au monastère marseillais les églises dédiées à sainte Marie, saint Étienne protomartyr et celle récemment construite en l'honneur de saint Jean, située in ipso Poio, ainsi que les terres qui les entourent (Guérard 1857, 2, n 764). Le terme de Poio renverrait alors à la butte de Piégut, sur laquelle existent toujours une tour médiévale de très belle facture, dont la construction paraît remonter au début du XIII' siècle (53). D'autres établissements fortifiés coexistent à Thorame-Basse et Thorame-Haute. On signalera ainsi le site de Tracastel, où plusieurs pans de murs en moyen appareil subsistent encore sur le promontoire à l'extrémité sud de la crête éponyme, qui culmine à $1300 \mathrm{~m}$ au nord-est Thorame-Haute. Le site n'apparaît pas sur la carte de Cassini où figure uniquement, en contrebas de la crête, la petite chapelle Saint-Roch de construction moderne. Il pourrait correspondre au castrum Toramine Superioris mentionné dans l'acte 1019 du cartulaire de Saint-Victor de Marseille, en 1218. On notera enfin que le plateau de Saint-Pierre, sur la commune de Thorame-Basse, est jouxté à l'ouest par une autre éminence naturelle dotée d'un toponyme évocateur, le Chastel. Sur la carte de Cassini, un château ruiné est indiqué à cet emplacement. Ce site n'a encore jamais fait l'objet de repérages archéologiques.

À la diversité de ces établissements fortifiés correspond une densité particulièrement importante de lieux de culte. Ainsi, la butte de Piégut abrite encore une église dédiée à Saint-Jean. Cette dernière apparaît sous le vocable de Notre-Dame sur la carte de Bourcet, sur celle de Cassini et sur le cadastre napoléonien, conservant ainsi les deux anciens vocables rattachés à ce lieu dans la charte de 1056. La plus ancienne mention connue de cette église est un prix-fait qui atteste une réparation de la voûte en 1620 , mais son plan et quelques observations rapides sur les élévations intérieures indiquent que sa construction pourrait remonter à l'époque médiévale. Aucune trace d'une église Saint-Étienne n'est toutefois connue sur ce site, ni dans le reste de la vallée. En 1122, l'évêque de Senez Aldebert confirme la possession par l'abbaye marseillaise des deux églises Sainte-Marie et SaintÉtienne-ecclesias cellule sancte Marie et sancti Stephani de Thoramina - déjà mentionnées dans la charte de 1056 (Guérard 1857, 2, $\mathrm{n}^{\circ}$ 777). Par la suite, les chartes ne citent plus que l'église Sainte-Marie, qui est à nouveau évoquée en 1135 et en 1218. Les comptes de décime de 1300 indiquent une église à Thorame-Basse (ecclesia Thoramine Inferioris), sans préciser son vocable et une église SaintJulien à Thorame-Haute (ecclesia Sancti Juliani Thoramine Superioris) qui correspond à l'actuelle église paroissiale Saint-Georges, encore dénommée Saint-Julien sur le cadastre napoléonien. Ils mentionnent en outre l'église du Serret (ecclesia de Serreto), placée sous le vocable de sainte Marie dans les comptes de procuration de 1376. Cette dernière correspond à la chapelle NotreDame du Serret, sous laquelle ont été découvertes des sépultures tardo-antique en 1986 (54).

\section{CONCLUSION}

Il paraît sans doute prématuré de vouloir tirer des conclusions à partir d'un ensemble de données que nous avons présentées comme lacunaires, pour ne pas dire inexistantes. Ce bilan historiographique permet toutefois de mieux apprécier le potentiel archéologique de ce secteur et d'esquisser quelques pistes de recherche pour l'avenir.

\footnotetext{
${ }^{53}$ Le promontoire de Piégut est situé à l'ouest du bourg de Thorame-Basse. Il s'agit d'une butte assez étendue, sur 50 hectares environ, au sommet de laquelle existe toujours une tour de plan carrée, élevée en moyen appareil à bossage et dotée d'une porte d'accès à tympan en plein-cintre sur linteau droit, qui évoque la fin du XII ${ }^{\mathrm{e}}$ ou le XIII ${ }^{\mathrm{e}}$ siècle. La salle basse conserve l'amorce d'une voûte d'arêtes en moyen appareil. Les vues aériennes du site laissent clairement apparaître des traces concentriques au sommet de la butte, qui évoquent la présence d'un habitat fortifié assez étendu au sommet du relief. Sur la pente orientale de celui-ci, le long du chemin qui descend vers le bourg, la chapelle Saint-Jean, placée sous le vocable de la Vierge dans les cartes anciennes, existe toujours. Il s'agit d'un édifice de plan simple, doté d'une abside semi-circulaire et dont la construction pourrait remonter en partie à l'époque médiévale.

${ }^{54}$ D'après Damase Arbaud, c'est plutôt autour de cette dernière commune et de l'église du Serret que se situeraient les biens restitués à l'abbaye marseillaise (Arbaud 1905).
} 
Toute réflexion sur l'évolution de l'ancien diocèse de Senez entre Antiquité et Moyen Âge repose en premier lieu sur une meilleure connaissance de son substrat romain ; la densité et les formes de l'occupation antique nous échappant encore, aussi bien pour ce qui concerne les agglomérations que pour les autres types d'établissements. De ce point de vue, il convient de remarquer que le territoire des hautes vallées de l'Asse et du Verdon semble appartenir - avec la haute vallée du Var et dans une moindre mesure avec les Préalpes dignoises - à un ensemble relativement cohérent, qui se différencie des zones voisines de Narbonnaise, dans lesquelles l'ancienneté de l'implantation romaine a sans doute permis une structuration plus précoce des nouvelles formes d'organisation de l'habitat. La zone d'étude se distingue également des vallées de la Durance et de l'Ubaye ainsi que de la zone littorale, marquées par l'intensité des échanges et des circulations permis par la fréquentation de ces grandes voies de passage. De fait, elle apparaît comme un espace intercalaire et marginal, à l'écart des grands axes et des principaux centres administratifs de la région. Pour autant, la notion de zone de confins ou de marge, souvent convoquée par l'historiographie du monde antique (Bedon 2014 ; Besson et al. 2016), est ici contrebalancée par une densité tout à fait singulière de capitales de cité, connues à travers les sources textuelles et épigraphiques, qui recréent de nouvelles centralités à l'échelle de cette microrégion. Les conditions de conservation des sites de plaine, et notamment le rôle important joué par la torrentialité, complexifient les modalités d'étude de ces agglomérations et limitent les possibilités des prospections archéologiques. Comme dans les autres zones de montagne, ces dernières doivent adopter une méthodologie particulière (Trément, Delpy et al. 2016), qui n'a pas encore été mise en œuvre à l'échelle de ce territoire.

Les occupations de l'Antiquité tardive sont essentiellement perçues grâce aux découvertes fortuites de sépultures sous tuiles, en dehors du cas particulier de Senez. Pour l'instant, ces indices sont les seuls éléments auxquels se raccrocher pour envisager des investigations plus poussées sur certains sites de la zone d'étude. On retiendra en outre que les modifications territoriales qui interviennent au cours de l'Antiquité tardive ne paraissent pas conduire à la création d'agglomérations pérennes, mais plutôt perpétuer le dense réseau des agglomérations à travers la mise en place des sièges épiscopaux, tout en encourageant des phénomènes de regroupement, illustrés par le cas particulier du transfert de Thorame et de Castellane vers Senez (55). De ce point de vue, l'étude des établissements perchés constituent un enjeu majeur dans ces paysages de moyenne et de haute montagne. Comme le montrent les exemples de Petra Castellana ou du plateau de Saint-Pierre, l'érosion de pente subie par ces occupations permet d'apprécier rapidement, dans le cadre de prospections et de sondages archéologiques, la nature et l'ampleur des vestiges conservés ainsi que leurs rythmes d'occupation et d'abandon. La continuité d'occupation entre Antiquité et Moyen Âge devrait également pouvoir être mieux perçue grâce à l'étude d'autres points de fixation de l'occupation, comme les sources salées de Moriez, Tartonne ou Castellane, dont l'exploitation a constitué un enjeu économique essentiel pour ce territoire, depuis l'âge du Bronze au moins. Après l'an mil, l'étude comparative des trois anciennes agglomérations antiques prend une nouvelle dimension, en raison de la forte dichotomie des pouvoirs qui caractérise l'opposition entre l'ancienne cité épiscopale et le pôle seigneurial et monastique de Castellane.

Les indices ponctuellement recueillis à Senez, Castellane ou Thorame invitent enfin à systématiser, autant que possible, les études de bâti et les suivis archéologiques aux abords des églises. Afin de répondre aux questions précédemment posées sur les continuités d'occupation entre Antiquité et Moyen Âge, mais aussi pour apporter un nouveau regard sur de nombreux édifices isolés, qui forment le maillage monastique et paroissial des hautes vallées au cours du Moyen Âge central. Des enquêtes spécifiques seraient ainsi à conduire sur le réseau des possessions victorines et lériniennes - dont il n'a pas été ici particulièrement question - afin de mesurer la part des créations nouvelles et des établissements antérieurs.

\section{SOURCES}

\section{Sources imprimées ou éditées}

Benoit 1925 : BENOIT (F.), Recueil des actes des comtes de Provence appartenant à la Maison de Barcelone: Alphonse II et Raimond Bérenger $V$ (1196-1245), Monaco, Paris, Impr. de Monaco, Picard, 1925.

Bernard et al. 1871 : BERNARD (A.), BRUEL (A.) dir., Recueil des chartes de l'abbaye de Cluny, Paris, Imprimerie Nationale, 1871.

Bouche 1664 : BOUCHE (H.), La Chorographie ou description de Provence, et l'histoire chronologique du même pays, Aix-en-Provence, C. David, 1664.

Caby et al. 2010 : CABY (C.), COTTIER (J.-F.) et al., dir., Vie d'Isarn, abbé de Saint-Victor de Marseille, $X I^{e}$ siècle, Paris, les Belles Lettres, 2010.

Clouzot 1923 : CLOUZOT (É.), éd., Pouillés de la Province d'Aix, d'Arles et d'Embrun, Paris, Imprimerie Nationale, 1923.

Guérard 1857 : GUÉRARD (B.), éd., Cartulaire de l'abbaye de Saint-Victor de Marseille, Paris, Typogr. de Ch. Lahure, 1857.

\footnotetext{
${ }_{55}^{5}$ À l'inverse, par exemple, du phénomène d'émiettement territorial mis en évidence en Septimanie par les travaux de Laurent Schneider (Schneider 2008).
} 
Mommsen 1892 : MOMMSEN (T.), Chronica minora saec. IV, V, VI, VII, Berlin, Weidmannos, coll. « Monumenta Germaniae Historica (MGH) », $\mathrm{n}^{\circ}$ 91, 1892.

Moris et al. 1883 : MORIS (H.), BLANC (E.), éd., Cartulaire de l'abbaye de Lérins, Paris, H. Champion, 1883, 2 volumes.

Sainte-Marthe 1725 : SAINTE-MARTHE (D. de), Gallia Christiana, in provincias ecclesiasticas distributa. Tomus tertius, Paris, Imprimerie royale, coll. « Gallia Christiana », n 3, 1725.

\section{BIBLIOGRAPHIE}

Arbaud 1905 : ARBAUD (D.), Les possessions de l'abbaye Saint-Victor de Marseille dans les Basses-Alpes avant le XII ${ }^{\mathrm{e}}$ siècle, avec des recherches sur l'origine de quelques familles de Provence : Diocèse de Senez (suite), Annales des Basses-Alpes (Bulletin de la Société scientifique et littéraire des Basses-Alpes), XII, 1905, p. 96-110.

Aulagnier 2013 : AULAGNIER (H.), Polyptique de Wadalde: l'assise territoriale de 1'Ager Galadius, Chroniques de Haute-Provence, 370, 2013, p. $97-150$.

Auran et al. 2006 : AURAN (Ph.), BARRUOL (G.) et al., D'une rive à l'autre: les ponts de HauteProvence de l'Antiquité à nos jours, Forcalquier, les Alpes de lumière, 2006.

Barge 2004 : BARGE (H.), Le dépôt de bronzes de Moriez (Alpes-de-Haute-Provence), Documents d'archéologie méridionale. Protohistoire du Sud de la France, 27, 2004, p. 141-170.

Barruol 1969 : BARRUOL (G.), Les peuples préromains du Sud-Est de la Gaule: étude de géographie historique, Paris, Editions E. de Boccard, 1969.

Barruol 1977 : BARRUOL (G.), Provence romane, Saint-Léger-Vauban, Zodiaque, 1977.

Barruol 1998 : BARRUOL (G.), Les agglomérations gallo-romaines des Alpes du Sud, in : GROS (P.) dir., Villes et campagnes en Gaule romaine, Paris, France, Comité des travaux historiques et scientifiques, 1998, p. $27-44$.

Barruol 2004a : BARRUOL (G.), Castellane / Salinae (Alpes-de-Haute-Provence), in : FERDIÈRE (A.), éd., Capitales éphémères, Tours, France, FÉRACF, coll. «Supplément à la Revue archéologique du Centre de la France », 2004, p. 393-395.

Barruol 2004b : BARRUOL (G.), Thorame-Haute / Eturamina (Alpes-de-Haute-Provence), in : FERDIÈRE (A.), éd., Capitales éphémères, Tours, France, FÉRACF, coll. "Supplément à la Revue archéologique du Centre de la France », 2004, p. 479-480.

Barruol et al. 2004 : BARRUOL (G.), FALQUE-VERT (H.), Les biens du patrice Abbon en 739, in : JOURDAIN-ANNEQUIN (C.), LE BERRE (M.), éd., Atlas culturel des Alpes occidentales, Paris, Picard, 2004, p. 248-249.
Beaujard et al. 2004 : BEAUJARD (B.), PRÉVOT (F.), Introduction à l'étude des capitales " éphémères 》 de la Gaule ( ${ }^{\text {er }}$ s. - début VII ${ }^{\mathrm{e}} \mathrm{s}$.), in : FERDIÈRE (A.), éd., Capitales éphémères, Tours, FÉRACF, coll. «Supplément à la Revue archéologique du Centre de la France », 2004, p. 17-37.

Bedon 2014 : BEDON (R.) dir., "Confinia »: confins et périphéries dans l'Occident romain, Limoges, Pulim, 2014.

Bérard 1997 : BÉRARD (G.), Les Alpes-de-HauteProvence, Paris, Académie des inscriptions et belleslettres, 1997.

Bertrand et al. 1994 : BERTRAND (D.), DELAGE (M.-J.) et al., dir., Césaire d'Arles et la christianisation de la Provence actes des Journées Césaire (Aixen-Provence - Arles - Lérins 3 - 5 novembre 1988, 22 avril 1989), Paris, Éd. du Cerf, 1994.

Bertrand 1986 : BERTRAND (R.), Mgr Soanen en visite pastorale, ou le diocèse de Senez dans tous ses états, Provence Historique, 36, 146, 1986, p. 413-433.

Besson et al. 2016 : BESSON (C.), BLIN (O.) et al., dir., Franges urbaines, confins territoriaux: la Gaule dans l'Empire (actes du colloque international, Versailles, 29 février-3 mars 2012), Bordeaux, Ausonius, 2016.

Bigot 2004 : BIGOT (C.), La cité de Glandèves au Moyen Âge, ses pôles et son territoire: permanences et mutations, Mémoire de Maîtrise en Histoire, sous la direction de Monique Bourin, Paris I - PanthéonSorbonne, Paris, 2004

Boulhol et al. 2014 : BOULHOL (P.), JACOB (P.-A.), dir., Maxime de Riez : entre l'histoire et la légende, Valensole, France, Aurorae libri, 2014.

Bouiron, Codou 2015 : BOUIRON (M.), CODOU (Y.), Entre antiquité et Moyen Âge classique : naissance et développement d'une chrétienté, in : BOUIS (G.) dir., Le diocèse de Nice, histoire et identités d'une terre de contrastes, Strasbourg, Éditions du Signe, 2015 , p. 14-33.

Bouiron, et al. 2015 : BOUIRON (M.), JANNETVALLAT (M.), SANCHEZ (É.), Nice, Cimiez et Sospel, in : CODOU (Y.), PECOUT (T.), éd., Cathédrales de Provence, Strasbourg, la Nuée bleue, coll. « La grâce d'une cathédrale », 2015, p. 435-462.

Brisset 2014 : BRISSET (É.), Sensibilité des milieux de montagne aux forçages climatiques et anthropiques depuis 14000 ans dans les Alpes du Sud: Approche multidisciplinaire (sédimentologie, géochimie, palynologie) et multi-sites (lac Petit, lac de Vens et lac d'Allos), Thèse de doctorat, sous la direction d'Edward Anthony, Frédéric Guiter et Cécile Miramont, Aix-Marseille Université, Aix-enProvence, 2014.

Brisset et al. 2014 : BRISSET (É.), MIRAMONT (C.) et al., Données nouvelles sur la chronologie de la déglaciation dans la vallée du Haut-Verdon (lac d'Allos, Alpes françaises du sud), Quaternaire. Revue de l'Association française pour l'étude du Quaternaire, vol. $25 / 2,2014$, p. 147-156. 
Buccio, 2018 : BUCCIO (V.), Castellane, Petra Castellana, in : Bulletin scientifique régional 2017, Service régional de l'archéologie, DRAC Paca, Aixen-Provence, 2018.

Buccio et $\boldsymbol{a l}$., à paraître : BUCCIO (V.), DEDONDER (Y.), DUPUIS (M.) et al., Castellane. Premiers éléments de réflexion sur l'évolution et la transformation des enceintes urbaines médiévales, in : Enceintes urbaines médiévales et modernes en Provence (actes du XI colloque historique de Fréjus, 23, 24 septembre 2016).

Buschhausen 1971 : BUSCHHAUSEN (H.), Die spätrömischen Metallscrinia und frühchristlichen Reliquiare. 1, Katalog, Vienne, H. Böhlaus Nachf, 1971.

Cantino Wataghin et al. 2004 : CANTINO WATAGHIN (G.), MICHELETTO (E.), Les "villes éphémères" de l'Italie du Nord, in : FERDIÈRE (A.) dir., Capitales éphémères, Tours, France, FÉRACF, 2004, p. 269-296

Chavane 1995 : CHAVANE (V.), Une voie romaine entre Vence et Digne, Archeologia, 315, 1995, p. 42-49.

Chavane et al. 1995 : CHAVANE (V.), SEHET (A.), Contribution à la connaissance de Salinae (Castellane gallo-romain), Archéam, 3, 1995, p. 25-28.

Codou 2003 : CODOU (Y.), Le Paysage religieux et l'habitat rural en Provence de l'antiquité tardive au XII ${ }^{\mathrm{e}}$ siècle, Archéologie du Midi médiéval, 21, 2003, p. 33-69.

Codou 2015 : CODOU (Y.), Les temps des cathédrales : temps et rythmes des chantiers des cathédrales en Provence de l'Antiquité tardive au XIII ${ }^{\mathrm{e}}$ siècle, Provence Historique, LXV-257, 2015, p. 43-78.

Codou et al. 2007 : CODOU (Y.), COLIN (M.-G.), La christianisation des campagnes (IV ${ }^{\mathrm{e}}-\mathrm{VIII}^{\mathrm{e}} \mathrm{s}$.), Gallia, 64, 1, 2007, p. 57-83.

Codou et al. 2009 : CODOU (Y.), LAUWERS (M.), éd., Lérins, une île sainte de l'Antiquité au moyen âge, Turnhout, Brepols, 2009.

Codou, Pécout 2015 : CODOU (Y.), PÉCOUT (T.), éd., Cathédrales de Provence, Strasbourg, la Nuée bleue, coll. « La grâce d'une cathédrale », 2015.

Cru 1987 : CRU (J.), Les limites des «comtés»en Provence centrale avant le XII ${ }^{\mathrm{e}}$ siècle, in : Territoires, seigneuries, communes: les limites des territoires en Provence, Mouans-Sartoux, Centre régional de documentation occitane, coll. "Journées d'histoire de l'espace provençal », 1987, p. 53-59.

Cru 2001 : CRU (J.), Histoire des gorges $d u$ Verdon : $d u$ Moyen Age à la Révolution, Aix-en-Provence, Edisud, 2001.

Cruvellier 1889 : CRUVELLIER (J.-F.), Histoire de Barrême, Calais, Impr. des orphelins, 1889.

Démians d'Archimbaud 1990 : DÉMIANS D'ARCHIMBAUD (G.), dir., Une vie de cathédrale, Digne-les-Bains, Musée de Digne, 1990.
Démians d'Archimbaud 1995 : DÉMIANS D'ARCHIMBAUD (G.), Digne, église Notre-Dame du Bourg. Ancienne cathédrale, in : DUVAL (N.), éd., Les premiers monuments chrétiens de la France. 1, Sud-Est et Corse, Paris, Picard, Ministère de la culture et de la francophonie, 1995, p. 69-80.

Démians d'Archimbaud 1999 : DÉMIANS D'ARCHIMBAUD (G.), Bourg et Castrum à Digne: dichotomie et complémentarité, Provence Historique, 195-196, 1999, p. 191-203.

Démians d'Archimbaud 2002 : DÉMIANS D'ARCHIMBAUD (G.), La cathédrale dans la ville romane provençale: l'exemple de Digne, in : Naissance et renaissance de la ville à l'époque romane, Codalet, Association culturelle de Cuxa, coll. « Les Cahiers de Saint-Michel de Cuxa », n 33, 2002, p. 71-88.

Démians d'Archimbaud et al. 2010 : DÉMIANS D’ARCHIMBAUD (G.), PELLETIER (J.-P.), NotreDame du Bourg à Digne, Digne-les-Bains, Plan Patrimoine Antique, 2010.

Devroey 2004 : DEVROEY (J.-P.), Élaboration et usage des polyptyques: quelques éléments de réflexion à partir de l'exemple des descriptions de l'église de Marseille (VIII ${ }^{\mathrm{e}}-\mathrm{IX}^{\mathrm{e}}$ siècles), in : HÄGERMANN (D.) et al., éd., Akkulturation: Probleme einer germanischromanischen Kultursynthese in Spätantike und frühem Mittelalter, Berlin, New-York, De Gruyter, 2004, p. 436-472.

Devroey 2006 : DEVROEY (J.-P.), Puissants et misérables : système social et monde paysan dans l'Europe des Francs, $V I^{e}-I X^{e}$ siècles, Bruxelles, Académie royale de Belgique, 2006.

Duchesne 1907 : DUCHESNE (L.), Fastes épiscopaux de l'ancienne Gaule, Paris, A. Fontemoing, 1907.

Dupuis 2014 : DUPUIS (M.), Castellane (04), gymnase Notre-Dame, Rapport de diagnostic, Département des Alpes de Haute-Provence, Digne-les-Bains, 2014.

Dupuis 2018 : DUPUIS (M.), Senez, cathédrale NotreDame de l'Assomption, in : Bulletin scientifique régional 2017, Service régional de l'archéologie, DRAC Paca, Aix-en-Provence, 2018.

Dupuis et al. 2015 : DUPUIS (M.), THÉVENON (L.), Glandèves et Entrevaux, Notre-Dame de la Seds et Notre-Dame de l'Assomption, in : CODOU (Y.), PÉCOUT (T.), éd., Cathédrales de Provence, Strasbourg, la Nuée bleue, coll. « La grâce d'une cathédrale », 2015, p. 366-382.

Dupuis et al. 2017 : DUPUIS (M.), HENRION (É.), DEDONDER (Y.), Senez (Alpes-de-Haute-Provence). Étude archéologique de la cathédrale Notre-Dame de l'Assomption : bilan des diagnostics et de la première campagne de fouille programmée, Bulletin du centre d'études médiévales d'Auxerre, BUCEMA, 21.1 (en ligne), https://cem.revues.org/14668, DOI : 10.4000/cem.14668, consulté le 2017-11-30 22:32:39. 
Duval et al. 1986 : DUVAL (Y.) et al., Topographie chrétienne des cités de la Gaule, des origines au milieu du VIII siècle. II, Provinces ecclésiastiques d'Aix et d'Embrun (Narbonensis secunda et Alpes maritimae), Paris, De Boccard, 1986.

Ferdière 2004 : FERDIÈRE (A.), éd., Capitales éphémères, Tours, France, FÉRACF, coll. «Supplément à la Revue archéologique du Centre de la France », 2004.

Février 1964 : FÉVRIER (P.-A.), Le développement urbain en Provence: de l'époque romaine à la fin $d u$ $X I V^{e}$ siècle, Paris, E. de Boccard, 1964.

Février 1980 : FÉVRIER (P.-A.), La tradition apostolique des Églises provençales, Annales du CRDP de Marseille, 1980, p. 63-89.

Février 1985 : FÉVRIER (P.-A.), Les saints évêques de la fin de l'Antiquité et du Haut Moyen Age dans le sud-est de la Gaule : genèse et développement de leur culte, Mémoires de l'Académie de Vaucluse, VI, 1985 , p. $17-40$.

Février et al. 1989 : Février P.-A. et $a l$, éd., $L a$ Provence des origines à l'an mil : histoire et archéologie, Rennes, Ouest-France, 1989.

Fisquet 1864 : FISQUET (H.), La France pontificale (Gallia christiana), histoire chronologique et biographique des archevêques et évêques de tous les diocèses de France depuis l'établissement du christianisme jusqu'à nos jours, divisée en 17 provinces ecclésiastique. Digne - $2^{\mathrm{e}}$ partie contenant Sisteron, Senez et Glandèves, Paris, E. Repos, coll. « Gallia Christiana », 1864.

Fixot et al. 1996 : FIXOT (M.), CODOU (Y.), Églises doubles et familles d'églises en Provence, in : DUVAL (N.), CAILLET (J.-P.), dir., Les églises doubles et les familles d'églises (dossier rassemblé à la suite de la table ronde organisée à Grenoble, juin 1994), Turnhout, Brepols, 1996, p. 196-210.

Fixot et al. 2009 : FIXOT (M.), PELLETIER (J.-P.), éd., Saint Victor de Marseille: études archéologiques et historiques (Actes du colloque Saint-Victor, Marseille, 18-20 novembre 2004), Turnhout, Brepols, 2009.

Gauthier 2014 : GAUTHIER (N.), Christianisation et espace urbain, in : PRÉVOT (F.) et al., éd., Topographie chrétienne des cités de la Gaule des origines au milieu du VIII siècle, Paris, Éditions de Boccard, 2014, p. 359-399.

Geary 1985 : GEARY (P.J.), Aristocracy in Provence: the Rhone Basin at the dawn of the Carolingian age, Stuttgart, A. Hiersemann, 1985.

Gras-Bourguet 1842 : GRAS-BOURGUET, Antiquités de l'arrondissement de Castellane (Basses-Alpes), Deuxième édition, Digne, Repos, 1842.

Guyon 2006 : GUYON (J.), Émergence et affirmation d'une topographie chrétienne dans les villes de la Gaule méridionale, Gallia, 63, 2006, p. 85-110.
Guyon et al. 2001 : GUYON (J.), HEIJMANS (M.), éd., D'un monde à l'autre : naissance d'une chrétienté en Provence, $I V^{e}-V I^{e}$ siècle, Arles, Musée de l'Arles antique, 2001.

Guyon et al. 2013 : GUYON (J.), HEIJMANS (M.), L'Antiquité tardive en Provence, $I V^{e}-V I^{e}$ siècle naissance d'une chrétienté, Arles, Actes Sud, 2013.

Hartmann-Virnich 2015 : HARTMANN-VIRNICH (A.), Saint-Paul-Trois-Châteaux, in : CODOU (Y.), PECOUT (T.), éd., Cathédrales de Provence, Strasbourg, la Nuée bleue, coll. « La grâce d'une cathédrale », 2015, p. 491-507.

Heijmans et al. 2006 : HEIJMANS (M.), GUYON (J.), éd., Antiquité tardive, haut Moyen Age et premiers temps chrétiens en Gaule méridionale, Paris, France, CNRS éditions, coll.« Gallia », n 63, 2006.

Heijmans et al. 2009 : HEIJMANS (M.), PIETRI (L.), Le « lobby » lérinien : le rayonnement du monastère insulaire $\mathrm{du} \mathrm{V}^{\mathrm{e}}$ siècle au début $\mathrm{du} \mathrm{VII}^{\mathrm{e}}$ siècle, in : CODOU (Y.), LAUWERS (M.), éd., Lérins, une île sainte de l'Antiquité au moyen âge, Turnhout, Brepols, 2009, p. 36-61

Igolen 1952 : IGOLEN (J.), Sur un petit coffret en plomb trouvé à Senez (basses-Alpes) et portant le monogramme du Christ, Annales des Basses-Alpes (Bulletin de la Société scientifique et littéraire des Basses-Alpes), XXXII, 193-194, 1952, p. 22-30.

Jorda, Nalin 1990 : JORDA (Ch.), NALIN (S.), La ville de Digne. Histoire naturelle d'un site urbain et de son environnement, in : DÉMIANS D'ARCHIMBAUD (G.) dir., Une vie de cathédrale, Digne-lesBains, Musée de Digne, 1990, p. 8-13

Jourdain-Annequin et al. 2004 : JOURDAIN-ANNEQUIN (C.), LE BERRE (M.), éd., Atlas culturel des Alpes occidentales, Paris, Picard, 2004.

Laguerre 1967 : LAGUERRE (G.), Saint-Pons de Cimiez, Provence Historique, 17, 70, 1967, p. 396-432.

Laurensi 1775 : LAURENSI (J.), Histoire de Castellane... Avec une suite chronologique des évêques de Senez, Castellane, 1775.

Lauwers 2007 : LAUWERS (M.), Consécration d'églises, réforme et ecclésiologie monastique. Recherches sur les chartres de consécration provençales du $11^{\mathrm{e}}$ siècle, in : MÉHU (D.), Mises en scène et mémoires de la consécration d'église au Moyen Age, Collection d'études médiévales de Nice, 7, Turnhout, Brepols, 2007, p. 145-194.

Lauwers 2008 : LAUWERS (M.), Territorium non facere diocesim... Conflits, limites et représentation territoriale du diocèse $\left(\mathrm{V}^{\mathrm{e}}\right.$-XIII ${ }^{\mathrm{e}}$ siècle), in : MAZEL (F.), éd., L'espace du diocèse : genèse d'un territoire dans l'Occident médiéval, $V^{e}-X I I I^{e}$ siècle, Rennes, Presses universitaires de Rennes, 2008, p. 23-65.

Leveau et al. 2008 : LEVEAU (P.), RÉMY (B.), La ville des Alpes occidentales à l'époque romaine, Actes $d u$ colloque international " La ville des Alpes occidentales à l'époque romaine », 6, 7 et 8 octobre 2006, Grenoble, Université Pierre Mendès France, UFR Sciences Humaines, Grenoble, CRHIPA, 2008. 
Magnani 1999 : MAGNANI (E.), Monastères et aristocratie en Provence, milieu $X^{e}$-début XII siècle, Münster, 1999.

Magnani 2013 : MAGNANI (E.), Don aux églises et don d'églises dans le sud-est de la Gaule : du testament d'Abbon (739) aux chartes du début du $\mathrm{XI}^{\mathrm{e}}$ siècle, in : BOUGARD (F.) et al., éd., Sauver son âme et se perpétuer : Transmission du patrimoine et mémoire au haut Moyen-Âge, Rome, Publications de l'École française de Rome, coll. "Collection de l'École française de Rome », 2013, p. 379-400.

Manteyer 1924 : MANTEYER de (G.), Les origines chrétiennes de la IIe Narbonnaise, des AlpesMaritimes et de la Viennise (364-483) (suite), Bulletin de la société d'étude des Hautes-Alpes, 9-10, 1924, p. 10-269.

Mazel 2008 : MAZEL (F.), éd., L'espace du diocèse : genèse d'un territoire dans l'Occident médiéval, Ve$X I I I^{e}$ siècle, Rennes, Presses universitaires de Rennes, 2008

Mazel 2009 : MAZEL (F.), De l'emprise aristocratique à l'indépendance monastique : patrimoine et culte des saints à Saint-Victor de Marseille, in : FIXOT (M.), PELLETIER (J.-P.), éd., Saint Victor de Marseille: études archéologiques et historiques (Actes du colloque Saint-Victor, Marseille, 18-20 novembre 2004), Turnhout, Brepols, 2009, p. 255-282.

Mazel 2016 : MAZEL (F.), L'évêque et le territoire: l'invention médiévale de l'espace, Paris, Éditions du Seuil, 2016.

Morabito 2007 : MORABITO (S.), La province romaine des Alpes Maritimes, des origines à la fin de l'Antiquité, Thèse de doctorat, sous la direction de Michel Gayraud, Université Paul Valéry, Montpellier, 2007.

Morabito 2010a : MORABITO (S.), Inscriptions latines des Alpes maritimes, Nice, 2010.

Morabito 2010b : MORABITO (S.), Entre Narbonnaise et Italie: le territoire de la Province des Alpes Maritimae pendant l'Antiquité romaine ( $\mathrm{I}^{\mathrm{er}} \mathrm{s}$. av. J.-C. - V ${ }^{\mathrm{e}}$ s. apr. J.-C.), Gallia, 67, 2, 2010, p. 99-124.

Morin et al. 2007 : MORIN (D.) et al., Aux origines de l'extraction du sel en Europe ( $\mathrm{VI}^{\mathrm{e}}$ millénaire av. J.-C.). La source salée de Moriez (Alpes-de-HauteProvence), in : EVIN (J.), THAUVIN-BOULESTIN (E.), éd., Un siècle de construction du discours scientifique en préhistoire, Paris, Société préhistorique française, 2007, p. 341-352.

Palanque 1951 : PALANQUE (J.-R.), Les évêchés provençaux à l'époque romaine, Provence historique, $1,3,1951$, p. 105-143.

Pécout 2011 : PÉCOUT (T.), Ultima ratio. Vers un État de raison l'épiscopat, les chanoines et le pouvoir des années 1230 au début du XIV siècle (provinces ecclésiastiques d'Arles, Aix et Embrun), Habilitation à diriger les recherches, sous la direction de Laurent Feller, Université Panthéon-Sorbonne, Paris, 2011.
Pécout 2016 : PÉCOUT (T.), Senez: le calendrier obituaire de la cathédrale Sainte-Marie (Carpentras, bibliothèque Inguimbertine, ms. 72), Valensole, Aurorae libri, 2016.

Pécout et al. 2011 : PÉCOUT (T.) et al., L'enquête générale de Leopardo da Foligno en Provence centrale (novembre-décembre 1332 et juin-août 1333), Paris, Éd. du Comité des travaux historiques et scientifiques, 2011.

Pellissier 1901 : PELLISSIER (J.-E.), Histoire d'Allos depuis les temps les plus reculés jusqu'à nos jours, Digne, Chapoul et Vve Barbaroux, 1901, 2 volumes.

Poly 1976 : POLY (J.-P.), La Provence et la société féodale: 879-1166, Paris, France, Bordas, 1976.

Poly 1997 : POLY (J.-P.), La «Petite Valence», Les avatars de la noblesse romane en Provence, in : Saint Mayeul et son temps : millénaire de la mort de Saint Mayeul, 4e abbé de Cluny, 994-1994 (actes du Congrès International " Saint Mayeul et Son Temps ", Valensole 12-14 mai 1994), Digne-lesBains, Soc. scientifique et littéraire des Alpes de Haute-Provence, coll. " Chroniques de HauteProvence », n³30-331, 1997, p. 137-183.

Poteur 1981 : POTEUR (J.-C.), Archéologie des châteaux de Provence orientale au Moyen Age, Thèse de doctorat, Ecole des hautes études en sciences sociales (EHESS), [S.1.], 1981.

Prévot et al. 2014 : PRÉVOT (F.) et al., éd., Topographie chrétienne des cités de la Gaule des origines au milieu du VIII siècle, Paris, Éditions de Boccard, 2014.

Roux 1971 : ROUX (J.-M.), Les évêchés provençaux de la fin de l'époque romaine à l'avènement des Carolingiens (476-751), Provence historique, 21, 86, 1971, p. 373-420.

Sauze 1983 : SAUZE (E.), Le polyptyque de Wadalde : problèmes de toponymie et de topographie provençales au IX ${ }^{\mathrm{e}}$ siècle, Provence historique, 34, 135, 1983, p. 3-33.

Schneider 2008 : SCHNEIDER (L.), Aux marges méditerranéennes de la Gaule mérovingienne : Les cadres politiques et ecclésiastiques de l'ancienne Narbonnaise Iere entre Antiquité et Moyen Age ( $\mathrm{V}^{\mathrm{e}}$-IX $\mathrm{I}^{\mathrm{e}}$ siècles), in : MAZEL (F.), éd., L'espace du diocèse: genèse d'un territoire dans l'Occident médiéval, $V^{e}$-XIII siècle, Rennes, Presses universitaires de Rennes, 2008, p. 69-95.

Thirion 1957 : THIRION (J.), L'ancienne cathédrale de Senez (Basses-Alpes), Bordighera, Section française de l'Institut international d'études ligures, 1957.

Thirion 1980 : THIRION (J.), Alpes romanes, SaintLéger-Vauban, Zodiaque, 1980. 
Trément et al. 2016 : TRÉMENT (F.), DELPY (M.) et $a l$., Centres et périphéries dans les cités antiques du Massif central. Occupation, mise en valeur et intégration des territoires de montagne dans la cité des Arvernes (fin de l'âge du Fer - début du Moyen Âge), in : BESSON (C.), BLIN (O.) et al., dir., Franges urbaines, confins territoriaux: la Gaule dans l'Empire (actes du colloque international, Versailles, 29 février-3 mars 2012), Bordeaux, Ausonius, 2016, p. $575-600$.

Vaizey 2002 : VAIZEY (N.), L'évêché de Senez (Alpesde-Haute-Provence) et la famille des Castellane, Bulletin de la Société d'Études Scientifiques et Archéologiques de Draguignan et du Var, 42, 2002, p. 23-45.

Ventre 1930 : VENTRE (L.), L'ancien diocèse de Senez. Essais divers d'union ou de translation du siège, Annales des Basses-Alpes (Bulletin de la Société scientifique et littéraire des Basses-Alpes), XXIII, 1930, p. 23-45.
Viré 1992 : VIRÉ (M.-M.), éd., Les cathédrales (Tome 1): Glandèves, Entrevaux, Senez, Riez, Digne-lesBains, Annales de Haute-Provence, n 315, 1992, $284 \mathrm{p}$.

Weiss 1990 : WEISS (J.-P.), Une œuvre de la renaissance carolingienne la "Passion de Pons Cimiez", in : GRANAROLO (J.), dir., Hommage à René Braun. T. 2, Autour de Tertullien (Publications de la faculté des lettres et sciences humaines de Nice, $n^{\circ} 56$ ), Nice, 1990.

Zadora-Rio 2008 : ZADORA-RIO (É.), dir., Des paroisses de Touraine aux communes d'Indre-etLoire: la formation des territoires, Tours, FERACF, 2008.

Zerner 1981 : ZERNER (M.), Enfants et jeunes au IX $^{\mathrm{e}}$ siècle. La démographie du polyptyque de Marseille, 813-814, Provence Historique, 31, 126, 1981, p. 355-384. 
